\title{
WestVirginiaUniversity
}

THE RESEARCH REPOSITORY @ WVU

Graduate Theses, Dissertations, and Problem Reports

2017

\section{Three Essays on Monetary Policy, Income Inequality, and Capital Flows}

John Meszaros

Follow this and additional works at: https://researchrepository.wvu.edu/etd

\section{Recommended Citation}

Meszaros, John, "Three Essays on Monetary Policy, Income Inequality, and Capital Flows" (2017).

Graduate Theses, Dissertations, and Problem Reports. 6224.

https://researchrepository.wvu.edu/etd/6224

This Dissertation is protected by copyright and/or related rights. It has been brought to you by the The Research Repository @ WVU with permission from the rights-holder(s). You are free to use this Dissertation in any way that is permitted by the copyright and related rights legislation that applies to your use. For other uses you must obtain permission from the rights-holder(s) directly, unless additional rights are indicated by a Creative Commons license in the record and/ or on the work itself. This Dissertation has been accepted for inclusion in WVU Graduate Theses, Dissertations, and Problem Reports collection by an authorized administrator of The Research Repository @ WVU.

For more information, please contact researchrepository@mail.wvu.edu. 


\title{
Three Essays on Monetary Policy, Income Inequality, and Capital Flows
}

\author{
John Meszaros
}

\author{
Dissertation submitted \\ to the College of Business and Economics \\ at West Virginia University \\ Doctor of Philosophy in \\ Economics \\ Eric Olson, Ph.D., chair \\ Arabinda Basistha, Ph.D. \\ Shuichiro Nishioka, Ph.D. \\ Stratford Douglas, Ph.D. \\ Jack Dorminey, Ph.D. \\ Department of Economics \\ Morgantown, West Virginia \\ 2017
}

in partial fulfillment of the requirements for the degree of

Keywords: monetary policy, VAR, income inequality, household debt, central bank independence, capital flows.

Copyright (C) 2017 John Meszaros 


\title{
Abstract \\ Three Essays on Monetary Policy, Income Inequality, and Capital Flows
}

\author{
John Meszaros
}

This dissertation is a collection of essays centered on monetary policy and central bank institutions and how they affect capital flows and income inequality. The first chapter concerns household debt and income inequality, which are both effected by the interest rate environment. As such, the high leverage ratio of households outside the top end of the income distribution has led many economists to assert that household debt has been an important component of the increase in income inequality in the United States. Mason and Jayadev (2014) define 3 variables that may affect household debt: an effective interest rate measure, inflation, and economic growth. Mason and Jayadev identify these as "Fisher Dynamics." The first chapter examines, using a VAR methodology, how the "Fisher Dynamics" affect income inequality in the United States, through a debt channel, over the period 1929 to 2009. The results indicate that increases in the effective interest rate measure increase income inequality; whereas, increases in income growth tend to decrease income inequality. The inflation channel contribution contributes negatively to income inequality, but the statistical significance is not consistent across the two inequality measures and model specifications.

The second chapter investigates monetary policy's spillover effect on the economy of an emerging economy: South Africa. The second chapter, particularly examines the impact of the Federal Reserve's quantitative easing program from 2009 to 2014 on the economy of South Africa. A qualitative background is provided on the policy actions of the South African Reserve Bank and, quantitatively, a VAR model, including South Africa's inflation, output, a stock market index, exchange rate, and South Africa's policy rate, is examined to determine the impact of the Federal Reserve's actions. The chapter's results show that the Federal Reserve's quantitative easing programs had different effects on South Africa's economy than regular Federal Reserve easing programs. Namely, the effects between the periods were similar, but quantitative easing caused much larger effects on the economic variables in terms of magnitude.

Finally, chapter three examines the effect of central bank reforms on capital flows into international economies. The third chapter models the effect of a rise in a central bank's independence on foreign direct investment and portfolio investment using panel data. The estimates show that a rise in independence leads to a small but statistically significant rise in foreign direct investment as a percentage of GDP. The estimates for portfolio investment are positive but not statistically significant. The results indicate that the institutional structure of monetary authorities may be important for foreign investors. 


\section{Acknowledgements}

The past five years have given me the opportunity to meet, learn from, and collaborate with many good colleagues. I would like to thank my dissertation committee of Eric Olson, Arabinda Basistha, Shuichiro Nishioka, Stratford Douglas, and Jack Dorminey for their help and guidance in the dissertation process. In particular, I am grateful for the many hours and meetings that Eric Olson sat through that helped me improve my research and writing. I am also thankful for the support over my years in the program from Arabinda Basistha and Shuichiro Nishioka. I would also like to thank my parents, John Meszaros Sr. and Jill Myers, for their constant support and guidance through the duration of my Ph.D. studies. Lastly, I would like to thank Ed Berisha for his help with my research, writing, and for his good humor throughout our time at WVU. 


\section{Table of Contents}

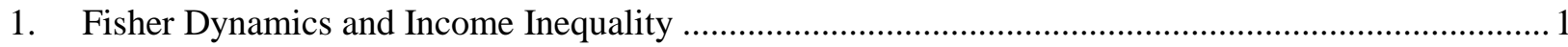

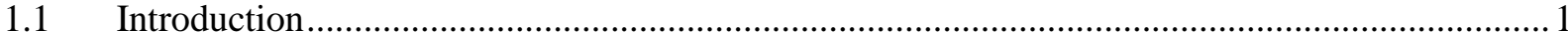

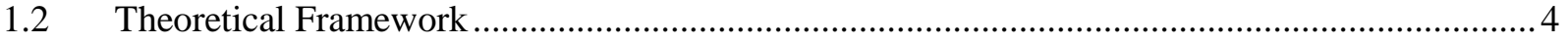

1.3 The Role of Debt in Household Balance Sheets ....................................................................... 6

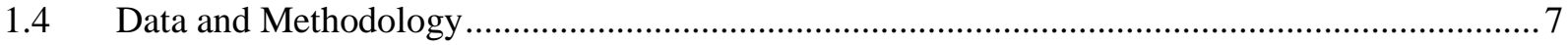

1.4.1 Data

1.4.2. VAR and Generalized Impulse Responses ............................................................... 11

1.4.3. Generalized Variance Decompositions ....................................................................... 13

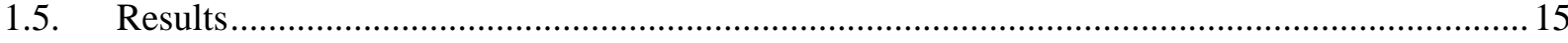

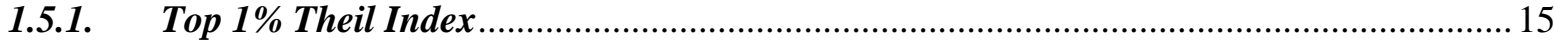

1.5.2 Inverted Pareto-Lorenz Coefficient …......................................................................... 17

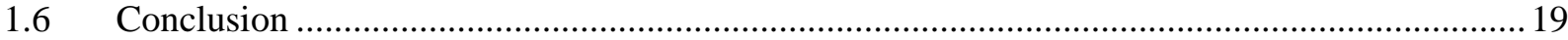

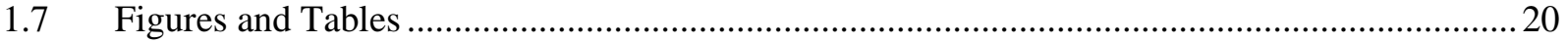

2. Central Bank Independence's Effect on Foreign Direct and Portfolio Investment...........................36

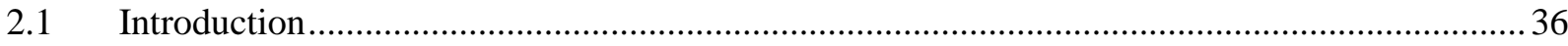

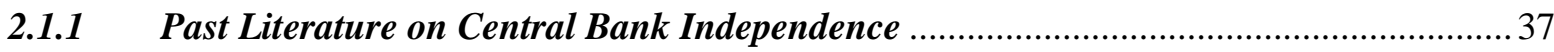

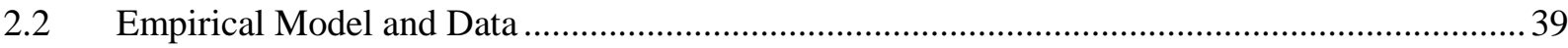

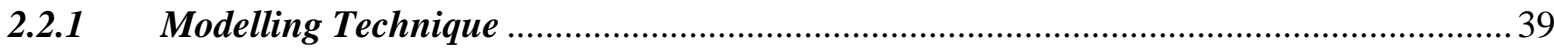

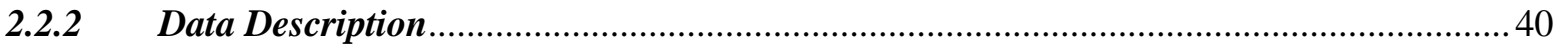

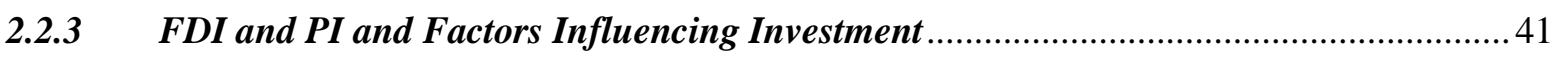

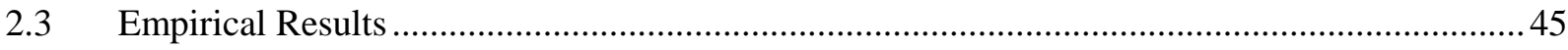

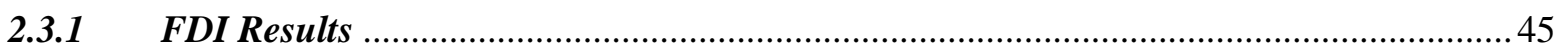

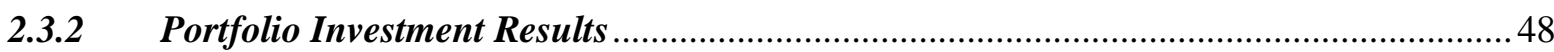

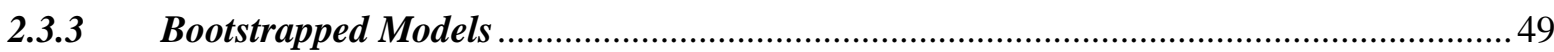

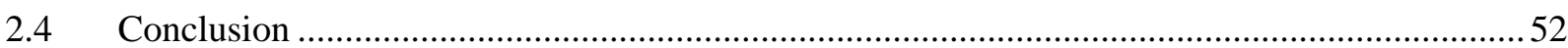

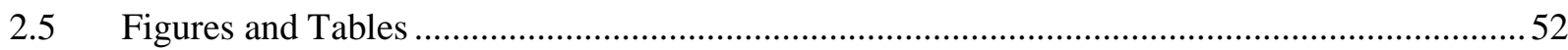

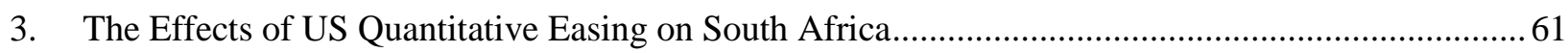

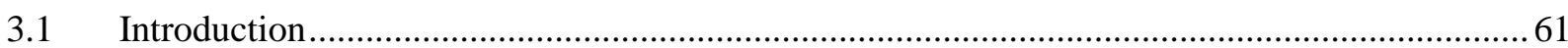

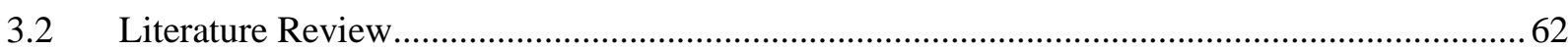

3.3 South African Reserve Bank's (SARB) Statements \& Response .............................................63

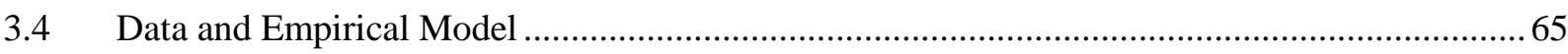

3.4.1 Data

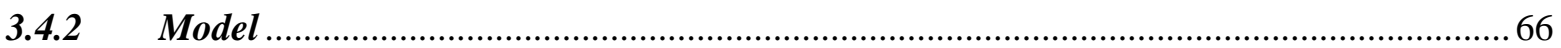




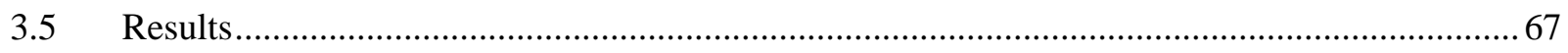

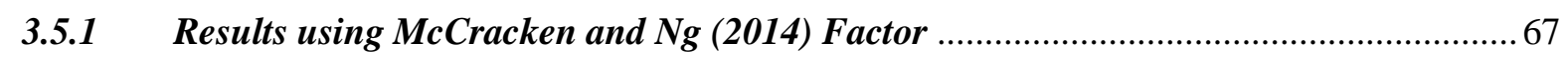

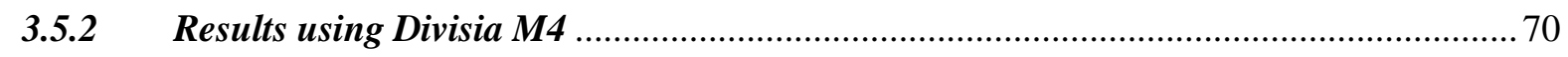

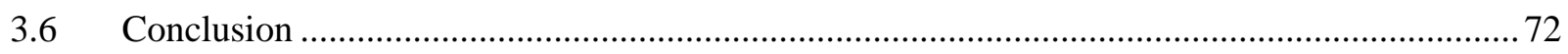

3.7 Appendix 1: Robustness Check Using US Shadow Rate Measure ........................................78

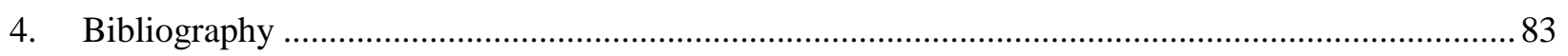




\section{List of Figures}

Figure 1.1 Time Series of Hosusehold Credit and Inverted Pareto-Lorenz Coefficient......................21

Figure 1.2 Time Series of Contributions of Fisher Variables to Debt..............................................22

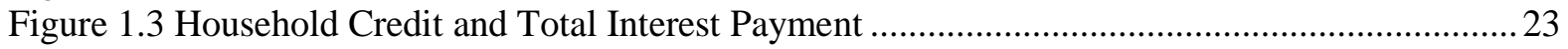

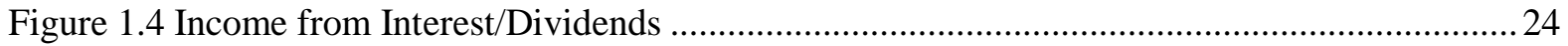

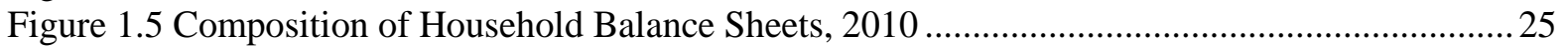

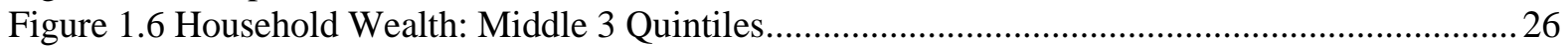

Figure 1.7 Leverage Ratio By Household Income Percentile ...................................................2

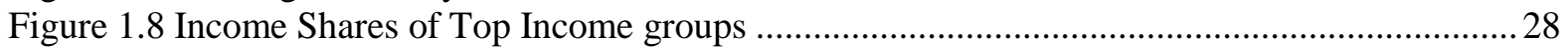

Figure 1.9 Generalized Impulse Responses Using Top 1\% Theil Index as Income Inequality

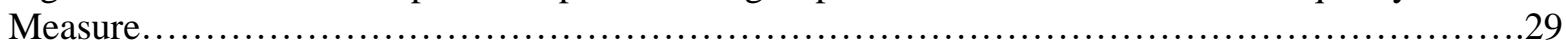

Figure 1.10 Variance Decompositions of Top 1\% Theil Index ...................................................... 30

Figure 1.11 Generalized Impulse Responses Using Inverted Pareto-Lorenz coefficient (including capital gains) as Income Inequality Measure ............................................................................. 31

Figure 1.12 Variance Decompositions of Inverted Pareto-Lorenz Coefficient .................................. 32

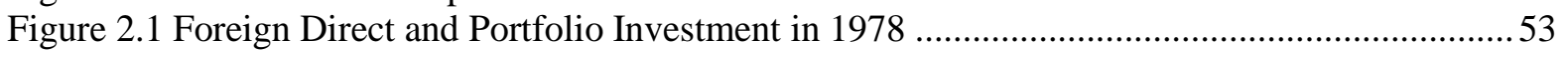

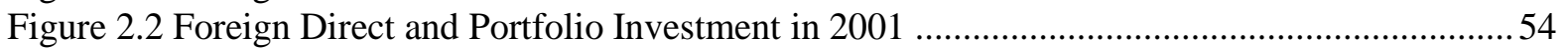

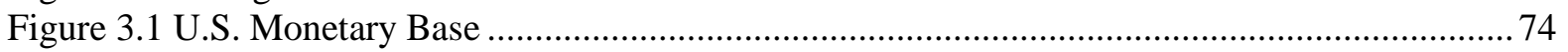

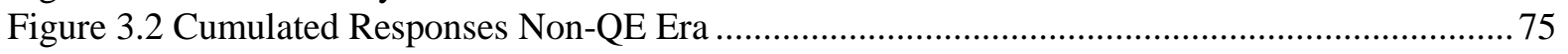

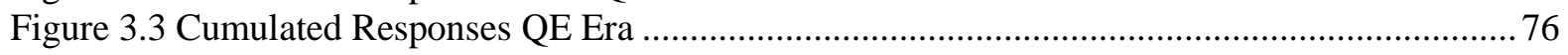

Figure 3.4 Cumulated Responses Non-QE Era using Shadow Rate .............................................. 79

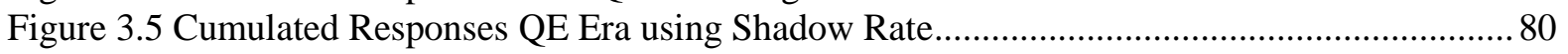

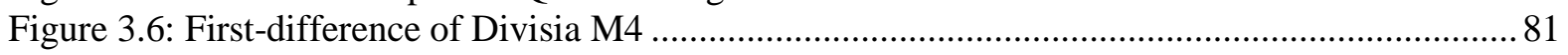

Figure 3.7 Impulse Responses during QE period using Divisia M4 .............................................. 82 


\section{List of Tables}

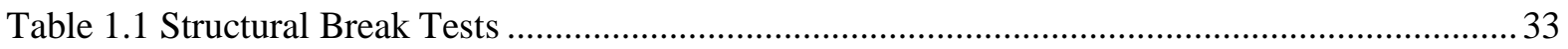

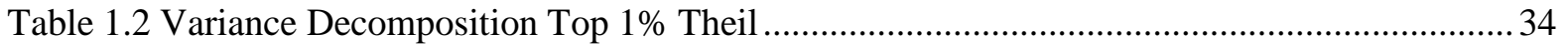

Table 1.3 Variance Decomposition Inv. Pareto-Lorenz ....................................................................... 35

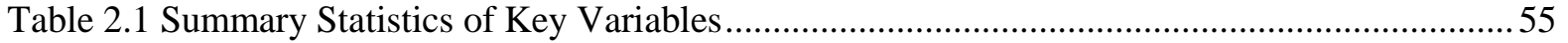

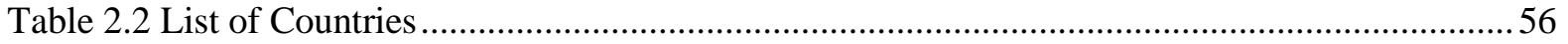

Table 2.3 Foreign Direct Investment Regression Results ..............................................................57

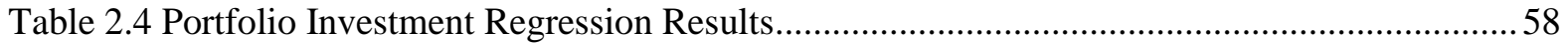

Table 2.5 Bootstrapped FDI Results with OECD and Non-OECD samples ....................................59

Table 2.6 Bootstrapped Foreign Direct Investment with Split Samples ............................................60

Table 3.1 Adjusted Dickey-Fuller Unit Root Tests ............................................................................ 77 


\section{Fisher Dynamics and Income Inequality}

\subsection{Introduction}

One of the many contributing factors to rising income inequality in the United States is consumer debt. From Figure 1.1 it can be seen that consumer debt, together with income inequality, increased dramatically over the years, particularly after the 1980s. Hence, many economists have asserted that increases in debt have been an important counterpart of the redistribution of income in the U.S. The key mechanism is that increases in the size and importance of the financial sector to the U.S. economy over the years have made it easier for high income households to back their financial investments with loans to the rest of the population. As such, lower income households were able to sustain their consumption levels; whereas, the high income households gained additional income, further exacerbating income inequality (Kumhof et al. (2013)). Similarly, Barba and Pivetti (2008) claim that, over the past 25 years, "keeping up with the Joneses" contributed to household indebtedness as families financed consumption at levels in excess of current income. The dissaving was mainly concentrated among households in the lower $90 \%$ of the income distribution, which has been compensated with savings by the upper $10 \%$ of the income distribution. Thus, top earners "allowed" those at the low and middle levels of the income distribution to minimize the drop in their consumption through increased debt. Wolff (2010) reports that the debt-to-equity and debtto-income ratios for the top $1 \%$ of the income distribution declined from 1983 to 2007 , but increased for the next $19 \%$ of the income distribution and the middle quintiles. Cynamon and Fazzari (2013) illustrate that, from the 1960s to the 1980s, household leverage was roughly 
constant in the U.S., at around $60 \%$ of disposable income. However, since 1989, the debt to income ratio for the bottom $95 \%$ of U.S. households increased by 73 percentage points.

It is likely that the greater indebtedness of the households outside the top end of the income distribution makes their welfare more sensitive to fluctuations in interest rates, income, and prices, known as the Fisher variables. Increases in the interest rate lead to higher shares of income being devoted to debt service, restraining the upward income mobility of the indebted households. In contrast, increases in the interest rate will be beneficial for the suppliers of the loanable funds (wealthy households) because their stream of income from their savings will further increase. Debelle (2004) shows that low nominal interest rates increase the amount of credit financial institutions are willing to loan to households. When this is combined with low inflation, real debt burdens tend to increase when interest rates rise. Likewise, Coibion et al. (2012) suggest that contractionary monetary policy actions increase income inequality as this causes real debt burdens to increase for households. Accordingly, there is reason to believe interest rates, through the debt channel, have an effect on income inequality.

In contrast to increases in the interest rate, increases in income and the price level are anticipated to be favorable to indebted households. Increases in the price level mean the real value of debt is being eroded relatively faster as described in Mason and Jayadev (2014). This relationship was actually hinted at much earlier by Budd and Seiders (1971) who mention that mild increases in the price level $(5 \%)$ tend to correspond with decreases in income inequality, particularly, benefiting households in the middle of the income distribution. This is because, relative to top income earners, households in the middle of the income distribution hold much more debt. Similarly, Kirshner (2001), in a survey article, notes that most prior studies on inflation fail to find a significant impact on economic growth for inflation that is at a moderate to 
low level. As Kirshner notes, low levels of inflation may help savers and financial institutions and their clients; conversely, slightly higher levels of inflation may erode the real value of debt and help the households that hold more debt (typically low to middle income families). In addition, Brennan (2016) notes that, as inflation fell in the United States, particularly since the late 1970s and early 1980s, this tended to redistribute income from lower income families to those higher up in the income distribution (p.37-43). Furthermore, straightforwardly, increases in income make it easier for households to pay off their debt. Once their debt is paid off, households can then engage in more productive investment (stocks, bonds, going to college) or save and earn interest. Thus, we presume, through the debt channel explanation, that positive changes in these two variables contribute to decreasing income disparities.

Mason and Jayadev (2014) break down the contribution of inflation, income growth, and interest rates on the net levels of U.S. consumer debt; they call these factors the "Fisher Dynamics." They show that, since 1980, the effective interest rate in the U.S. has been higher than income growth and inflation, increasing real debt burdens. This is similar to the Great Depression era, when households were burdened with stable or increasing debt levels due to deflation and high interest rates. Das (2011) conducts an analysis comparable to Mason and Jayadev (2014) using data from the United Kingdom and the United States and gets broadly similar results.

Figure 1.2 shows that one of the major contributors to debt accumulation has been interest rate payments. We can see that the interest rate dominates the other two Fisher variables in influencing debt over time. Similarly, Figure 1.3 suggests that debt increases are very closely followed by increases in total interest rate payments. 
Thus, we contribute to the existing literature by examining the relevance of the Fisher Effects, using a debt channel explanation, to describe rising income inequality in the United States. Particularly, we build on Mason and Jayadev's (2014) model and use the calculated contributions of the Fisher Effects on debt evolution, known as "Fisher Dynamics", and examine the impact these contributions have on income inequality in the U.S. We use Koop, Pesaran, and Potter's (1996) generalized impulse responses and Diebold and Yilmaz's (2012) generalized variance decompositions to identify the link between the calculated Fisher Dynamics and income inequality. For robustness, we compare two measures of income inequality. As far as we know, this will be the first paper to use time-series analysis in an attempt to determine the effects of the Fisher Dynamics on income inequality. In addition, to ensure structural interpretation of the estimated VARs, Choleski factorizations of the shocks are also calculated. To preview our results, we find that an increase in the interest rate measure developed by Mason and Jayadev tends to increase inequality. Income growth reduces inequality. Inflation is found to have a negative impact on income inequality, but the statistical significance is not consistent across the two inequality measures and the methods applied to capture the dynamics across the variables. The rest of the paper proceeds as follows: section II discusses Mason and Jayadev's theoretical framework used to calculate the Fisher Dynamics, section III examines debt's effect on households, section IV discusses our data and methodology, section V presents our results, and section VI concludes.

\subsection{Theoretical Framework}

In order to estimate the contribution of the Fisher Effects to private leverage, Mason and Jayadev (2014) assume that private debt follows the law of motion below:

$$
\text { (1) } b_{t+1}=d_{t}+\left(\frac{1+i}{1+g+\pi}\right) b_{t}
$$




$$
\text { (2) } \Delta b_{t}=b_{t+1}-b_{t}=d_{t}+\left(\frac{i-g-\pi}{1+g+\pi}\right) b_{t}
$$

where $b_{t}$ is the end-of-period value of total credit market liabilities, divided by adjusted personal income and $d_{t}$ is the household primary deficit calculated as net borrowing minus interest payments (divided by adjusted disposable personal income). $i_{t}$ is the effective interest rate on debt, which is total interest payments divided by the debt stock at the beginning of each time period. $g_{t}$ is the percent change in the level of adjusted income from the previous year, and $\pi_{t}$ is the percent change in the level of the personal consumption expenditure (PCE) deflator from the previous year. This is identical to the approach used for government debt but personal income takes the place of GDP. In order to decompose the contribution of these variables to the evolution of debt, Mason and Jayadev use a linear approximation of (2):

$$
\text { (3) } \Delta b_{t} \approx d_{t}+\left(i_{t}-g_{t}-\pi_{t}\right) b_{t-1}
$$

Mason and Jayadev use the approximation in (3), rather than equations (1) and (2), as $i_{t}, g_{t}$, and $\pi_{t}$ are almost always smaller than 0.1 in absolute value. Thus, the approximation in (3) is nearly identical to (2). Then, from (3), they distinguish changes in debt resulting from changes in the Fisher variables. These changes in the Fisher variables are the primary focus of this paper.

Mason and Jayadev show that debt will rise during periods of high $i_{t}$ and low $g_{t}$ and low $\pi_{t}(i>g+\pi)$, and will fall when $(i<g+\pi)$. Over the 1929 to 2011 time period, the two cases are approximately equally likely to occur. Before World War II, income growth fluctuated above and below the effective interest rate (due to shocks from the Great Depression and World War II). From 1945 to 1980, income growth and the effective interest rate were stable and approximately equal. After 1980, income growth is almost always less than the effective interest rate. A key determinant of whether $(i>g+\pi)$ or $(i<g+\pi)$ over the whole time period is inflation, which fluctuated widely. As before, Figure 1.2 shows the contribution of each variable 
to leverage over the sample period. The effective interest rate has risen consistently since the 1940s. Mason and Jayadev call this a "slow-motion" debt-deflation setting, as income growth and inflation have not kept pace with the rising effective interest rate. This has increased debt burdens for households since the 1980s. In this paper, we use the calculated contributions, the "Fisher Dynamics", and examine their impact on the evolution of income inequality in the U.S. This enables us to explore the impact the Fisher Effects have on income inequality through a debt channel.

\subsection{The Role of Debt in Household Balance Sheets}

Understanding the evolution of the different income groups and how they hold their wealth and earn their income over time gives a better understanding behind the significance of the debt channel. We believe that differences in how households earn their income and hold their wealth is the mechanism through which household debt and the associated channels are affecting the top households differently than lower income households. This has then contributed to the increasing income disparities within the United States. Figure 1.4 shows the amount of income the top $0.1 \%$, the top $1 \%$, and bottom $90 \%$ of income groups earn from interest/dividends. Approximately, $15 \%$ of income for the top 1\% group and almost $20 \%$ of income for the top $0.1 \%$ group comes from interest or dividend income. This relates directly to the interest rate effect of the debt channel. For instance, as the interest rate goes up, not only would the wealthier families earn higher incomes based purely on the increase in the interest rate, households lower in the income distribution would pay relatively more on servicing their debt, further exacerbating inequality. Also notice, for the bottom $90 \%$ group, interest income is almost zero.

Furthermore, Figure 1.5 and Figure 1.6 decompose the balance sheet components of wealthy households and households in the bottom $60 \%$ of the income distribution. As can be 
seen, for the top $1 \%$ group, $80 \%$ of wealth is held in business equities, financial instruments, and liquidity assets. On the other hand, the three components represent less than $25 \%$ of wealth for the bottom $60 \%$ of households. Roughly $2 / 3$ rds of their wealth is in housing, which will likely be composed of a large amount of mortgage debt. The proposed channels from Mason and Jayadev tie in easily given the differing levels of debt among households. For instance, if the interest rate increases, not only would wealthy households earn more from interest income, but poorer households face higher debt service on their mortgages, further driving income levels apart. Also, if inflation increases, this would decrease the burden of outstanding mortgage debt for lower income households, which would help close the income gap. Lastly, as economic growth picks up, this may particularly help lower income households as they have more income to pay off their debt faster. As such, their shares of overall income would likely increase. Also, recall that in the 1950s through late 1970s, economic growth in the U.S. was particularly strong, and this period, correspondingly, showed historically low levels of inequality.

Lastly, to further support the debt channel, we present data on the leverage ratio for various levels of income from the Survey of Consumer Finances. As can be seen in Figure 1.7, only households in the top $10 \%$ of the income distribution have had their debt-to-assets ratio remain constant over the last 24 years. Whereas, for the other households, increases in leverage ranged from $5 \%$ to nearly a $10 \%$ increase depending on the specific income groups. Again, this highlights the difference in the debt burdens between different levels of the income distribution.

\subsection{Data and Methodology \\ 1.4.1 Data}

Our data for the Fisher Dynamics comes from Mason and Jayadev's (2014) paper in the American Economic Journal: Macroeconomics. The annual data used for our measures of inequality were obtained from The World Wealth and Income Database due to its relatively long 
time series. Piketty and Saez (2001) give a detailed description on how the top income shares are estimated. The top income shares are based on tax returns data published by the Internal Revenue Service (IRS). The income definition they use is a gross income definition including all the income items reported on tax returns (prior to deductions): salaries and wages, small business and farm income, partnership and fiduciary income, dividends, interest, rents, royalties, and other small items reported as other income. Then, the income shares are estimated by dividing the income amounts accruing to each top fractile by total personal income computed from the National Accounts.

To measure inequality, we used Piketty's inverted Pareto-Lorenz coefficient, including capital gains, and constructed a Theil index using data on income from the top $1 \%$ and bottom 99\% of income earners. The inverted Pareto coefficient measures the inequality within a given income range; in our case we use the data from Piketty and Saez which measures income inequality between the top $0.1 \%$ and $1 \%$ in the income distribution of the United States. This allows us to determine whether the Fisher variables have any impact on the top income earners. The Theil index, on the other hand, provides a measure of the discrepancies between the distribution of income and the distribution of population between groups of individuals. If all population groups have an income share equal to their population share, the Theil index is zero. For instance, the top 1 percent of earners would get 1 percent of income and the bottom 99 percent of earners would get 99 percent of the income in a country. As such, the index for the top $1 \%$ is constructed as follows:

$$
\text { (4) } T=I_{\text {top } 1} \times\left|I_{\text {top } 1}-N_{\text {top } 1}\right|+I_{b 99} \times\left|I_{b 99}-N_{b 99}\right|
$$


where the I's indicated the income share of the various income percentiles and the N's indicate the size of the respective percentiles (here they would simply be 0.01 and 0.99 ). All data was collected for the 1929 to 2009 time period.

Figure 1.8 shows the share of total income going to the top decile group. Interestingly, most of the growth in the income shares within the top decile is due to large changes in the top centile. The "10\%-1\%" income group measures the income shares of the top decile, excluding the top $1 \%$. Note that we do not see large changes in the income shares of this group over time. The " $10 \%-1 \%$ " share increased from $24.61 \%$ in 1980 to $26.24 \%$ in 2007 . On the other hand, the income share of the top $1 \%$ increased from $10 \%$ to $23.5 \%$ over the same period. Within the top $1 \%$ group, it is the top $0.1 \%$ that has experienced the biggest increase in income. We believe that analyzing income inequality in terms of the evolution of income shares for the groups at the top end of the income distribution is better than using the most common measure of income inequality, the Gini coefficient. The Gini coefficient is more sensitive to changes in the lower to middle income groups. If these groups have seen relatively little movement in income/wealth over broad sections of time, then this measure may not fully capture changes at the top of the income distribution. As shown in the prior section, the biggest differences in debt and how households hold their wealth is between those at the very top of the distribution (top 10\%, top $1 \%$ ) and households lower in the distribution. Thus, if we focused on a measure such as the Gini coefficient, we may not observe much effect from the debt channel as households in the bottom $80 \%$ of the income distribution have largely similar spending and debt patterns. Therefore, shocks to the various debt channels may not appear to have much impact, since the households are very similar, when, in fact, changes in the debt channels actually produce significantly different results when comparing top and low income households. Further, Piketty (2014) claims 
that summarizing income inequality "between the bottom and the middle of the hierarchy as well as between the middle and the top or between the top and very top" into a single coefficient can be misleading (p. 266). Additionally, the length of our series is important as it allows us to capture the effects of the Fisher dynamics prior to the Great Moderation.

However, it is possible there may be a structural break in the income inequality series' around or in the 1980s. Perhaps the "Reagan Revolution", lower unionization, and financial deregulation had large impacts on inequality and the other variables. Also, the "Volcker disinflation" occurred in the early 1980s which may have affected the income distribution. Levy and Temin (2007) provide further details on many institutional changes in the U.S. for the interested reader. Dickey-Fuller tests suggested the inequality series' have unit roots. However, if there is a structural break, differencing the series may lead to incorrect estimation as there may be multiple regimes that are stationary when looking at different sections of time. To address the concern of a structural break, we performed the two-break minimum LM unit root test that endogenously determines two structural breaks $\left(T_{B}\right)$ in the level and trend developed by Lee and Strazicich (2003) and Strazicich, Lee, and Day (2004). "Model A" allows for two structural breaks in levels under the null, whereas "Model C" allows for two structural breaks in levels and trend under the null. The advantage of the test is that it is not subject to spurious rejections of the null hypothesis in the presence of a unit root with possible breaks.

Test results from Table 1.1 suggest that given the calculated LM test statistics we cannot reject the null hypothesis of a unit root from Model A even after allowing for two structural breaks in levels. $\hat{k}$ is the optimal number of lagged first-differenced terms included in the unit root test to correct for serial correlation, whereas $\widehat{T_{b}}$ stands for the time period of the breaks which is endogenously determined from the data via a grid search by selecting the break where 
the value of the unit root test statistic is at its minimum. Results indicate that the two identified breaks in the intercept are not statistically significant at the 5\% level.

Similarly, the calculated test statistics from Model C in Table 1.1 indicate that, at the 5\% level of significance, across the two measures of income inequality, we cannot reject the null hypothesis of a unit root after allowing for two changes in level and trend. None of the identified break points are statistically significant. Critical values for Model C depend (somewhat) on the locations of the breaks $\lambda=\left(\frac{T_{B 1}}{T}, \frac{T_{B 2}}{T}\right)$, which are provided below Table 1.1 from Lee and Strazicich (2003). Overall, our empirical findings provide evidence that the income inequality measures have a unit root even after allowing for two structural breaks in level and trend. Thus, we are confident that differencing the inequality measures is appropriate as both inequality measures show no signs of structural breaks.

\subsubsection{VAR and Generalized Impulse Responses}

Furthermore, we had no a priori knowledge regarding the ordering of the variables in our VAR. Based on the introduction and Section II, we have an idea about what might happen regarding inequality and the Fisher variables but there is not a specific theoretical model (that we are aware of) describing interactions between all of the variables. Instead of attempting to impose a specific causal ordering, the generalized approach allows correlated shocks but accounts for them appropriately using the historically observed distribution of the errors. As such, the method overcomes the identification problem and provides meaningful characterization of the dynamic responses of income inequality to shocks in the Fisher variables. Specifically, the generalized impulse responses allow us to quantify and trace the time-paths of income inequality in response to one unit shocks of each Fisher variable. Thus, we follow Koop, Pesaran, and Potter (1996) and Diebold and Yilmaz (2012) to estimate generalized impulse response functions and generalized variance decompositions. 
Therefore, we estimate the following 4-variable VAR $(p)$,

(5) $Z_{t}=\sum_{i=0}^{p} \Phi_{i} Z_{t-p}+\varepsilon_{t}$

such that $Z_{t}=\left[\Delta\right.$ ConInflation $_{t}, \Delta$ ConInterest $_{t}, \Delta$ ConGrowt $_{t}, \Delta$ Inequality $\left._{t}\right]$ where $\Delta$ ConInflation $_{t}, \Delta$ ConInterest $_{t}, \Delta$ ConGrowt $_{t}$ are the contribution of inflation, the contribution of the interest rate, and the contribution of income growth to the evolution of debt as defined by Mason and Jayadev. Inequality $_{t}$ represents the two income inequality measures we considered and $\varepsilon \sim(0, \Sigma)$ is a vector of independent and identically distributed error terms. A lag length for (5) was selected using the Akaike Information Criteria and the Bayesian/Schwarz Information Criteria which both suggested $p=1$. All variables are in a stationary form.

From (5) we can identify the infinite moving average of $Z_{t}$ as follows:

$$
\text { (6) } Z_{t}=\sum_{i=0}^{\infty} A_{i} \varepsilon_{t-i}
$$

Where the $m \times m$ coefficient matrices $A_{i}$ can be obtained using the following recursive relations:

$$
\text { (7) } A_{i}=\phi_{1} A_{i-1}+\phi_{2} A_{i-2}+\cdots+\phi_{p} A_{i-p}
$$

From (6) impulse responses that measure the effect of shocks at a given point in time on the (expected) future values of $Z_{t}$ in a dynamic system are estimated. Particularly, we follow Koop, Pesaran and Potter (1996) and Pesaran and Shin (1997) and generate generalized impulse response functions. Instead of shocking all elements of $\varepsilon_{t}$, we choose to shock only one element, say its $j$ th element, and integrate out the effects of other shocks using the historically observed distribution of errors. Therefore, defining the known history of the economy up to time $t$ - 1 by the non-decreasing information set $\Omega_{t-1}$, the generalized impulse function of $Z_{t}$ at horizon $n$ is defined by

$$
\text { (8) } G I_{z}\left(n, \delta_{j}, \Omega_{t-1}\right)=E\left(Z_{t+n} \mid \varepsilon_{j t}, \Omega_{t-1}\right)-E\left(Z_{t+n} \mid \Omega_{t-1}\right)
$$


where $\delta$ represents the shocks hitting the economy, and assuming $\varepsilon_{t}$ has a multivariate normal distribution following Koop et al. (1996) it can be shown that

$$
\text { (9) } E\left(\varepsilon_{t} \mid \varepsilon_{j t}=\delta_{j}\right)=\left(\sigma_{1 j}, \sigma_{2 j}, \ldots, \sigma_{m j}\right)^{\prime} \sigma_{j j}^{-1} \delta_{j}=\Sigma e_{j} \sigma_{j j}^{-1} \delta_{j}
$$

where $\sum$ is the variance matrix for the error vector $\varepsilon, \sigma_{j j}$ is the standard deviation of the error term for the $j$ th equation, and $e_{j}$ is an $m \times 1$ selection vector, with one as its $j$ th element and zeros otherwise.

The $m \times 1$ vector of the (unscaled) generalized impulse response of the effect of a shock in the $j$ th equation at time $t$ on $z_{t+n}$ is given by

$$
\text { (10) }\left(\frac{A_{n} \Sigma e_{j}}{\sqrt{\sigma_{j j}}}\right)\left(\frac{\delta_{j}}{\sqrt{\sigma_{j j}}}\right), \quad n=0,1,2, \ldots
$$

Letting $\delta_{j}=\sqrt{\sigma_{j j}}$, the scaled generalized impulse response function by:

$$
\text { (11) } \psi_{j}^{g}(n)=\sigma_{j j}^{-\frac{1}{2}} A_{n} \Sigma e_{j},=0,1,2, \ldots
$$

which measures the effect of one standard error shock to the $j$ th equation at time $t$ on expected values of $Z_{t}$ at time $t+n$.

\subsubsection{Generalized Variance Decompositions}

From (6) we estimated variance decompositions. As noted in Diebold and Yilmaz

(2012), the variance decompositions allow one to assess the fraction of the $H$-step-ahead error variance in forecasting $z_{i}$ that is due to shocks to $z_{j}, \forall j \neq i$, for each $i$. Diebold and Yilmaz (2012) use the structure of Koop, Pesaran, and Potter (1996) to produce variance decompositions that are invariant to the ordering of the variables because of the use of the historically observed distribution of the errors. Diebold and Yilmaz (2012) define the own variance shares as the fraction of the $\mathrm{H}$-step-ahead error variances in forecasting $z_{i}$ that are due to shocks to $z_{i}$ for $i=$ $1,2, \ldots \ldots, N$ and cross variance shares as the fraction of the $\mathrm{H}$-step-ahead error variances in 
forecasting $z_{i}$ that are due to shocks to $z_{i j}$ for $i, j=1,2, \ldots \ldots, N$ such that $i \neq j$. The Koop, Pesaran, and Potter (1996) H-step-ahead forecast error variance decompositions are

$$
\text { (12) } \theta_{i j}^{g}(H)=\frac{\sigma_{j j}^{-1} \sum_{h=0}^{H-1}\left(e_{i}^{\prime} A_{h} \sum e_{j}\right)^{2}}{\sum_{h=0}^{H-1}\left(e_{i}^{\prime} A_{h} \sum e_{i}\right)}
$$

where $\sum$ is the variance matrix for the error vector $\varepsilon, \sigma_{j j}$ is the standard deviation of the error term for the $j$ th equation, and $e_{i}$ is the selection vector, with one as the $i$ th element and zeros otherwise. Because the sum of the elements in each row of the variance decomposition table need not equal 1, Diebold and Yilmaz (2012) normalize each entry in the variance decomposition matrix by:

$$
\text { (13) } \tilde{\theta}_{i j}^{g}(H)=\frac{\theta_{i j}^{g}(H)}{\sum_{j=1}^{N} \theta_{i j}^{g}(H)}
$$

such that by construction $\sum_{j=1}^{N} \theta_{i j}^{g}(H)=1$. Diebold and Yilmaz (2012) then use the volatility contributions from the above generalized variance decomposition to construct the total spillover index as:

$$
\begin{aligned}
& \sum_{i, j=1}^{N} \widetilde{\theta}_{i j}^{g}(H) \\
& \text { (14) } S^{g}(H)=\frac{\underset{i \neq j}{N} * 100}{N}
\end{aligned}
$$

Thus, the total spillover index measures the contribution of volatility shocks across the four variables in our VAR to the total forecast error variance. The directional volatility spillovers Diebold and Yilmaz (2012) subsequently layout provide a decomposition of the total spillovers to those coming from (or to) a particular variable. The volatility spillover by variable $i$ to all other variables is $j$ is

$$
\text { (15) } S_{i}^{g}(H)=\frac{\sum_{\substack{j=1 \\ j \neq i}}^{N} \widetilde{\theta}_{i j}^{g}(H)}{N} * 100
$$

Similarly, the directional volatility spillovers transmitted by variable $i$ to all other variables $j$ is 


$$
\text { (16) } S_{i}^{g}(H)=\frac{\sum_{\substack{j=1 \\ j \neq i}}^{N} \widetilde{\theta}_{j i}^{g}(H)}{N} * 100
$$

The net spillover from variable $i$ to all other variables $j$ is

$$
\text { (17) } S_{i}^{g}(H)=S_{\cdot i}^{g}(H)-S_{i \cdot}^{g}(H)
$$

The net pairwise volatility spillovers, are defined as

$$
\text { (18) } S_{i}^{g}(H)=\frac{\widetilde{\theta}_{j i}^{g}(H)-\widetilde{\theta}_{i j}^{g}(H)}{N} * 100
$$

\subsection{Results}

\subsubsection{Top 1\% Theil Index}

a) Generalized Impulse Response Functions

Figure 1.9 shows the generalized impulse responses of income inequality represented by the Top 1\% Theil Index. As expected, debt service, as measured by the interest rate, intensifies income inequality. A one standard deviation positive shock to the interest rate increases income inequality by 0.5 standard deviations. This corresponds with, Coibion et al. (2012) where increases in the interest rate increase debt burdens, which exacerbates income inequality.

A one standard deviation shock to the inflation rate has a contemporaneous, statistically significant impact on income inequality of -0.5 standard deviations. The impact of the shock remains significant across the ten year period. The findings imply that the inflation rate, through the debt channel, leads to decreases in income inequality. This is an important contribution as past literature identified that inflation reduces the income shares of households at the bottom quantile of the income distribution and, thus, increases inequality (Easterly and Fischer (2001), Romer and Romer (1999)). However, note that these studies examined inflation's effect on low income earners through the income channel. Increases in inflation reduce the relative income of the poor, leading to higher income inequality. However, we find inflation, through the debt channel, reduces the income disparity between the top and low income earners, echoing the 
findings of Budd and Seiders (1971) and pointed out in Kirshner (2001). Given that households outside the top of the income distribution are mainly debtors, as inflation increases, the value of their real debt decreases. Thus, their upward income mobility improves. As is known, the control of inflation is vital to central banks because low inflation promotes growth and public confidence in the economy. On the other hand, from our findings, we can see that low inflation comes with a cost for debt holders. It takes longer for them to pay off debt, which hinders their upward income mobility.

In contrast, policies that are associated with positive economic growth are beneficial for debt holders and their income mobility. A one standard deviation positive shock to income growth is followed by a decrease in income inequality of more than 0.5 standard deviations. Since positive income growth, through the debt mechanism, contributes more to the decrease in income inequality than inflation, we believe that, as the central bank targets low inflation to promote growth, it should lead to lower income disparity between the top $1 \%$ and bottom $99 \%$ of income earners.

\section{b) Generalized Variance Decompositions}

Table 1.2 displays the Diebold and Yilmaz (2012) generalized variance decompositions using the top $1 \%$ Theil index as the measure of inequality. Figure 1.10 shows the variance decomposition graphically. We are primarily concerned with row 4, the inequality measure. Note that $10 \%$ of the variation in the Top $1 \%$ Theil index is explained by the interest rate measure, $18.8 \%$ is explained by the income growth measure, and $6.9 \%$ is explained by the inflation measure. In sum, $36 \%$ of the variation in the Top $1 \%$ Theil index is explained by the Fisher Dynamics in the VAR. These results confirm the significance of income growth in decreasing 
income disparities between the top $1 \%$ and bottom $99 \%$ of income earners, which is greater than the sum of the impact from the interest rate and inflation.

\subsubsection{Inverted Pareto-Lorenz Coefficient \\ a) Generalized Impulse Response Functions}

Figure 1.11 shows the generalized impulse responses of income inequality as measured by the inverted Pareto-Lorenz coefficient. Similar to the results from the Top 1\% Theil index, all three Fisher Dynamics have statistically significant impacts on income inequality. A one standard deviation shock to the interest rate increases income inequality by approximately 0.6 standard deviations. Whereas, a one standard deviation positive shock to inflation and income growth decrease income inequality by approximately 0.25 standard deviations. The results suggest that the Fisher Dynamics have a significant impact on the distribution of income even within the top $1 \%$ of income earners. Thus, ignoring the income shares of the top centile would underestimate the influence of the Fisher dynamics on the distribution of top incomes in the U.S.

In comparison with the results where the Top $1 \%$ Theil Index is used as the income inequality measure, the magnitude of the impact from income growth and inflation to income inequality drops by almost half. Furthermore, the significance of inflation disappears after 2 years, signifying that inflation might not have a long lasting impact on income share disparities across top income earners. Recall, that the inverted Pareto coefficient measures the disparity between the top 1 and $0.1 \%$ of earners in the U.S. The impulse response suggests that top earners, in response to inflation, adjust their assets to counteract the effects of inflation. For example, high earning households hold relatively little in housing/mortgage debt. Thus, if inflation increases, these households are more likely to have better access to financial instruments that hedge against inflation. Thus, inflation might not have a strong impact on the 
value of their real wealth. On the other hand, the magnitude of the interest rate impact remains at the same level as it was when income inequality was defined by the Top $1 \%$ Theil Index. It suggests that service to debt is an important factor in influencing income disparities across different sections of the income distribution.

\section{b) Generalized Variance Decompositions}

Table 1.3 displays the Diebold and Yilmaz (2012) generalized variance decompositions with the inverted Pareto coefficient as the measure of inequality. Figure 1.12 shows the variance decomposition graphically. Recall that the inverted Pareto coefficient measures the divergence in income between the top $0.1 \%$ and top $1 \%$ of income earners in the U.S. As can be seen, $7.1 \%$ of the variation in inequality is due to the interest rate measure, $13.3 \%$ is accounted for by income growth and $5 \%$ is explained by inflation. Overall, $25 \%$ of the variation in the inverted Pareto coefficient is explained by the Fisher Dynamics. It provides further evidence that the components of debt have significant effects on inequality within the U.S. Particularly, note that income growth is relatively more important than inflation or the interest rate.

Further, to ensure structural interpretation of the estimated impulse responses and variance decompositions, the Choleski factorization is implemented in the order: income contribution, inflation contribution, interest rate contribution, and income inequality. The rationale for this ordering is based on the following considerations. Contributions of the income growth rate and inflation are placed first because changes in these two variables depend on the overall economic state. The interest rate contribution is placed third since changes in the cost of money are expected to respond to changes in income and the inflation rate. Then, inequality is placed last in the ordering under the assumption that changes in the contributions of the income 
growth rate, inflation, and the interest rate feed into changes in income inequality. ${ }^{1}$ The estimated orthogonalized impulse responses indicate that the negative impact of inflation on income inequality remains, but it is not statistically significant. The orthogonalized impulse responses of income inequality to changes in the income and the interest rate contributions are very similar to the generalized impulse responses presented above. ${ }^{2}$ Similarly, variance decompositions from the Choleski factorizations show that the economic significance of the inflation contribution in explaining changes in income inequality drops significantly in magnitude. The magnitude of the income growth rate and interest rate contributions are almost identical to the Generalized Variance Decompositions. As such, we are confident in asserting that policies that are associated with positive economic growth are beneficial for debt holders and their income mobility. Whereas, policies that lead to high interest rates, such as contractionary monetary policy, contribute to increasing debt burdens, which exacerbates income inequality.

\subsection{Conclusion}

Debt as a cause for financial crises and a source of economic distress for households dates back at least as far as Fisher (1933). Fisher showed that, in a disinflationary or deflationary setting, real debt burdens may increase. More recently, debt has gained recognition as an explanation for rising levels of inequality. Based on prior work, we argue that household indebtedness has contributed to increases in income inequality and then establish the effects of the Fisher variables on inequality. We find evidence, through a debt channel, that increases in Mason and Jayadev's interest rate measure increase debt burdens and, thus, increases inequality.

\footnotetext{
${ }^{1}$ To ensure the consistency of the orthogonalized impulse responses, we place the interest rate in the first place. The results are not influenced by changing the order of the variables.

${ }^{2}$ To save space, we do not report the Impulse Responses and the Variance Decompositions under the Choleski factorization, but they are available upon request.
} 
The interest rate results were statistically significant and consistent across the 2 measures of inequality. Our findings support Coibion et al. (2012) who show that contractionary policies increase income inequality. Furthermore, we find evidence income growth decrease inequality, which supports the early research of Kuznets (1955). Even though, inflation contributes negatively to the income inequality growth rate, the statistical significance is weak. This is no surprise since the Federal Reserve has committed to a low, stable inflation rate. Thus the inflation channel is unlikely to be widely used in the future to reduce debt burdens.

There are two policy implications from our findings. First, low interest rates may induce households to borrow unsustainable amounts. When rates inevitably rise, this exacerbates debt levels and can slow down economic growth. As the Federal Reserve contemplates raising interest rates in the near future, they would be wise to consider how this might affect household debt burdens and the level of inequality in the U.S. Second, income growth is another way to alleviate households' debt burdens. This is probably the most politically desirable and feasible channel to reduce income inequality. There are no drawbacks to high levels of economic growth. However, unlike interest rates, which can be controlled by monetary policy, there is no corresponding mechanism to induce economic growth. Thus, although the most desirable way to reduce inequality, economic growth is the hardest to consistently produce.

\subsection{Figures and Tables}


Figure 1.1 Time Series of Hosusehold Credit and Inverted Pareto-Lorenz Coefficient
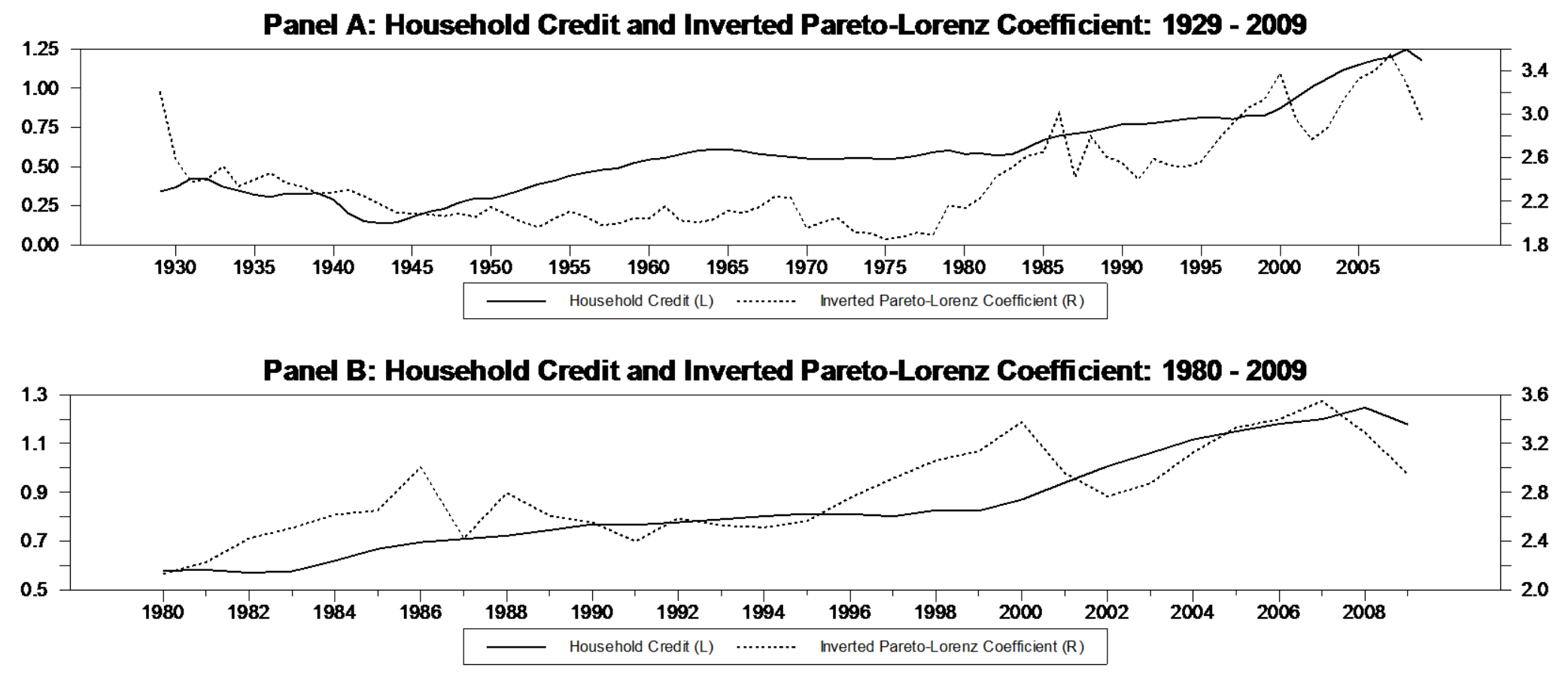

Notes: Household credit represents the end-of-period value of total credit market liabilities, divided by adjusted personal income. Source: Mason and Jayadev (2014). The inverted Pareto-Lorenz coefficient measures the level of income inequality between the top $0.1 \%$ and $1 \%$ in the income distribution of the United States. Source: The World Wealth and Income Database. 
Figure 1.2 Time Series of Contributions of Fisher Variables to Debt

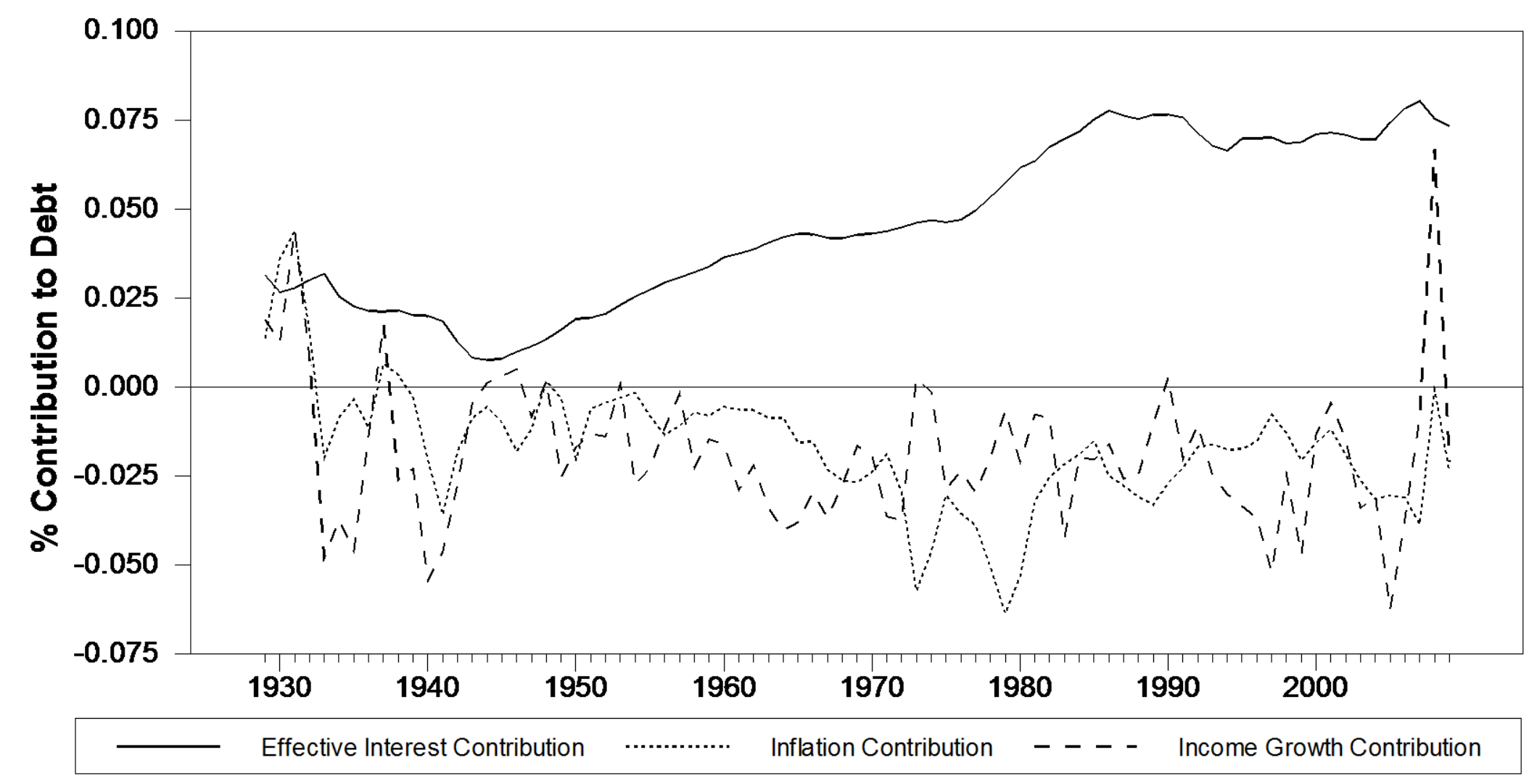

Notes: This figure shows the shares of household credit explained by the three Fisher variables. The positive contribution from the interest rate measure indicates that the effective interest channel has positively influenced debt. Even as the policy rate has fallen since the 1980s, this has been offset by an increase in borrowing by households. The inflation and income contributions are negative because these channels have helped to reduce the burden of debt for households. Notice during the Great Recession, income growth contributed positively to debt. This is because incomes fell so severely households actually experienced an increase in debt burden through this channel. Source: Mason and Jayadev (2014). 
Figure 1.3 Household Credit and Total Interest Payment

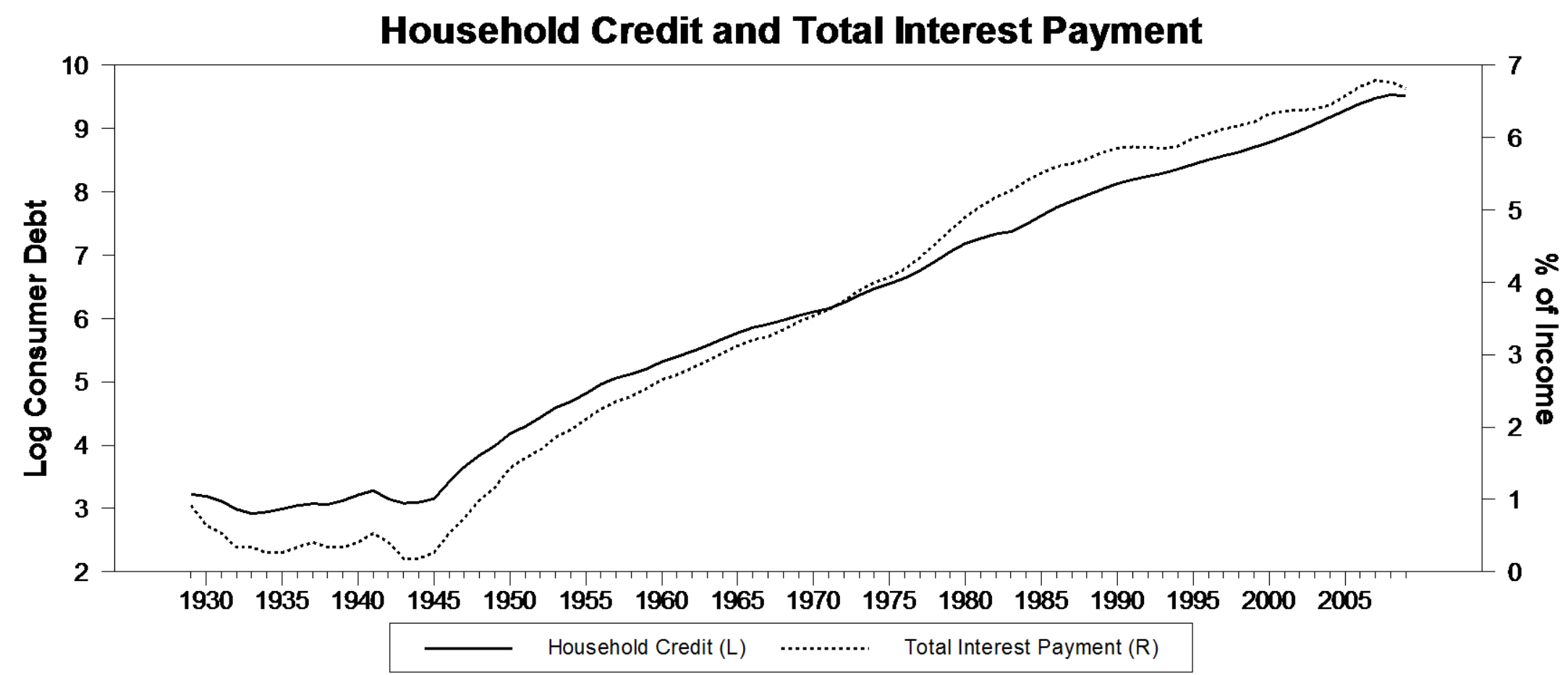

Notes: Household credit is the log of consumer debt. Total Interest Payment equals the total annual interest payments by households divided by household credit market liabilities for the first quarter of the year. Source: Mason and Jayadev (2014). 
Figure 1.4 Income from Interest/Dividends

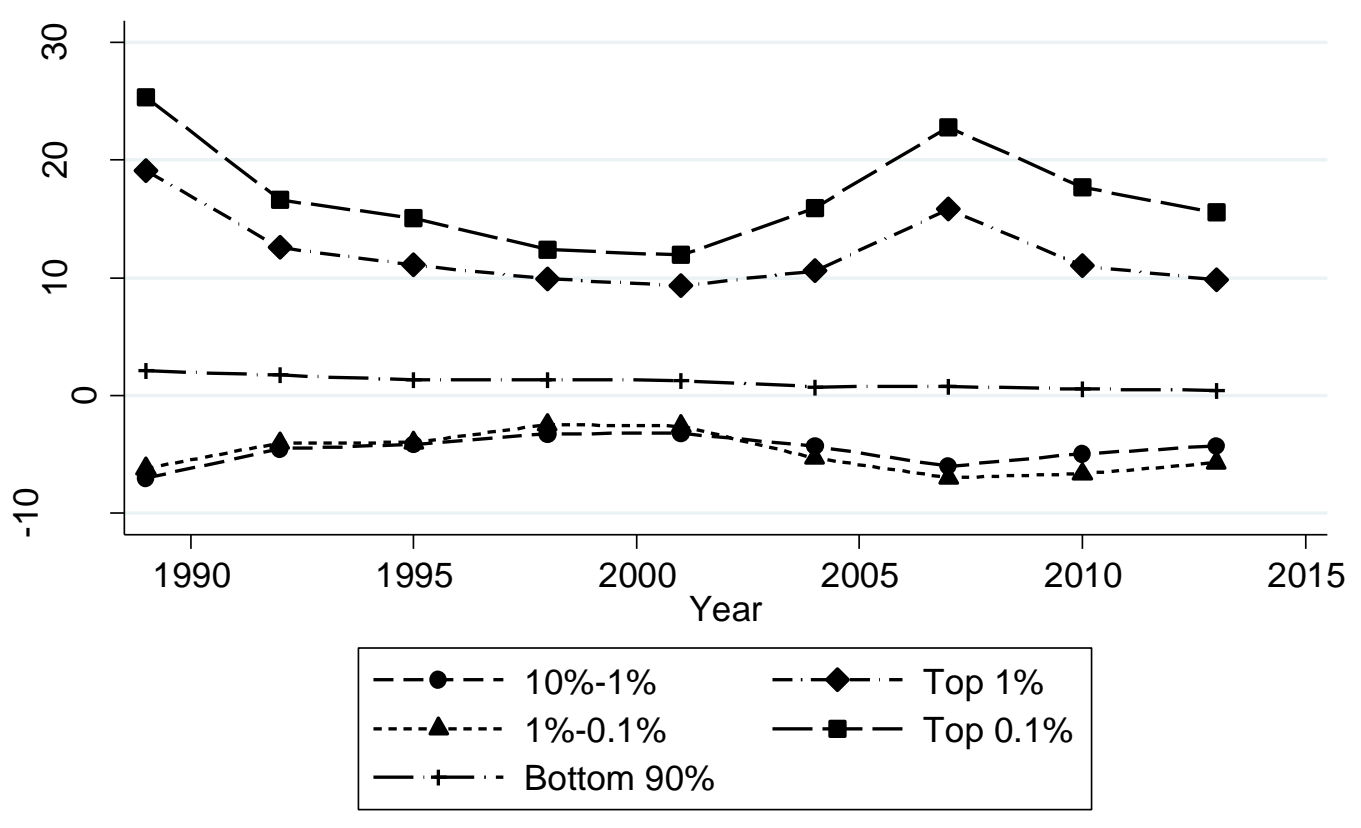

Notes: The graph shows the share of income from interest/dividends for households at different levels of the income distribution. $10 \%-1 \%$ shows the income shares of the households in the top $9 \%$ of the income distribution. $1 \%-0.1 \%$ shows the income shares of the households in the top $0.9 \%$ of the income distribution. Top $1 \%$ and Top $0.1 \%$ show the income shares of the households at the top $1 \%$ and $0.1 \%$ of the income distribution. Source: The World Wealth and Income Database. Bottom $90 \%$ shows the income shares of the households in the bottom $90 \%$ of the income distribution. Source: Survey of Consumer Finances. 
Figure 1.5 Composition of Household Balance Sheets, 2010

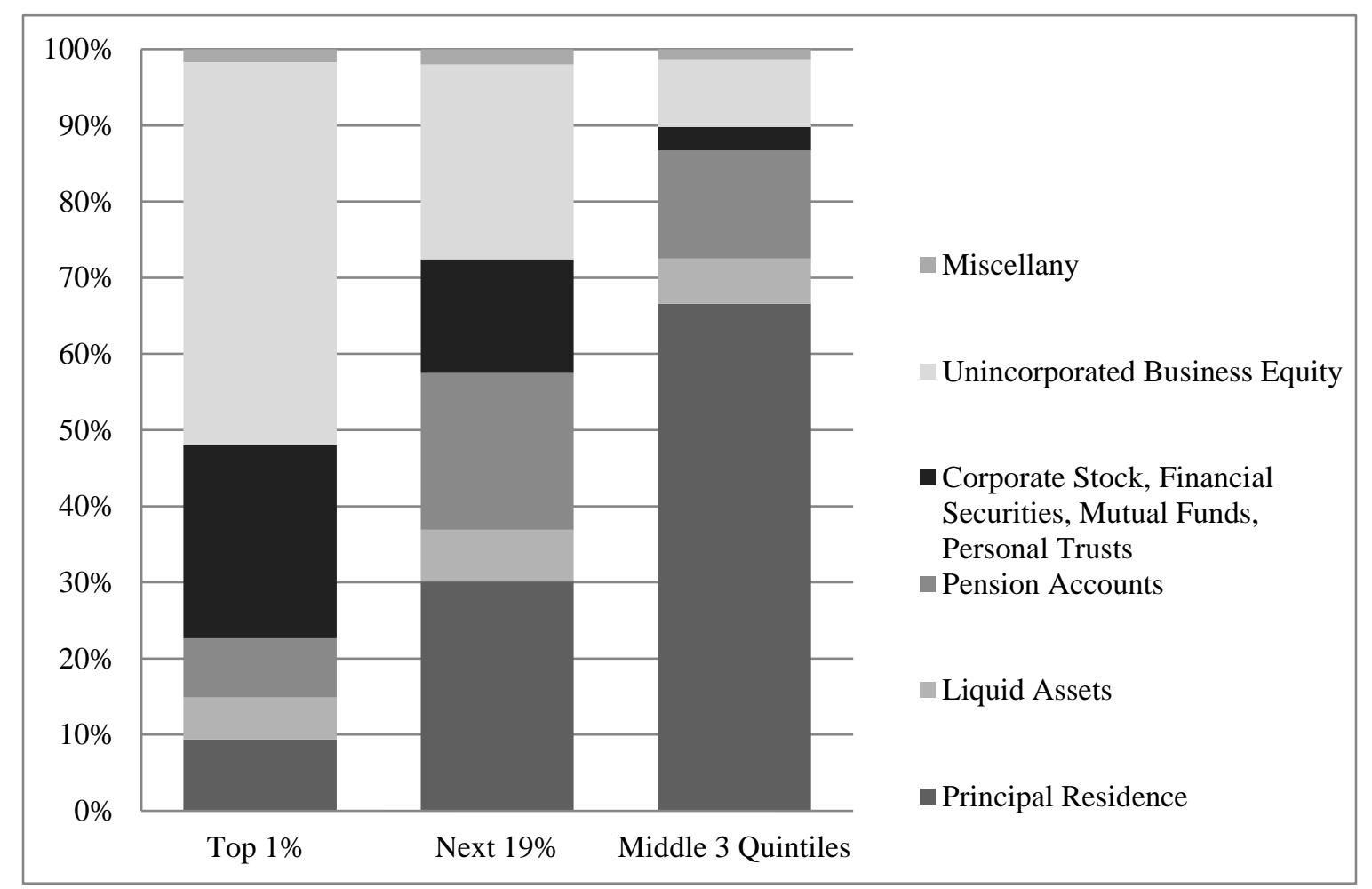

Notes: The graph illustrates differences across household's balance sheets at different levels of the income distribution. Source: Wolff (2012). 
Figure 1.6 Household Wealth: Middle 3 Quintiles

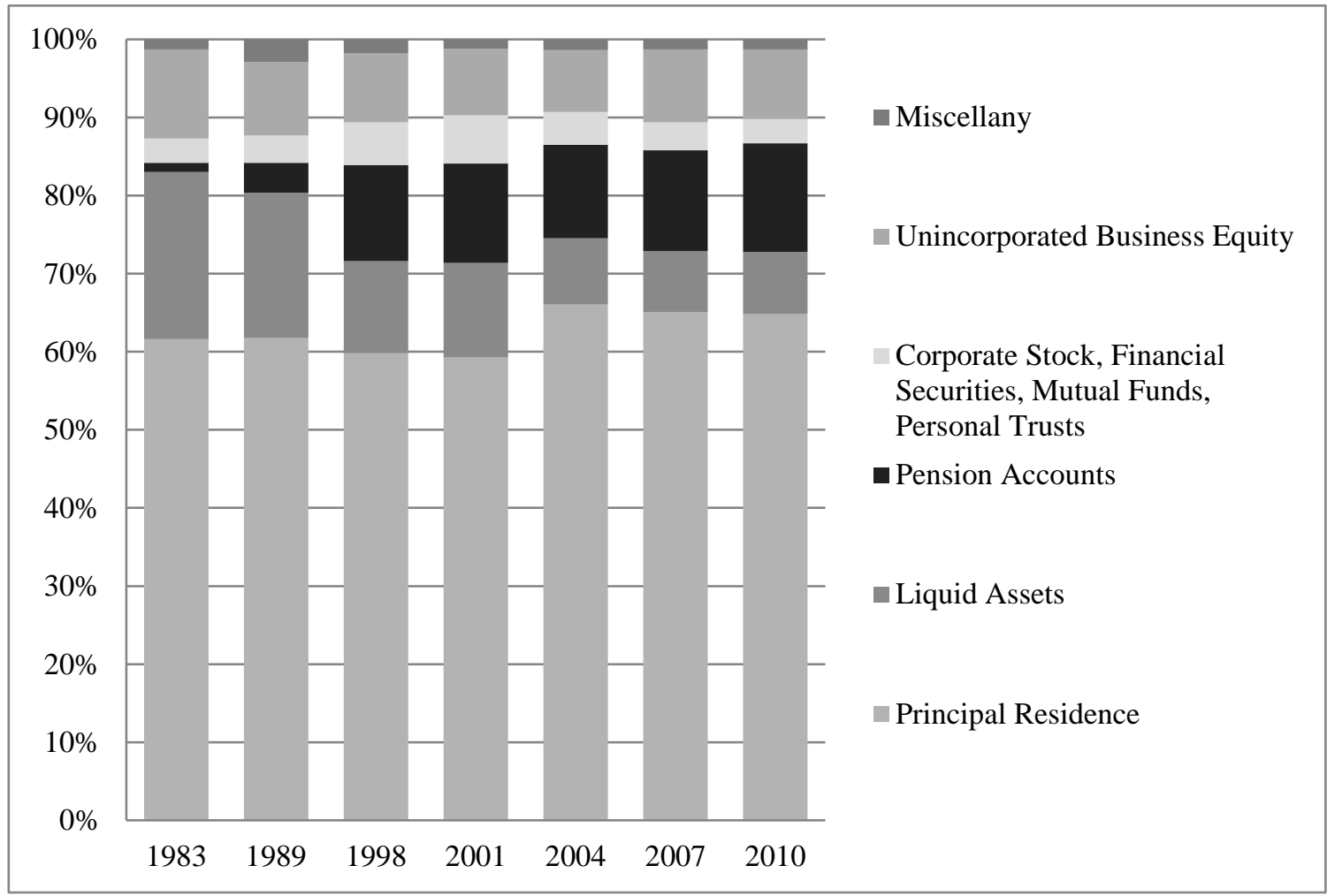

Notes: The graph illustrates that the largest share of household's balance sheets in the middle 3 quintiles of the income distribution is represented by housing, suggesting high levels of mortgage debt. Source: Wolff (2014). 
Figure 1.7 Leverage Ratio By Household Income Percentile

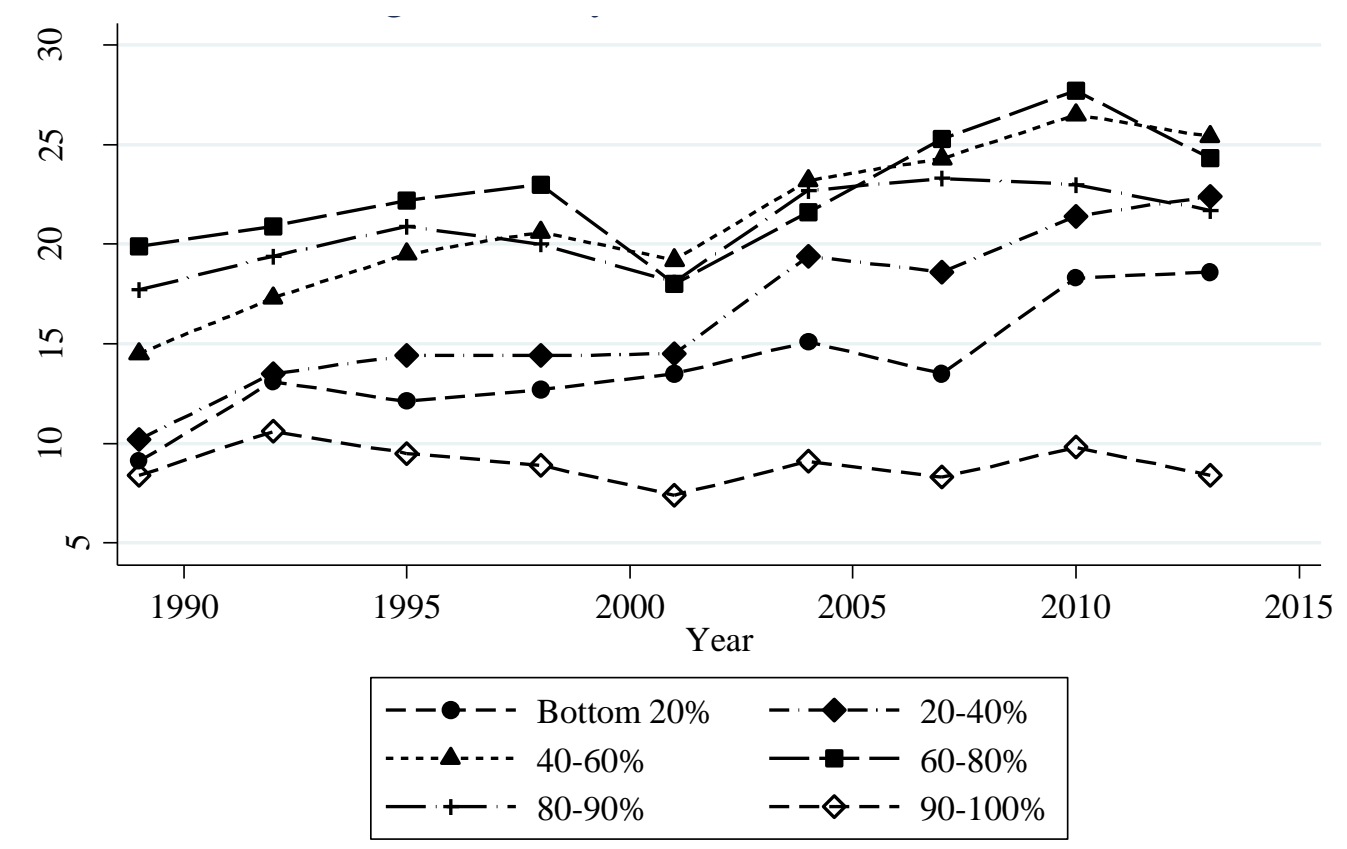

Notes: The graph shows the leverage ratio of households (debt-to-assets) across the income distribution. Source: Survey of Consumer Finances. 
Figure 1.8 Income Shares of Top Income groups

\section{Top Income Shares}

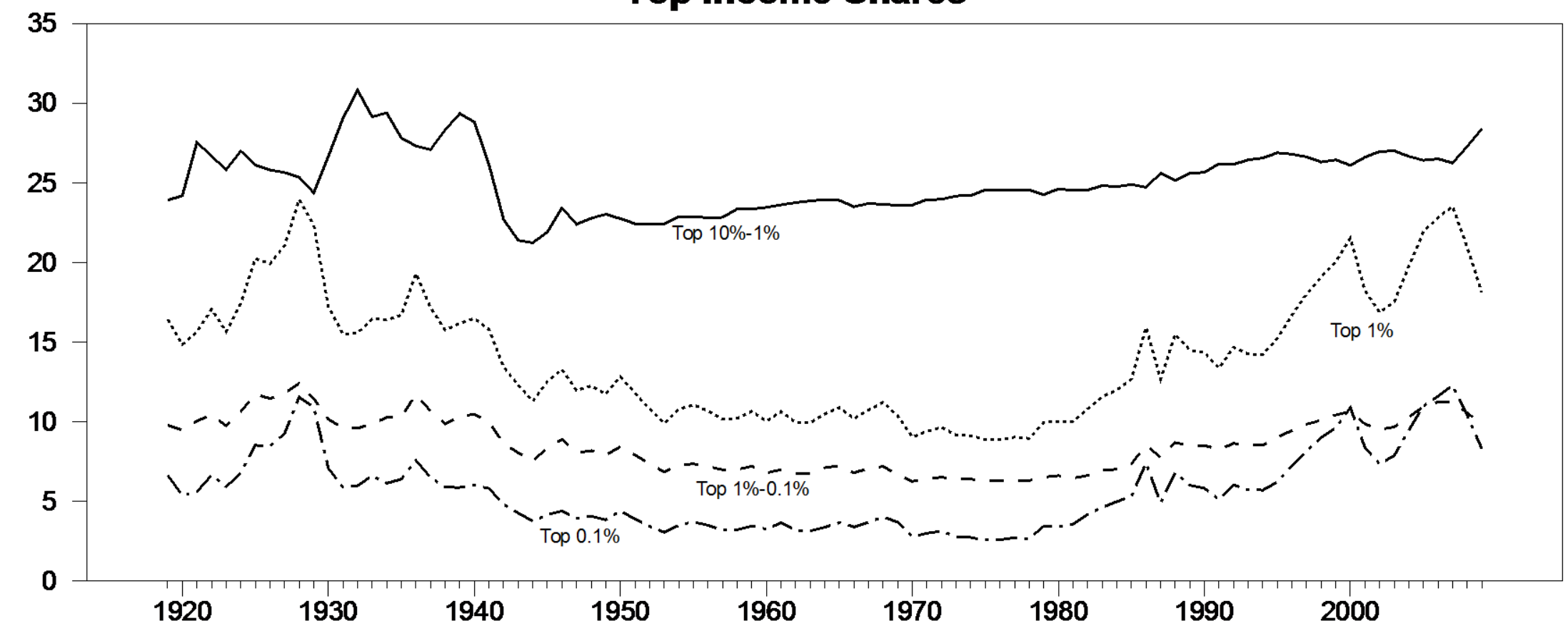

Notes: Top $10 \%$ - 1\% represents the income shares of the top $9 \%$ group. Top $1 \%-0.1 \%$ represents the income shares of the top $0.9 \%$ group. 
Figure 1.9 Generalized Impulse Responses Using Top 1\% Theil Index as Income Inequality Measure
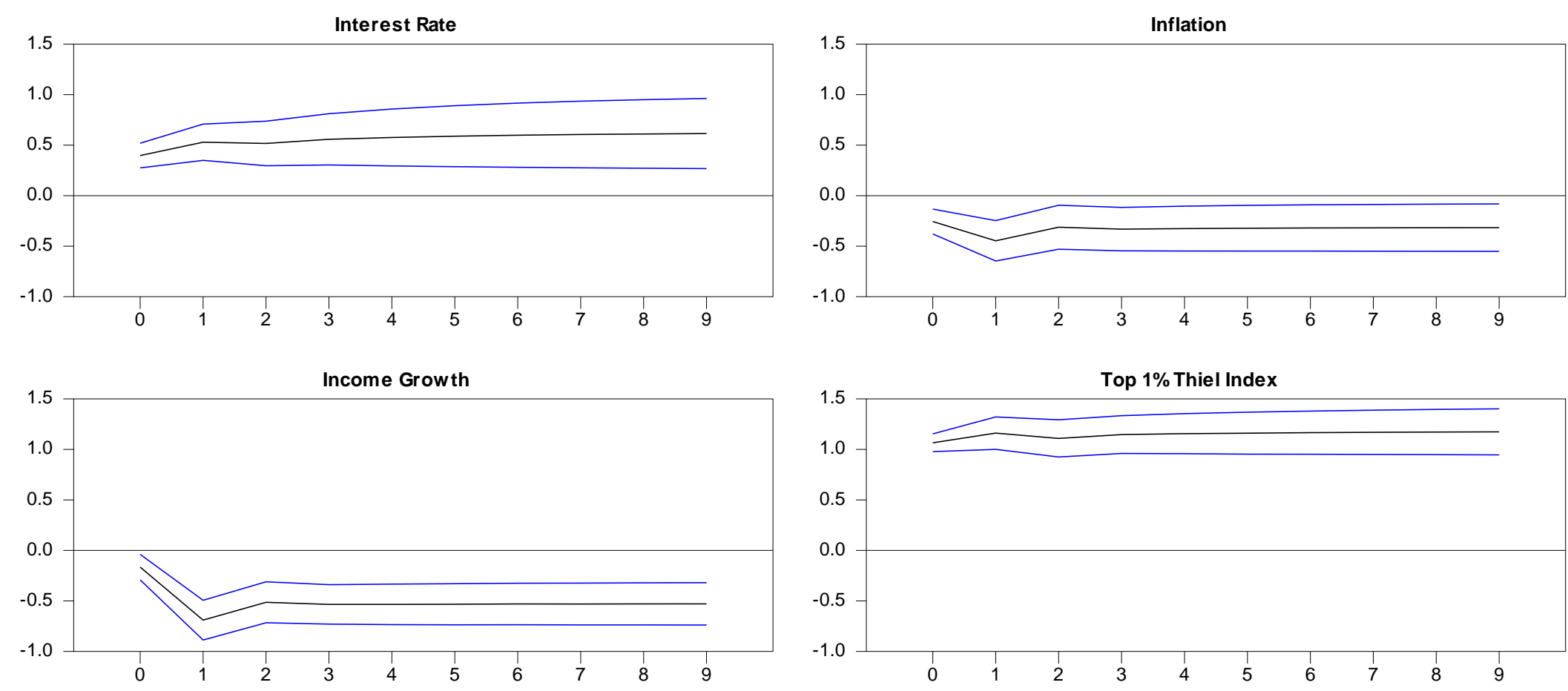

Notes: $95 \%$ confidence bands are generated using 10,000 replications in a Monte Carlo simulation. 
Figure 1.10 Variance Decompositions of Top 1\% Theil Index

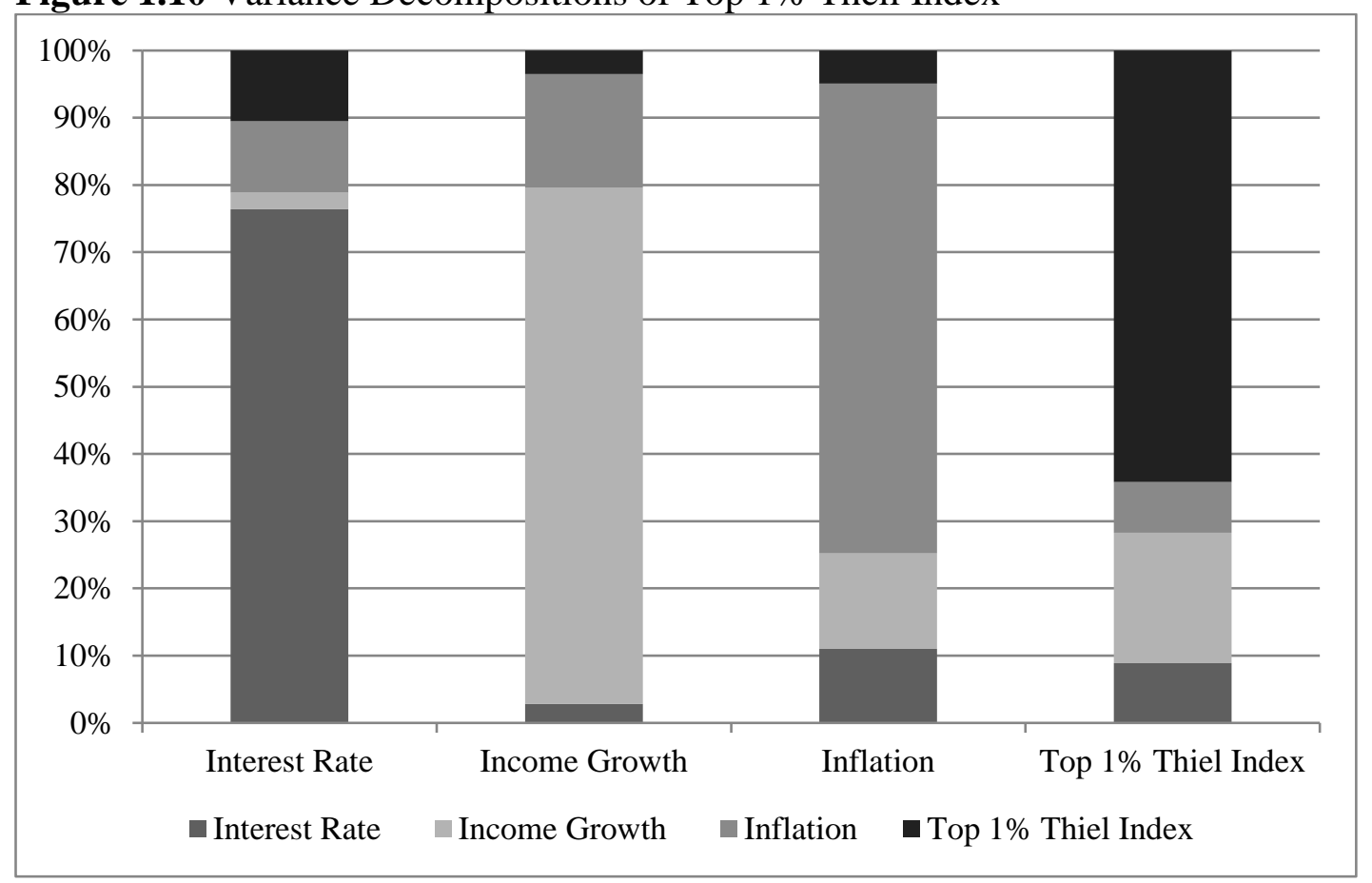


Figure 1.11 Generalized Impulse Responses Using Inverted Pareto-Lorenz coefficient (including capital gains) as Income Inequality Measure
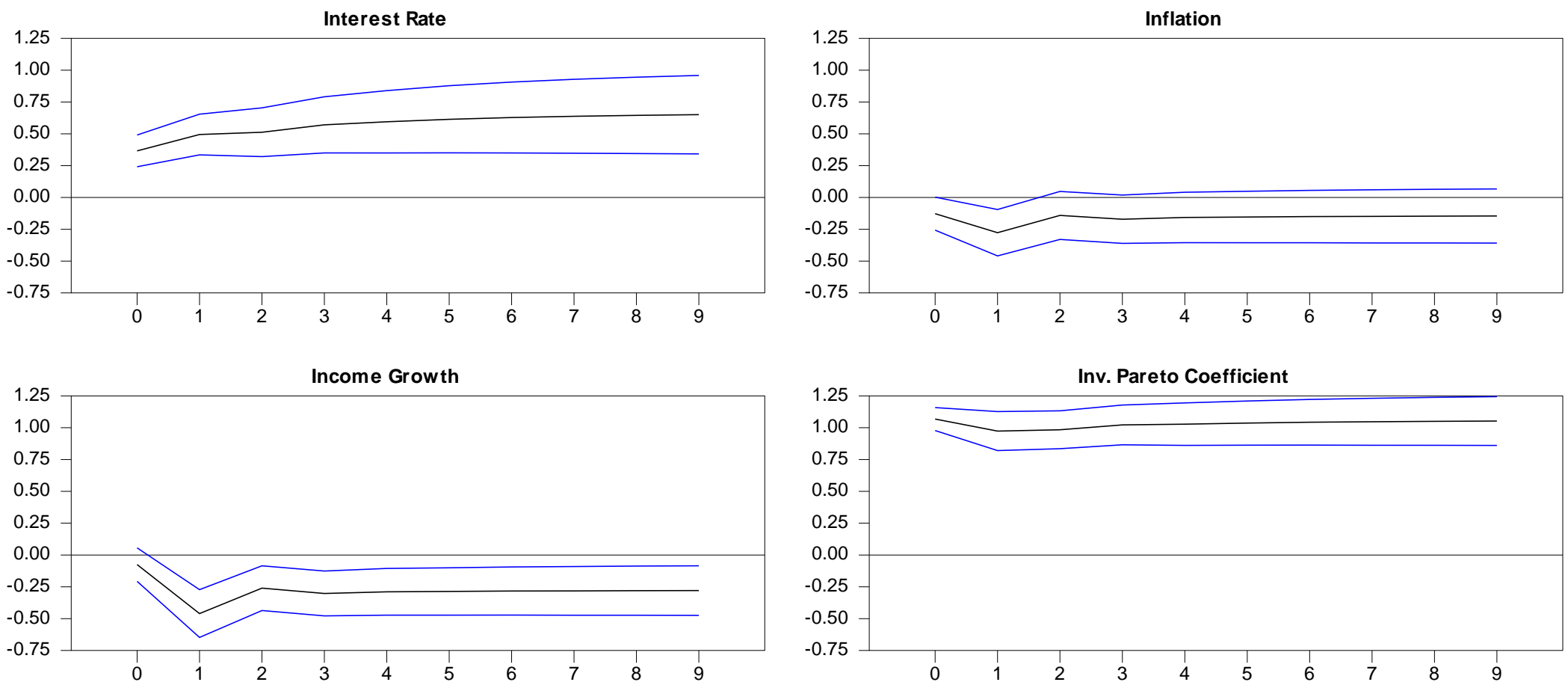

Notes: $95 \%$ confidence bands are generated using 10,000 replications in a Monte Carlo simulation. 
Figure 1.12 Variance Decompositions of Inverted Pareto-Lorenz Coefficient

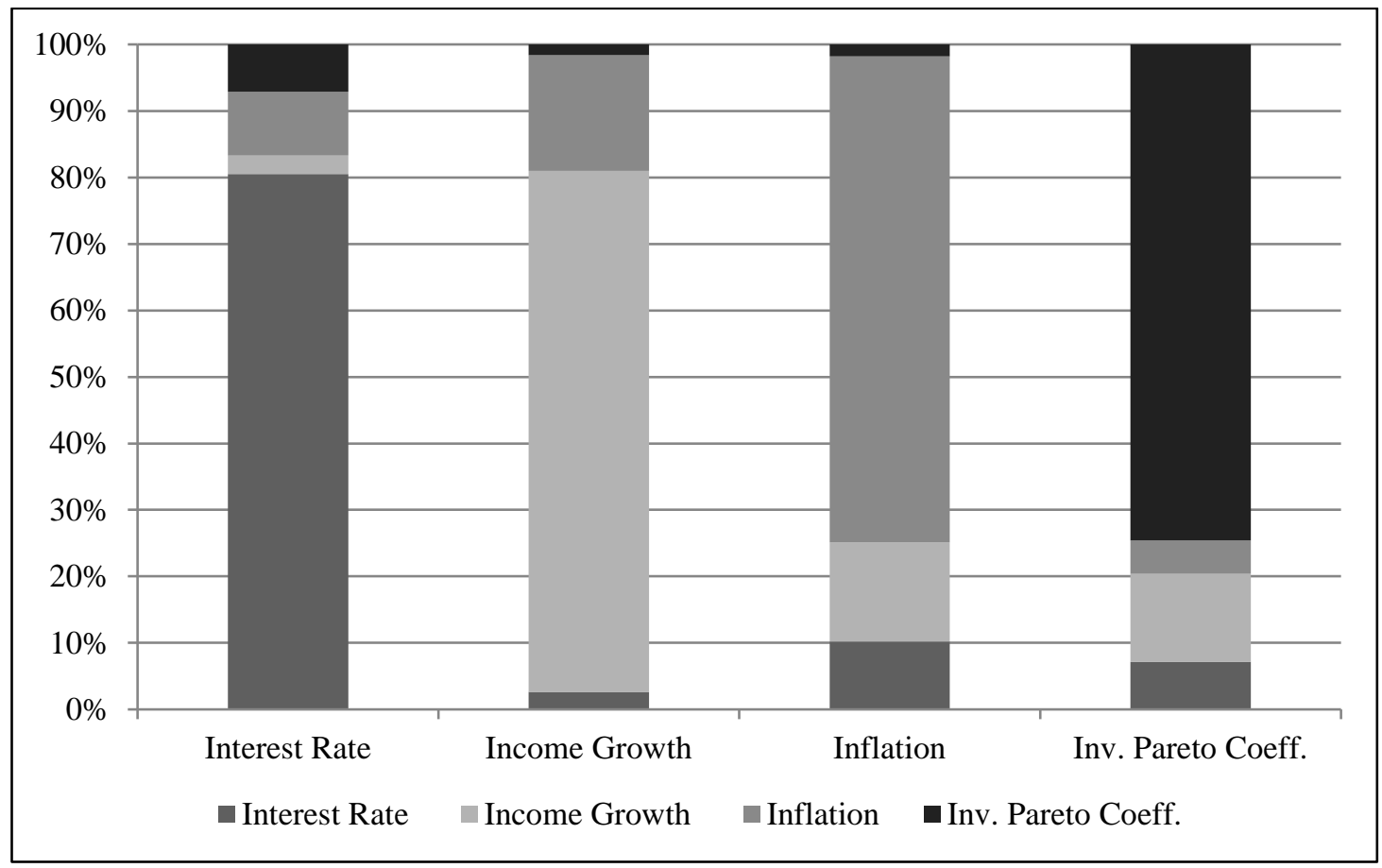


Table 1.1 Structural Break Tests

\begin{tabular}{|c|c|c|c|}
\hline \multirow{2}{*}{$\begin{array}{c}\text { Model A } \\
\text { Series }\end{array}$} & \multicolumn{3}{|c|}{$\begin{array}{c}\text { Table 1A: Minimum LM Unit Root Test with } \\
\text { Two Breaks in Levels } \\
\end{array}$} \\
\hline & $\hat{k}$ & $\widehat{T_{b}}$ & $\begin{array}{l}\text { LMt-test } \\
\text { statistic }\end{array}$ \\
\hline Inverted Pareto Coef. & 7 & 1987,2000 & -1.3822 \\
\hline Top $1 \%$ Thiel Index & 1 & 1950,1987 & -1.4060 \\
\hline
\end{tabular}

Notes: $\hat{k}$ is the optimal number of lagged first-differenced terms included in the unit root test to correct for serial correlation. $\widehat{T_{b}}$ denotes the estimated break points. Critical values for the twobreak minimum LM unit root test at the $10 \%, 5 \%$, and $1 \%$ level of significance are -3.504, 3.842 , and -4.545 .

\begin{tabular}{|c|c|c|c|c|}
\hline \multirow{2}{*}{$\begin{array}{c}\text { Model C } \\
\text { Series }\end{array}$} & \multicolumn{4}{|c|}{$\begin{array}{l}\text { Table 1B: Minimum LM Unit Root Test with Two } \\
\text { Breaks in Levels and Trend }\end{array}$} \\
\hline & $\hat{k}$ & $\widehat{T_{b}}$ & $\begin{array}{l}\text { LMt-test } \\
\text { statistic }\end{array}$ & $\begin{array}{l}\text { Critical values } \\
\text { break points }\end{array}$ \\
\hline Inverted Pareto Coef. & 8 & 1945,1977 & -4.5264 & $\lambda=(0.2,0.6)$ \\
\hline Top $1 \%$ Thiel Index & 2 & 1946,1980 & -5.2439 & $\lambda=(0.2,0.6)$ \\
\hline
\end{tabular}

Notes: $\hat{k}$ is the optimal number of lagged first-differenced terms included in the unit root test to correct for serial correction. $\widehat{T_{b}}$ denotes the estimated break points. Critical values for the twobreak minimum LM unit root test with linear trend at the $10 \%, 5 \%$, and $1 \%$ level of significance depend (somewhat) on the location of the breaks $\lambda=\left(\frac{T_{B 1}}{T}, \frac{T_{B 2}}{T}\right)$. The critical values shown below come from Table 2 in Lee and Strazicich (2003).

\begin{tabular}{|c|c|c|c|}
\hline Break Points & \multicolumn{3}{|c|}{ Critical Values } \\
\hline$\lambda=\left(\frac{T_{B 1}}{T}, \frac{T_{B 2}}{T}\right)$ & $\mathbf{1 \%}$ & $\mathbf{5 \%}$ & $\mathbf{1 0 \%}$ \\
\hline$\lambda=(0.2,0.4)$ & -6.16 & -5.59 & -5.27 \\
\hline$\lambda=(0.2,0.6)$ & -6.41 & -5.74 & -5.32 \\
\hline$\lambda=(0.2,0.8)$ & -6.33 & -5.71 & -5.33 \\
\hline$\lambda=(0.4,0.6)$ & -6.45 & -5.67 & -5.31 \\
\hline$\lambda=(0.4,0.8)$ & -6.42 & -5.65 & -5.32 \\
\hline$\lambda=(0.6,0.8)$ & -6.32 & -5.73 & -5.32 \\
\hline
\end{tabular}


Table 1.2 Variance Decomposition Top 1\% Theil

TABLE 2: Variance Decomposition Top1\% Theil Index

\begin{tabular}{|c|c|c|c|c|c|}
\hline & Interest Rate & Income Growth & Inflation & Top 1\% Theil Index & From Others \\
\hline Interest Rate & 77.1 & 2.3 & 8.9 & 11.8 & 23 \\
\hline Income Growth & 2.6 & 77 & 16.9 & 3.5 & 23 \\
\hline Inflation & 10 & 14.5 & 71.2 & 4.7 & 29 \\
\hline Top 1\% Theil Index & 10 & 18.8 & 6.9 & 64.3 & 36 \\
\hline To Others & 22 & 36 & 33 & 20 & \\
\hline
\end{tabular}


Table 1.3 Variance Decomposition Inv. Pareto-Lorenz

TABLE 3: Variance Decomposition Inv. Pareto-Lorenz Coef.

\begin{tabular}{|c|c|c|c|c|c|}
\hline & Interest Rate & Income Growth & Inflation & Inv. Pareto Coeff. & From Others \\
\hline Interest Rate & 79 & 2.5 & 8.7 & 9.7 & 21 \\
\hline Income Growth & 2.5 & 78.7 & 17.3 & 1.5 & 21 \\
\hline Inflation & 9.5 & 15 & 73.7 & 1.8 & 26 \\
\hline Inv. Pareto Coeff. & 9.9 & 12.5 & 3.7 & 73.9 & 26 \\
\hline To Others & 22 & 30 & 30 & 13 & \\
\hline
\end{tabular}




\section{Central Bank Independence's Effect on Foreign Direct and Portfolio Investment}

\subsection{Introduction}

Recently, central banks have come into the public spotlight due to the international financial crisis of 2007 and for the actions they took following it, such as quantitative easing. Developing countries have come under particular scrutiny for both the effects of the financial crisis and quantitative easing on their economies and how they have responded to it. For instance, countries such as India, China, and Brazil, have experimented with capital controls to try and mitigate the effects of international capital flows. Recent work by Patnaik and Shah (2012) shows that capital controls may be helpful in the short-term for controlling capital flows, but seem to be ineffective over a long horizon.

In regards to central banks, Cukierman (1992) stoked initial interest in central bank independence. The basic idea is that more independence reduces the rate of inflation in a country as "conservative" central bankers are more likely to take action in response to potential or impending inflationary pressures. Although central bank independence has received much attention in the literature, most research has focused on four topics: GDP growth, GDP growth volatility, inflation, and inflation volatility. In light of the recent interest in capital flows, this paper takes the literature in a new direction and investigates how central bank independence affects capital inflows via foreign direct investment and portfolio investment. Intuitively, a more credible central bank may bring more capital and investment into a country as investors feel safer investing in a more stable financial environment. Additionally, more central bank independence 
may signal a more stable political environment. Figure 2.1 and Figure 2.2 show how foreign direct investment, portfolio investment, and central bank independence are related. Specifically, the figures show foreign direct investment and portfolio investment compared to central bank independence for the years 1978 and $2001 .{ }^{3}$ As can be seen, in 1978 , central bank independence surprisingly seems to have a slightly negative effect on capital flows. Also, in 1978, foreign direct and portfolio investment are relatively small: no more than $4 \%$ relative to nominal GDP in any country. However, by 2001, more independence seems to be more clearly related to increases in foreign direct and portfolio investment although the effect on portfolio investment is much weaker. Additionally, notice that the flows are much larger as percentages of GDP by 2001, showing that international capital movements have become more important for global economies over time.

\subsubsection{Past Literature on Central Bank Independence}

Central bank independence became a topic of interest as the result of several influential papers about inflation bias. Kydland and Prescott (1977) demonstrated that, if policy makers can convince the general public of a certain inflation rate and then "surprise" the public with a higher rate than expected, there will be a temporary boost to employment. However, this "surprise" comes at a cost. If agents are rational, they will, over time, anticipate the "surprise" inflation and, in the long run, the economy will only experience inflation, without the boost to employment. This higher inflation is typically viewed as harmful to long-run economic growth and, thus, inflationary policies should be avoided. Similarly, Barro and Gordon (1983) showed that a policy maker who follows an inflation rule will achieve the same level of output as a policy maker with discretion (i.e. the ability to change monetary policy freely) without the higher inflation. Therefore, it is beneficial to adopt an enforceable rule to constrain policy makers so they are not

\footnotetext{
${ }^{3}$ Ireland is excluded from the graphs due to scaling issues.
} 
tempted to inflate for a temporary boost in employment. Rogoff (1985), in response to these ideas on inflation bias, proposed that countries should make their central banks politically independent and appoint a "conservative" central banker, conservative in the sense that the central banker is more averse to inflation than policy makers. This insures that inflation will not be tied to the potentially politically motivated whims of policy makers. Another option to fight inflation bias is to create contracts that tie central banker's pay directly to inflation performance as suggested by Walsh (1995).

Empirically, one of the earliest papers employing Kydland and Prescott and Rogoff's theory was Bade and Parkin (1988). They analyzed 12 industrialized countries over the period 1972 to 1986 . Their independence measure focused on how the central bank was financed (whether the government or the bank determines salaries, etc.) and how central bank members were appointed (whether appointed by the country's government or not). They found that higher scores of central bank independence lowered inflation in their sample. Cukierman, Webb, and Neyapti (1992) expanded on this idea and created their own index of central bank independence. The independence index looked at how the central bank governor was appointed, whether or not the bank had a specific policy objective, among numerous other indicators, and they weighted this information and aggregated it to create the index for their sample of countries. They also developed a measure known as the turnover rate, which looked at how often the central bank governor was replaced, to proxy central bank independence. The idea behind the turnover rate was that a more politically independent central bank would have fewer changes in chairpersons and this would lead the country to have lower inflation. Their study found that a higher central bank independence index score lowered the rate of inflation in industrial countries and, similarly, a higher turnover rate increased inflation in developing countries. Likewise, Alesina and 
Summers (1993), using an index of central bank independence, showed that having a higher independence score lowered inflation among industrialized countries.

The key departure from the past literature in this paper is to analyze central bank independence's effect on capital flows and foreign direct investment into countries. As far as the author knows, there is little investigation of CBI's effect on variables other than inflation and output. The idea is that a more independent central bank is a signal to investors that a country is more credible and safer for investment than a country with weaker central bank institutions. This signal should, according to the simple hypothesis, lead to more investment as investors feel confident that their purchases will not have their value eroded by runaway inflation or other financial crises. Also, more independence may signal that the country is more politically stable and foreign investors may thus feel more confident that their investments will not be appropriated by the state. To preview the results, central bank independence has a small, positive affect on foreign direct investment, but seems to not influence portfolio investment. The rest of the paper is structured as follows. Section 2 explains the data used for this paper and the econometric models. Section 3 discusses the empirical results and Section 4 concludes.

\subsection{Empirical Model and Data}

\subsubsection{Modelling Technique}

The modelling technique used to test the "more independence, more investment" hypothesis has foreign direct investment and portfolio investment as the dependent variable. The modeling technique uses robust standard errors clustered by country. The specification is as follows:

$$
F_{i t}^{j}=\theta^{j} \omega_{i t}+\delta_{C B I}^{j} C B I_{i t}+\eta_{t}^{j}+\varepsilon_{i t}^{j}
$$

where $F_{i t}^{j}$ is the type of capital flow normalized by nominal GDP for each type of capital flow $j=1,2$ (foreign direct and portfolio investment) to each country $i=1 \ldots N$ and over time $t=1 \ldots T$. $\omega$ 
is a matrix of controls which will be discussed further below. $\eta_{t}^{j}$ are year dummies, which should help control for the global economic conditions affecting portfolio flows. Foreign direct investment covers $N=30$ countries over the period 1978 to 2007 for a total of 900 observations. ${ }^{4}$ Portfolio investment covers $N=20$ countries over the period 1978 to 2007 for a total of 600 observations. The panels are fully balanced. Countries used in each regression specification are listed in Table 2.2.

\subsubsection{Data Description}

The CBI data for each country comes from Acemoglu et al.'s (2008) paper. The innovation in the Acemoglu paper is that they calculate a Cukierman-type CBI index but the measure can change based on whether reforms occurred in a country's central bank. They exclude former communist countries and African countries as they feel these are hard to measure due to economic and political instability. However, many OECD and South American countries are included in the sample. Most of the changes in CBI occurred in the 1990s, but some changes occurred earlier. Thus, the measure, which ranges from 0 to 1 , provides a (potentially) time varying measure of independence, as opposed to the static measures used by Cukierman, Webb, and Neyapti and Klomp and Haan described earlier. I multiplied each CBI measure by 100 for ease of exposition in the results. ${ }^{5}$ The main advantage in using the Acemoglu et al. data is that it allows for a panel analysis as opposed to the older data that only allowed for cross-sectional analysis.

The left hand side variables for all the regression models are foreign direct and portfolio investment. Foreign direct investment (FDI) is defined by the International Monetary Fund as

\footnotetext{
${ }^{4} 2007$ was chosen as the cutoff date due to data availability and also to avoid confounding effects from the financial crisis.

${ }^{5}$ I can explain more clearly how CBI affects investment. For instance, for a 1 point increase in the CBI index, investment increases by " $\mathrm{X}$ " percentage points.
} 
"when a direct investor directly owns equity that entitles it to 10 percent or more of the voting power in the direct investment enterprise" (Balance of Payments Manual, p.101). The other measure used was portfolio investment liabilities (PI) defined by the IMF as "cross-border transactions and positions involving debt or equity securities, other than those included in direct investment or reserve assets" (Balance of Payments Manual, p.110). Liabilities were chosen, specifically, as this measure represents foreigners' portfolio investment in a given country. In the data, if foreigners buy stocks or undertake other portfolio type investments in a given country, this shows up as a positive number because it is a capital inflow into the country. Likewise, if foreigners are selling off portfolio investments, then this is recorded as a negative number by the IMF, a capital outflow (Danby (2014)). The variable is not a net measure. A net measure of capital flows was not used because the paper is specifically interested in how CBI attracts or repels investment into a specific economy, not how investors in a given country change their foreign and total capital holdings based on a change in their own country's CBI score.

\subsubsection{FDI and PI and Factors Influencing Investment}

Both FDI and PI were included to see if CBI had an effect on two narrow investment measures. The motivation for using both measures came from Hashimoto and Wacker (2012) who examined both to see if countries that participated in IMF data reforms had increased investment in both measures. The specific data series' for direct investment and portfolio investment used in this paper's analysis came from the IMF's International Financial Statistics database September 2010 edition. ${ }^{6}$ Both FDI and PI are measured in millions of US dollars. Additionally, FDI and PI were divided by nominal GDP to alleviate scale problems as some countries, such as the United States, have large FDI and PI compared to smaller countries, such

\footnotetext{
${ }^{6}$ Series codes: Direct Investment: DIR. INVEST. IN REP. ECON., N.I.E. Portfolio Investment: PORTFOLIO INVESTMENT LIAB., N.I.E.
} 
as Israel, but, when scaled by nominal GDP, the relative amounts are similar among most countries. ${ }^{7}$ In addition, some values of both the FDI and PI series are negative (indicating outflows) and thus taking the logarithm of the series' would be inappropriate as past authors have done.

Humanicki et al. (2013) and Hashimoto and Wacker (2012) provide excellent overviews of what factors might drive foreign direct and portfolio investment. Further, Alfaro et al. (2005) note that most international investment takes place between developed nations. Alfaro et al. (2005) argue that the quality of institutions (property rights, political stability, and so on) are the driving factors in the higher level of investment in the developed nations. Central bank independence would be one piece of quality institutions and is likely the primary institution that influences macroeconomic factors such as inflation and inflation volatility in countries. Dunning (1993) notes 3 factors influencing the amount of FDI: market-seeking (size of the economy, GDP growth), resource-seeking (natural resources, human capital), and efficiency-seeking (tax environment, labor costs). Central bank independence would likely fall in the efficiency-seeking category. Thus, a more independent central bank would make investing in a nation more attractive as economic conditions and financial practices would likely be more stable. Calvo et al. (1993, 1996) note that, during the late 1980s and early 1990s, many developing countries enacted reforms that stabilized macroeconomic conditions and exchange rates and this led to increasing capital investment. Greater central bank independence would certainly help stabilize macroeconomic conditions and exchange rate policy, so it makes sense that there may be a relationship between CBI and foreign direct and portfolio investment. Papaioannu and Duke

\footnotetext{
${ }^{7}$ Nominal GDP World Bank Code: NY.GDP.MKTP.CD
} 
(1993) corroborate Calvo et al. $(1993,1996)$ and suggest that institutional reforms (such as improving central bank independence) increase investor confidence and promote investment. Portfolio investment may be driven by related but slightly different factors. FernandezArias (1996) and Taylor and Sarno (1997) highlight what they call "push" and "pull" factors regarding capital flows. The "push" factors are best understood as global economic conditions, such as U.S. interest rates, U.S. output growth, and similar factors in other large economies (i.e. China, Europe). "Pull" factors are related to the country attracting the investment and include things such as capital openness, the country's credit rating, and other financial factors. Further, both Fernandez-Arias (1996) and Taylor and Sarno (1997) acknowledge that output growth and future expected output, the financial climate of the country, and financial openness play a part in portfolio investment. So, as far as central banks affect output and the investment climate of a country, there is reason to suspect that a more independent central bank may encourage portfolio investment. Bekaert (1995) also notes that credit ratings and the price of sovereign debt affects investment.

In addition, there is a related micro-oriented literature that discusses why firms and which firms engage in FDI. This is not the main focus of this paper but it is useful background information regarding micro-level firm behavior. Along these lines, Helpman (2006) provides an extensive overview of FDI and trade from the level of the firm on a theoretical basis. Specifically, Helpman et al. (2004), in a theoretical model, show that only the most productive firms will engage in FDI. Other firms may export, but these firms are slightly less productive than the FDI firms. The least productive firms neither export nor engage in FDI and produce only for the domestic market. These results were built on and confirm empirical studies of French firms by Eaton et al. (2004) and U.S. firms by Bernard et al. (2005) which show that only 
a small portion of firms export and only a small portion of their total output is exported. Thus, low-productivity firms are not exporting or engaging in FDI. Further, Goldstein et al. (2010) note that multinational corporations are more likely to engage in FDI while investment funds are more likely to engage in portfolio investment. This is built upon their theoretical model (Goldstein and Razin (2006)) where investors face a tradeoff between FDI and PI. Namely, FDI allows for greater control and better information about the firm, which allows for greater profitability. However, if the investor has an adverse liquidity shock, the FDI enterprise may prove harder to sell due to asymmetric information between the seller (the investor) and the potential buyers, which may result in the investor selling at a loss. Goldstein and Razin (2006) frame this as a "lemon" problem (as in Akerlof (1970)) where the potential buyers are unsure whether the investor is selling due to cash flow problems or if the enterprise is unprofitable and failing. Thus, multinational corporations, with more stable liquidity, are likely to pursue FDI and investment funds are likely to prefer PI as they face less of an information problem and can sell portfolio investments more quickly to satisfy liquidity needs.

In regards to the regression specifications, the controls used were based on variables used in Hashimoto and Wacker (2012) and on the literature review of Humanicki et al. (2013). I selected several variables that Hashimoto and Wacker found to be statistically significant across their FDI and PI specifications. Specifically, I included GDP growth using data from the IMF's International Financial Statistics database. This should help control for short-term growth opportunities in a country. For instance, perhaps an economy is growing rapidly, firms notice this, and this causes further investment as the country is seen as a "hot" market. This should be relevant for both portfolio and foreign direct investment. To capture countries' long-term growth prospects, I used gross capital formation as a percentage of GDP from the World Bank database 
as suggested by Hashimoto and Wacker, which captures the long-term investment potential of a country. This may be more informative for foreign direct investment as portfolio investment tends to be focused on a shorter time-horizon.

To control for market size, I use the logarithm of GDP for each country in current US dollars from the World Bank database. Intuitively, larger markets may attract more investment. For example, the US is a much larger market than Ireland and, thus, may attract more investment and capital flows simply by being larger. This is likely more important for foreign direct investment as market access is a key consideration when building production capacity in a nation. Portfolio investors are not necessarily concerned with market size, but, rather, profitability. Pfeffer (2008) explains the primary tradeoff between FDI and PI: more profitable, and less liquid FDI and less profitable, more liquid PI. Firms may invest through both methods though. Bevan and Estrin (2004) also note market size as an important component of investment for emerging markets (their study focused on former communist countries in Eastern Europe). Capital openness, which captures the ease of investing in a country, would likely attract more investment. To control for this, I use Chinn and Ito's (2006) measure of capital openness. ${ }^{8}$ Capital openness is likely more important for portfolio rather than foreign direct investment. Similarly to CBI, I multiply Chinn and Ito's openness measure by 100 for ease of exposition. Lastly, movements in the exchange rate may induce capital inflows or outflows. Thus, in the regressions, I use a real exchange rate measure created by Zsolt (2012). This also likely has more of an effect on PI than on FDI. Summary statistics for all variables are included in Table 2.1. A list of the countries used in the regressions is shown in Table 2.2.

\subsection{Empirical Results \\ 2.3.1 FDI Results}

${ }^{8}$ Specifically, I use Chinn and Ito's ka_open measure, which normalizes their index from 0 to 1. 
The estimates for the effect of FDI are modelled as follows:

$$
F D I_{i t}^{j}=\theta^{j} \omega_{i t}+\delta_{C B I}^{j} C B I_{i t}+\eta_{t}^{j}+\varepsilon_{i t}^{j}
$$

Table 2.3 shows the estimation results with FDI as the dependent variable, using both fixed effects (FE) and random effects (RE) estimation as alternate estimation techniques. The first two columns show the effect of CBI on FDI not including the controls, using fixed effects and random effects estimation, respectively. As can be seen, there does seem to be a positive, statistically significant effect on FDI. Columns 3 and 4 show the results with the full set of controls included. Using both fixed and random effects estimation, the coefficients on CBI are significant, albeit only at the $10 \%$ significance level, and have roughly the same magnitude.

However, the RE model makes additional assumptions on the regressors: namely, that the regressors are uncorrelated with the group-specific errors. The FE model only imposes that the regressors are uncorrelated with the idiosyncratic errors. This means the RE model is more efficient, but only if the restrictions hold. Thus, the additional conditions of the RE model are overidentifying restrictions and can be tested using the xtoverid package in STATA (using the artificial regression approach from Arellano (1993) and Wooldridge (2002)). This is similar to the standard Hausman test but allows for clustered and robust standard errors to be used. A rejection of the null hypothesis indicates that the additional restrictions imposed by the RE model are not valid and, thus, the FE model should be used. The test returns a Sargan-Hansen statistic of 1575.8 with a p-value of 0.000 , indicating strong rejection of the random effects estimation. The FE estimator also has an advantage in that, if the unobserved effect has a spatial element to it (i.e. countries near each other have similar FDI), then the FE estimator solves this problem. Adjustments are needed if one uses OLS or the RE estimator and there is spatial correlation (Wooldridge (2006)). Thus, column 3, the FE estimator is preferred. In addition, an F-test testing 
the condition that all the time dummies are equal to zero was run for the FE model in column 3. The F-statistic for the FE model time dummies was 203.2, strongly indicating that the coefficients are not all equal to zero and need to be included in the model.

Further, the standard errors are clustered by country for models 1-4. The STATA documentation on clustered standard errors states the following: "The cluster robust standard errors specify that the standard errors allow for intragroup correlation, relaxing the usual requirement that the observations be independent. That is, the observations are independent across groups (clusters) but not necessarily within groups." In other words, the clustered standard errors control for correlated errors within a group (in this case, a country), while the errors for different countries are assumed to be independent (Cameron and Miller (2015), Wooldridge (2006)). The clustered standard errors are advantageous as failure to control for the within-group error correlation can lead to misleadingly small confidence intervals and small p-values (Cameron and Miller (2015)). Further, an additional cluster specification (countries grouped by continent) was used in column 5. As seen, CBI remains statistically significant; whereas, many of the other variables do not. However, Wooldridge (2006) and Cameron and Miller (2015) both warn against using too few clusters (in the continent case there are only 5 clusters) so this estimate should be viewed with caution.

Regarding column 3, for a 1-point increase in the CBI index, the FDI to GDP ratio will go up by approximately 0.01 percentage points. If the CBI index increased by 10 points, this would lead to a 0.1 percentage point increase in the FDI to GDP ratio. Thus, if the central bank went from completely not independent (a CBI of 0 ) to completely independent (a CBI of 100) this would increase the FDI to GDP ratio by about 1.8 percentage points. This could potentially 
be a rather large effect, depending on the magnitude of the reform, as the mean value of (FDI/GDP) is 1.97 percent.

In addition, GDP growth was highly significant in both models 3 and 4 . As mentioned in Section 2, I included GDP growth using data from the IMF's International Financial Statistics database. This controls for short-term growth opportunities in a country. The coefficients indicate that, if GDP growth increases by 1 percent, the FDI/GDP ratio will increase by 0.1 , a much larger effect than for CBI. This indicates that current short-term market conditions matter significantly for direct investment. The proxy for market size (log GDP), which controls for larger markets having more investment, does not have a statistically significant effect. This was surprising given the strongly significant findings in Hashimoto and Wacker (2012). Capital openness has a small positive effect on the (FDI/GDP) ratio, but it is statistically insignificant in 2 out of the 3 regressions. Additionally, the real exchange rate does not have a statistically significant effect, similar to what Hashimoto and Wacker found across several of their models. Lastly, capital formation, which proxies for long-term investment potential, has a positive, statistically significant effect but only for the regression with continent clustering.

\subsubsection{Portfolio Investment Results}

The portfolio investment estimates are modelled as follows:

$$
P I_{i t}^{j}=\theta^{j} \omega_{i t}+\delta_{C B I}^{j} C B I_{i t}+\eta_{t}^{j}+\varepsilon_{i t}^{j}
$$

Table 2.4 shows the regression results involving portfolio investment. As can be seen, from specifications 1 and 2, CBI has a larger impact on portfolio investment than foreign direct investment, but the coefficients are statistically insignificant. When I add the control variables in specifications 3 and 4, surprisingly, none of them show up as statistically significant except for capital openness and CBI in the model with clustering by continent. As with FDI, the overidentification test was run. Similar to FDI, the test returned a Sargan-Hansen statistic of 91.3 
with a p-value of 0.000 , indicating strong rejection of the random effects estimation. Thus, model 3 is preferred to model 4 . In addition, an F-test testing the condition that all the time dummies are equal to zero was run for the FE model in column 3. The F-statistic for the FE model time dummies was 4.7 , indicating that the coefficients are not all equal to zero and need to be included in the model. As with FDI, another model using a different cluster (continent as opposed to country) was run and reported in column 5. Interestingly, CBI becomes statistically significant when using the alternate clustering. However, as mentioned in the FDI results, one should be cautious when the number of clusters is small.

In the results for model 3, GDP growth's coefficient is positive and relatively large. Log GDP, controlling for market size, increases portfolio investment, but, again, is statistically insignificant. Capital openness is associated with a small increase in portfolio investment. The real effective exchange rate is very slightly positive, similar to Hashimoto and Wacker's findings. Capital formation, controlling for long-term growth prospects, has a fairly large positive effect. Interestingly, I find no strong relationships involving CBI, the controls, and portfolio investment. This is similar to Hashimoto and Wacker's results, who find that many of their variables fail to explain portfolio investment. This could be a result of my limited sample and there seem to be other important factors influencing portfolio investment that I have failed to uncover. Perhaps in future work more financial variables (i.e. interest rates, credit ratings) could be used to further study portfolio investment.

\subsubsection{Bootstrapped Models}

Lastly, for additional robustness, I run several different models using bootstrapped standard errors with 1000 replications for FDI. Bootstrapping takes the observed distribution of coefficients or errors and resamples from this distribution any number of times to produce coefficient or standard error estimates. If the observed distribution is a good estimate of the 
population distribution, the bootstrap will perform well, particularly if you do not know the population distribution. From the bootstrap procedure, you can produce standard errors of your statistic of interest and also produce confidence intervals. The first two columns of Table 2.5 show the results for the full sample of countries. They are similar to the results from Table 2.3. In contrast, capital openness is now significant for both the fixed and random effects specification. Columns 3 and 4 show the results for only the OECD countries. The CBI index is statistically significant at the $10 \%$ level or above for both specifications and the coefficients are similar to the full sample regressions. GDP growth is statistically significant and positive as with the original regression results. The lag of GDP and capital openness switch significance based on the estimation technique used. Interestingly, the real exchange rate is negative and significant at the $99 \%$ level regardless of the estimation technique used, indicating an appreciation of the home country currency (for OECD nations) decreases FDI. Also, capital formation (a proxy for longterm investment stability) appears to be insignificant, perhaps because OECD countries are already seen as stable, long-term investment destinations, so this variable is not providing "new" information for investors.

Columns 5 and 6 show the results for the non-OECD countries. CBI is only weakly significant in the fixed effects model. GDP growth is highly significant for the non-OECD countries, similar to the developed nations. Capital openness is significant, but the effect is small. For the non-OECD countries, a real exchange rate appreciation increases FDI in a statistically significant manner in the RE regression, although the effect is small. This provides some evidence for Hashimoto and Wacker's assertion that real appreciation of a country's currency may stimulate FDI, particularly for developing countries (p.22). Capital formation's significance 
depends on the technique used. This may indicate that capital formation provides investment information for investors evaluating developing nations for possible FDI.

Finally, Table 2.6 shows the results of FDI regressions splitting the sample based on location. One excludes South American countries (Non-South America) and one excludes European countries (Non-Europe). The full sample results are included for comparison. As seen, the coefficients for CBI on both the Non-South America and Non-Europe sample are significant, at least at the $10 \%$ level. In addition, the size of the coefficients is similar to the full sample results. Furthermore, GDP growth is highly significant for both Non-South American and NonEuropean countries, although the size of the effect is larger for countries outside of South America. As before, the logged level of GDP switches signs and is not significant in the fixed effects models. Capital openness is significant across both specifications, indicating ease of doing business matters for investors. Consistent with Hashimoto and Wacker's original work, the real exchange rate is, in 5 out of 6 specifications, statistically insignificant insofar as FDI is concerned. Lastly, as with the original results in Table 2.3, capital formation is statistically significant for both Non-European and Non- South American countries, indicating that long term investment prospects are important for FDI.

The bootstrapped results highlight several additional important pieces of information concerning FDI. First, CBI may matter only for OECD/developed nations. Perhaps because, even if a developing nation has a high CBI score, investors are still skeptical about the stability of these countries. For OECD nations, it indicates that a more credible central bank can increase investment. Perhaps because investors believe credible central banks will keep financial conditions stable and thus feel more comfortable committing their resources to a nation with a strong central bank. Second, the real exchange rate has a different effect depending on whether 
the country is an OECD member or not. Lastly, capital formation, which indicates long-term investment suitability, primarily matters for developing countries. However, when I split the sample along geographic lines, non-Europe vs. non-South America, the results stay more consistent with the full sample results. The geographic split specifications show that CBI, GDP growth, capital openness, and capital formation all matter for investors regardless of location.

\subsection{Conclusion}

Central bank independence studies, in the past, primarily focused on GDP and inflation measures. This paper's purpose was to broaden the scope of the literature by examining how CBI affects portfolio investment and foreign direct investment. Based on the panel regressions run in this paper, there appears to be some evidence that CBI does have a small, statistically significant effect on foreign direct investment but not portfolio investment. CBI also appears to affect countries slightly differently depending on location and stage of economic development. This corresponds with a recent study by Bodea and Hicks (2013) who find that CBI has a larger impact on developing countries. The possible extensions to this initial investigation are numerous. For starters, more advanced empirical models could be specified such as a spatial model to capture the regional dependence of various countries. This paper kept the regression methods simple to see if there was any evidence that CBI affects PI or FDI. Also, it has been conjectured that the current indices may not measure CBI well. For instance, they do not attempt to take into account the operational efficiency of central banks. A new index that investigates this would be an interesting new direction in the central bank independence literature. In sum, this paper provides an avenue into a new central bank independence topic; whereas, the literature had previously been focusing on two interesting, but limited, topics.

\subsection{Figures and Tables}


Figure 2.1 Foreign Direct and Portfolio Investment in 1978

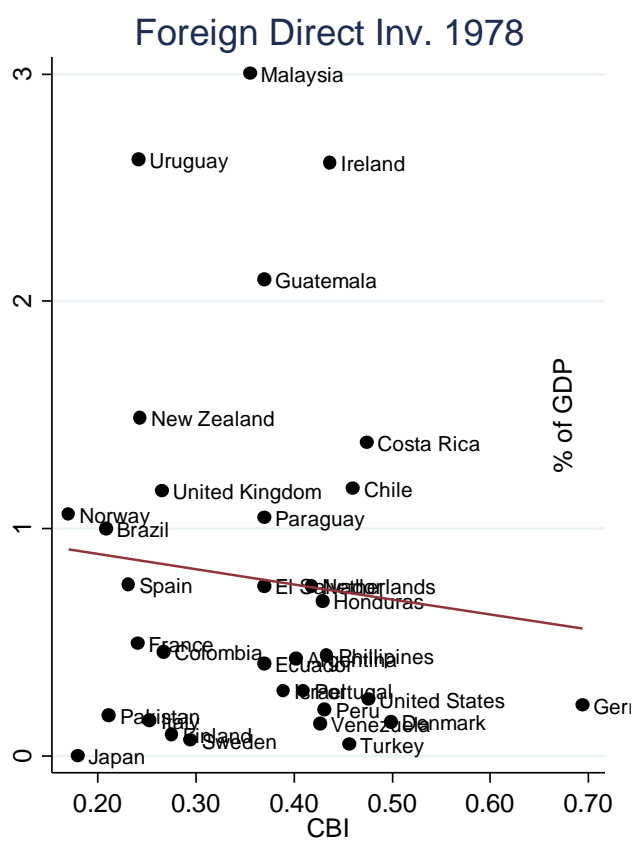

- Foreign Direct Investment_ Fitted values

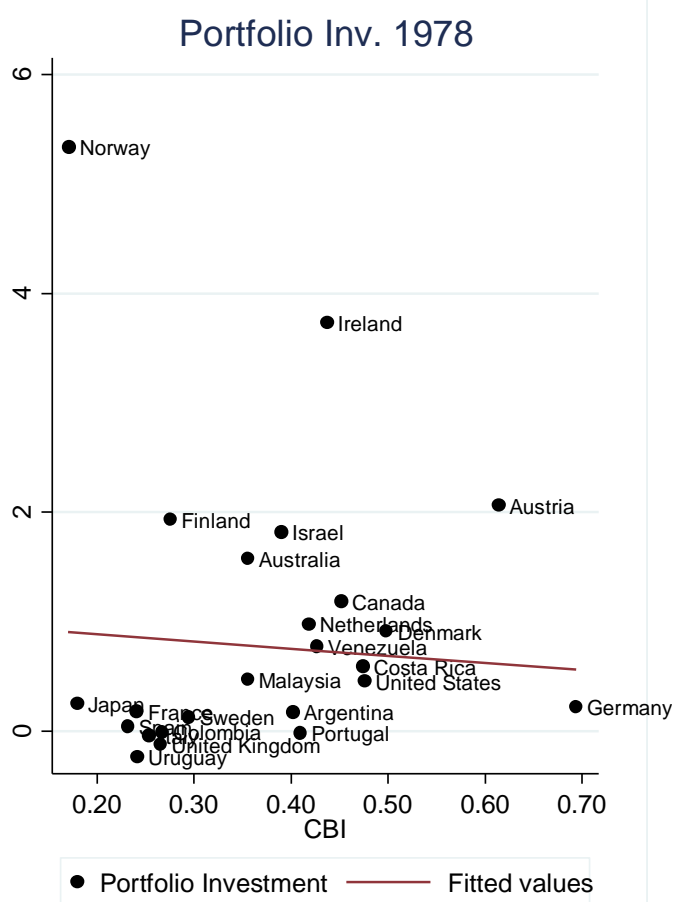

Note: Left graph shows foreign direct investment and central bank independence in 1978. The right graph shows portfolio investment in 1978. 
Figure 2.2 Foreign Direct and Portfolio Investment in 2001

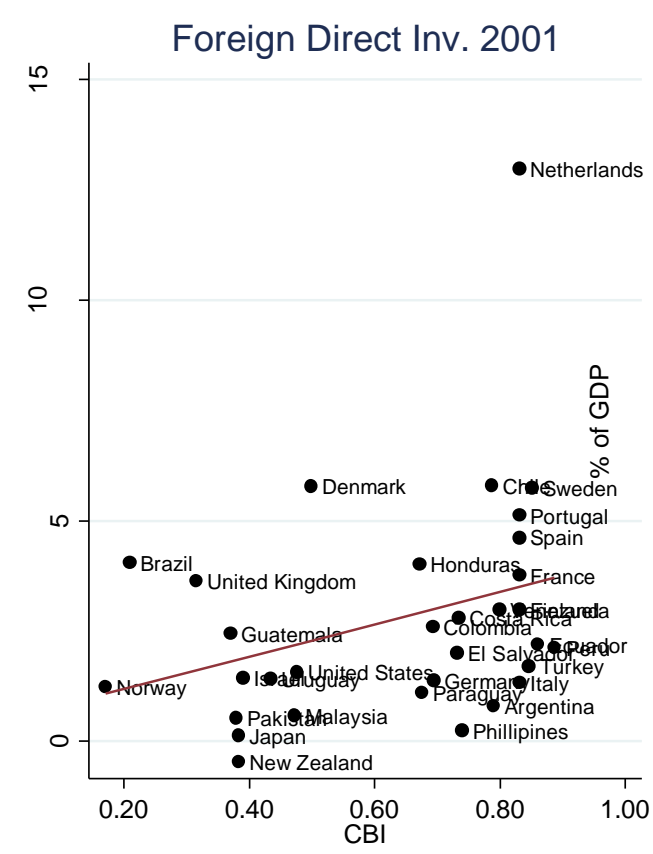

- Foreign Direct Investment_ Fitted values

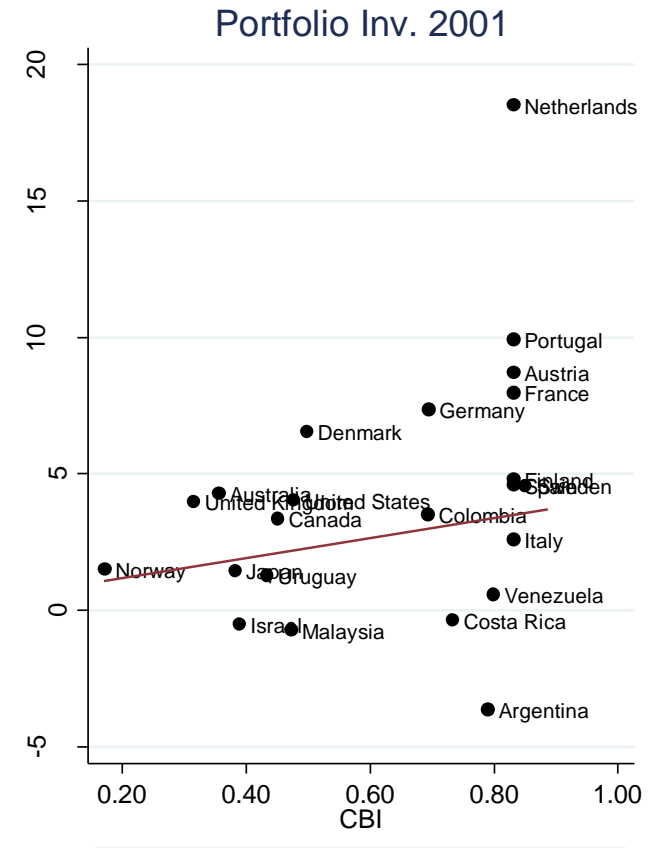

- Portfolio Investment — Fitted values

Note: Left graph shows foreign direct investment and central bank independence in 2001. The right graph shows portfolio investment in 2001. Ireland is excluded to alleviate scaling issues in the portfolio investment graph. 
Table 2.1 Summary Statistics of Key Variables

\begin{tabular}{|cccccc|}
\hline \multicolumn{6}{|c|}{ Summary Statistics - FDI Sample } \\
Variable & Obs. & Mean & Std. Dev. & Min & Max \\
\hline GDP Growth & 900 & 3.27 & 3.22 & -12.31 & 21.83 \\
Capital Openness & 900 & 59.85 & 36.85 & 0.00 & 100.00 \\
Real Eff. Exch. Rate & 900 & 98.89 & 24.12 & 27.12 & 228.69 \\
CBI & 900 & 48.77 & 22.23 & 17.06 & 88.73 \\
FDI/GDP & 900 & 1.97 & 2.75 & -14.97 & 26.20 \\
Log GDP & 900 & 25.47 & 1.84 & 21.38 & 30.30 \\
Gross Cap. Formation & 900 & 22.35 & 4.63 & 9.85 & 43.92 \\
\hline \multicolumn{6}{c}{ Summary Statistics - PIL Sample } \\
Variable & Obs. & Mean & Std. Dev. & Min & Max \\
\hline GDP Growth & 600 & 3.05 & 2.65 & -10.27 & 21.83 \\
Capital Openness & 600 & 79.88 & 26.79 & 0.00 & 100.00 \\
Real Eff. Exch. Rate & 600 & 98.73 & 15.99 & 70.74 & 181.27 \\
CBI & 600 & 46.42 & 21.51 & 17.06 & 85.10 \\
PIL/GDP & 600 & 4.38 & 11.19 & -8.66 & 112.87 \\
Log GDP & 600 & 26.33 & 1.62 & 22.28 & 30.30 \\
Gross Cap. Formation & 600 & 23.53 & 4.21 & 11.18 & 43.64 \\
\hline
\end{tabular}


Table 2.2 List of Countries

List of Countries in Foreign Direct Investment regressions: Brazil, Chile, Colombia, Costa

Rica, Denmark, Ecuador, El Salvador, Finland, France, Germany, Guatemala, Honduras, Ireland, Israel, Italy, Japan, Malaysia, Netherlands, New Zealand, Norway, Pakistan, Peru, Philippines, Portugal, Spain, Sweden, Turkey, United Kingdom, United States, Venezuela

List of Countries in Portfolio Investment regressions: Australia, Austria, Canada, Denmark, Finland, France, Germany, Ireland, Israel, Italy, Japan, Malaysia, Netherlands, Norway, Portugal, Spain, Sweden, United Kingdom, United States, Uruguay

List of OECD Countries: Chile, Denmark, Finland, France, Germany, Ireland, Israel, Italy, Japan, Netherlands, New Zealand, Norway, Portugal, Spain, Sweden, Turkey, United Kingdom, United States

List of European Countries with FDI data: Denmark, Finland, France, Germany, Ireland, Italy, Netherlands, Norway, Portugal, Spain, Sweden, United Kingdom 
Table 2.3 Foreign Direct Investment Regression Results

Dependent Variable: (FDI flow/nominal GDP)

\begin{tabular}{lccccc}
\hline \multicolumn{1}{c}{ Variables } & $(1)$ & $(2)$ & $(3)$ & $(4)$ & $(5)$ \\
\hline \multicolumn{1}{c}{ CBI } & $0.0237^{* *}$ & $0.0216^{* *}$ & $0.0188^{*}$ & $0.0158^{*}$ & $0.0188^{* * * *}$ \\
& $(0.0110)$ & $(0.00979)$ & $(0.0106)$ & $(0.00913)$ & $(0.00358)$ \\
GDP growth & & & $0.113^{* *}$ & $0.120^{* * *}$ & 0.113 \\
& & & $(0.0428)$ & $(0.0433)$ & $(0.0563)$ \\
Log GDP (-1) & & & -0.00679 & -0.161 & -0.00679 \\
& & & $(0.0995)$ & $(0.0982)$ & $(0.104)$ \\
Capital Openness & & & 0.00686 & $0.00897^{*}$ & 0.00686 \\
& & & $(0.00655)$ & $(0.00526)$ & $(0.00966)$ \\
Real exchange rate (-1) & & & -0.00131 & -0.00116 & -0.00131 \\
& & & $(0.00459)$ & $(0.00399)$ & $(0.00234)$ \\
Capital Formation (-1) & & & 0.0390 & 0.0436 & $0.0390^{*}$ \\
& & & $(0.0290)$ & $(0.0266)$ & $(0.0146)$ \\
$\quad$ Constant & -0.121 & -0.0477 & -1.346 & 2.565 & -1.346 \\
& $(0.466)$ & $(0.343)$ & $(2.694)$ & $(2.558)$ & $(2.109)$ \\
& & & & & \\
Estimation & FE & RE & FE & RE & FE \\
Time Dummies & Yes & Yes & Yes & Yes & Yes \\
Observations & 900 & 900 & 900 & 900 & 900 \\
within R-squared & 0.30 & 0.30 & 0.32 & 0.32 & 0.32 \\
\# of Countries & 30 & 30 & 30 & 30 & 30 \\
\hline
\end{tabular}

Robust standard errors clustered by country in parentheses for columns 1-4. Column 5 has robust standard errors clustered by continent.

$* * *, * *, *$ denote significance at the 1,5 , and $10 \%$ level respectively 
Table 2.4 Portfolio Investment Regression Results

Dependent Variable: (PI flow/nominal GDP)

\begin{tabular}{lccccc}
\hline Variables & $(1)$ & $(2)$ & $(3)$ & $(4)$ & $(5)$ \\
\hline CBI & 0.137 & 0.134 & 0.102 & 0.106 & $0.102^{*}$ \\
& $(0.112)$ & $(0.108)$ & $(0.0857)$ & $(0.0870)$ & $(0.0430)$ \\
GDP growth & & & 0.341 & 0.319 & 0.341 \\
& & & $(0.310)$ & $(0.327)$ & $(0.216)$ \\
Log GDP (-1) & & & 2.652 & 0.730 & 2.652 \\
& & & $(2.625)$ & $(0.777)$ & $(2.454)$ \\
Capital Openness & & & 0.0499 & 0.0455 & $0.0499^{*}$ \\
& & & $(0.0426)$ & $(0.0354)$ & $(0.0188)$ \\
Real exchange rate (-1) & & & 0.0382 & 0.0252 & 0.0382 \\
& & & $(0.0319)$ & $(0.0218)$ & $(0.0227)$ \\
Capital Formation (-1) & & & 0.585 & 0.556 & 0.585 \\
$\quad$ Constant & -3.910 & -3.825 & -94.21 & -41.27 & -94.21 \\
& $(5.190)$ & $(3.890)$ & $(86.54)$ & $(34.60)$ & $(73.29)$ \\
& & & & & \\
Estimation & FE & RE & FE & RE & FE \\
Time Dummies & Yes & Yes & Yes & Yes & Yes \\
Observations & 600 & 600 & 600 & 600 & 600 \\
within R-squared & 0.21 & 0.21 & 0.28 & 0.27 & 0.28 \\
\# of Countries & 20 & 20 & 20 & 20 & 20 \\
\hline
\end{tabular}

Robust standard errors clustered by country in parentheses for columns 1-4. Column 5 has robust standard errors clustered by continent.

$* * *, * *, *$ denote significance at the 1,5 , and $10 \%$ level respectively 
Table 2.5 Bootstrapped FDI Results with OECD and Non-OECD samples

Dependent Variable: (FDI flow/nominal GDP)

\begin{tabular}{|c|c|c|c|c|c|c|}
\hline \multirow[b]{2}{*}{ Variables } & \multicolumn{2}{|c|}{ Full Sample } & \multicolumn{2}{|c|}{ OECD } & \multicolumn{2}{|c|}{ Non-OECD } \\
\hline & $(1)$ & $(2)$ & $(3)$ & $(4)$ & $(5)$ & $(6)$ \\
\hline \multirow[t]{2}{*}{$\mathrm{CBI}$} & $0.0188 * * *$ & $0.0158 * * *$ & $0.0160 *$ & $0.0143^{* *}$ & $0.0120 *$ & 0.00729 \\
\hline & $(0.00664)$ & $(0.00427)$ & $(0.00877)$ & $(0.00605)$ & $(0.00694)$ & $(0.00580)$ \\
\hline \multirow[t]{2}{*}{ GDP growth } & $0.113 * * *$ & $0.120 * * *$ & $0.0791 *$ & $0.0956^{* *}$ & $0.0727 * * *$ & $0.0858 * * *$ \\
\hline & $(0.0247)$ & $(0.0286)$ & $(0.0405)$ & $(0.0464)$ & $(0.0215)$ & $(0.0217)$ \\
\hline \multirow[t]{2}{*}{$\log$ GDP (-1) } & -0.00679 & $-0.161 * * *$ & 0.0610 & $-0.326 * * *$ & 0.0456 & 0.00283 \\
\hline & $(0.126)$ & $(0.0420)$ & $(0.238)$ & $(0.0714)$ & $(0.147)$ & $(0.0688)$ \\
\hline \multirow[t]{2}{*}{ Capital Openness } & $0.00686^{* *}$ & $0.00897 * * *$ & 0.00650 & $0.0122 * * *$ & $0.00772 *$ & $0.00830 * *$ \\
\hline & $(0.00345)$ & $(0.00251)$ & $(0.00519)$ & $(0.00428)$ & $(0.00454)$ & $(0.00350)$ \\
\hline \multirow[t]{2}{*}{ Real Exchange Rate (-1) } & -0.00131 & -0.00116 & $-0.0261 * * *$ & $-0.0177 * * *$ & 0.00389 & $0.00413 * *$ \\
\hline & $(0.00281)$ & $(0.00227)$ & $(0.00731)$ & $(0.00562)$ & $(0.00274)$ & $(0.00207)$ \\
\hline \multirow[t]{2}{*}{ Capital Formation (-1) } & $0.0390 * *$ & $0.0436 * * *$ & 0.0152 & 0.0118 & 0.0284 & $0.0460 * *$ \\
\hline & $(0.0191)$ & $(0.0159)$ & $(0.0304)$ & $(0.0265)$ & $(0.0195)$ & $(0.0182)$ \\
\hline \multirow[t]{2}{*}{ Constant } & -1.346 & $2.565 * *$ & 0.0494 & $9.219 * * *$ & -2.489 & -1.701 \\
\hline & $(3.623)$ & $(1.191)$ & $(6.572)$ & $(1.799)$ & $(3.963)$ & $(1.948)$ \\
\hline Estimation & FE & $\mathrm{RE}$ & $\mathrm{FE}$ & $\mathrm{RE}$ & $\mathrm{FE}$ & $\mathrm{RE}$ \\
\hline Time Dummies & Yes & Yes & Yes & Yes & Yes & Yes \\
\hline Observations & 900 & 900 & 570 & 570 & 360 & 360 \\
\hline within R-squared & 0.32 & 0.32 & 0.37 & 0.37 & 0.42 & 0.42 \\
\hline Countries & 30 & 30 & 19 & 19 & 12 & 12 \\
\hline
\end{tabular}

Clustered robust standard errors in parentheses

***, **, * denote significance at the 1,5 , and $10 \%$ level respectively 
Table 2.6 Bootstrapped Foreign Direct Investment with Split Samples

Dependent Variable: (FDI flow/nominal GDP)

\begin{tabular}{|c|c|c|c|c|c|c|}
\hline \multirow[b]{2}{*}{ Variables } & \multicolumn{2}{|c|}{ Full Sample } & \multicolumn{2}{|c|}{ Non- South America } & \multicolumn{2}{|c|}{ Non-Europe } \\
\hline & $(1)$ & $(2)$ & $(1)$ & $(2)$ & (3) & (4) \\
\hline \multirow[t]{2}{*}{ CBI } & $0.0188 * * *$ & $0.0158 * * *$ & $0.0172 *$ & $0.0127 * *$ & $0.0168 * * *$ & $0.0158 * * *$ \\
\hline & $(0.00664)$ & $(0.00427)$ & $(0.00903)$ & $(0.00615)$ & $(0.00602)$ & $(0.00445)$ \\
\hline \multirow[t]{2}{*}{ GDP growth } & $0.113 * * *$ & $0.120 * * *$ & $0.188 * * *$ & $0.189 * * *$ & $0.0452 * * *$ & $0.0503 * * *$ \\
\hline & $(0.0247)$ & $(0.0286)$ & $(0.0431)$ & $(0.0482)$ & $(0.0172)$ & $(0.0181)$ \\
\hline \multirow[t]{2}{*}{$\log$ GDP (-1) } & -0.00679 & $-0.161 * * *$ & -0.0532 & $-0.375 * * *$ & 0.0195 & $-0.138 * * *$ \\
\hline & $(0.126)$ & $(0.0420)$ & $(0.244)$ & $(0.0664)$ & $(0.0952)$ & $(0.0395)$ \\
\hline \multirow[t]{2}{*}{ Capital Openness } & $0.00686 * *$ & $0.00897 * * *$ & $0.0140 * *$ & $0.0214 * * *$ & $0.0131 * * *$ & $0.0120 * * *$ \\
\hline & $(0.00345)$ & $(0.00251)$ & $(0.00607)$ & $(0.00352)$ & $(0.00352)$ & $(0.00275)$ \\
\hline \multirow[t]{2}{*}{ Real Exchange Rate (-1) } & -0.00131 & -0.00116 & -0.00656 & $-0.00787 * *$ & $6.08 \mathrm{e}-05$ & 0.00116 \\
\hline & $(0.00281)$ & $(0.00227)$ & $(0.00456)$ & $(0.00319)$ & $(0.00218)$ & $(0.00201)$ \\
\hline \multirow[t]{2}{*}{ Capital Formation (-1) } & $0.0390 * *$ & $0.0436 * * *$ & $0.0623 * *$ & $0.0581 * * *$ & $0.0327 *$ & $0.0391 * *$ \\
\hline & $(0.0191)$ & $(0.0159)$ & $(0.0298)$ & $(0.0224)$ & $(0.0184)$ & $(0.0170)$ \\
\hline \multirow[t]{2}{*}{ Constant } & -1.346 & $2.565 * *$ & -0.730 & $7.730 * * *$ & -1.899 & $2.091 *$ \\
\hline & $(3.623)$ & $(1.191)$ & $(6.936)$ & $(1.783)$ & $(2.628)$ & $(1.154)$ \\
\hline Estimation & $\mathrm{FE}$ & $\mathrm{RE}$ & $\mathrm{FE}$ & $\mathrm{RE}$ & $\mathrm{FE}$ & $\mathrm{RE}$ \\
\hline Time Dummies & Yes & Yes & Yes & Yes & Yes & Yes \\
\hline Observations & 900 & 900 & 600 & 600 & 540 & 540 \\
\hline within R-squared & 0.32 & 0.32 & 0.34 & 0.34 & 0.39 & 0.39 \\
\hline Countries & 30 & 30 & 20 & 20 & 18 & 18 \\
\hline
\end{tabular}

Clustered robust standard errors in parentheses

$* * *, * *, *$ denote significance at the 1,5 , and $10 \%$ level respectively 


\section{The Effects of US Quantitative Easing on South Africa}

\subsection{Introduction}

In 2012, Gill Marcus, the governor of the South African Reserve bank stated: “... a high degree of [macroeconomic] volatility has been experienced...this is not South Africa-specific, but a general emerging market phenomenon. ${ }^{99}$ Her contention was that advanced countries were causing volatility in and potentially harming emerging economies with large and unusual monetary policy programs. China's deputy representative to the World Trade Organization expressed a similar view regarding the Federal Reserve's large-scale asset purchase programs: "We, together with many other countries, have been critics of this irresponsible and beggar-thyneighbor policy." ${ }^{10}$ The primary concern of emerging economies is that as advanced economies adjust their monetary bases through quantitative easing programs it may cause rapid capital inflows (and outflows), inflationary pressures, and general macroeconomic instability. However, there has been pushback against this view. Former Federal Reserve Chairman, Ben Bernanke, argued that quantitative easing programs had little, if any, effect on emerging economies growth. ${ }^{11}$

We focus on the South African economy due to its membership in the so-called "BRICS" group of nations as well as its reliable and long-term data availability. ${ }^{12}$ Figure 3.1 displays the Adjusted St. Louis Monetary Base over the 1960 - 2014 time period. As can be seen in Figure 1, the monetary base has dramatically increased since the Federal Reserve began its quantitative

\footnotetext{
${ }^{9}$ Gill Marcus. "Monetary Policy and Inflationary Challenges in the Face of the Global Economic Crisis.Speech. Numsa's $9^{\text {th }}$ National Conference.

10 Tom Miles. "China Dismisses Brazil Currency Proposal at WTO, Criticizes QE.” Reuters, 26 Nov. 2012.

${ }^{11}$ Charles Riley. "Bernanke Defends Fed Against International Criticism.” CNN Money, 15 Oct. 2012.

${ }^{12}$ Investigation of the other BRICS (Brazil, Russia, India, and China) economies would be interesting, but we are unfortunately constrained by data availability.
} 
easing programs post-2008. Thus, the aim of this paper is to examine whether the Federal Reserve's quantitative easing (hereafter QE) programs have affected South Africa's economy and contribute to the broader literature examining the effects of the Federal Reserve's QE programs on emerging economies. Rather than examining whether QE programs affected international bond yields, our aim is to evaluate what effects the QE programs had on broader macroeconomic variables. Moreover, we use a principal component derived from several U.S monetary variables to capture the effects of the nonconventional monetary policy programs the Federal Reserve has implemented since 2008. Using a VAR, we seek to establish whether monetary policy in the US has an effect on the South African economy and whether the unconventional programs have had different effects than conventional open market operations. To preview our results, we do find that US monetary policy has statistically significant effects on the South African economy. In addition, during time periods in which the Federal Reserve was engaged in non-conventional monetary policy, the effects on the South African economy were roughly twice as large. The rest of the paper is structured as follows. In section 2, we discuss the extant literature regarding the international effects of the Federal Reserve's QE programs. Section 3 focuses on South Africa's policy response and their central bank's response to the financial crisis. Section 4 details our data and methodology. Section 5 displays our results and section 6 concludes.

\subsection{Literature Review}

Bauer and Neely (2014), Neely (2015), and Bauer and Rudebusch (2013) document two channels through which QE programs affect international economies: the portfolio balance channel and the signaling channel. The signaling channel focuses on how the Federal Reserve uses language in its announcements and forward guidance to communicate the expected path of future rates. The portfolio balance channel reflects the idea that investors adjust their portfolios 
to seek assets with higher yields due to the Federal Reserve's purchase of low-risk securities. Bauer, Neely, and Rudebusch demonstrate that both channels had significant effects on advanced economies. Similarly, Christensen and Rudebusch (2012) find that QE programs in the US and the United Kingdom lowered yields on bonds, primarily through the signaling channel. Krishnamurthy and Vissing-Jorgensen (2011) provide further evidence using an event-study methodology and find QE programs affected bond yields through forward guidance and asset purchases. Gagnon et al. (2011) establish that QE programs were successful in lowering the term premium, even when the zero lower bound was reached. Lastly, D'Amico et al. (2012), show that the Federal Reserve's large-scale asset purchases significantly eased monetary policy even though the zero lower bound was reached.

Empirical work on monetary policy spillovers by Ammer, Vega, and Wongswan (2010) shows that unexpected monetary tightening in the US reduces equity prices in the US and also in foreign countries. In addition, Hausman and Wongswan (2011) show that contractionary policies have a negative effect on equity returns and increase the domestic-to-foreign currency exchange rate. Ehrmann and Fratzscher (2009) show similar results: monetary tightening in the US reduces equity returns globally. Glick and Leduc (2012) show that a monetary easing in the US causes a depreciation of the US-to-foreign exchange rate. Lastly, Craine and Martin (2008) show that US monetary policy spills over to Australia but Australian monetary policy does not spillover to the US. Craine and Martin's finding is an important theoretical and empirical result as we assume South African policy has no effect on the Federal Reserve's policy.

\subsection{South African Reserve Bank's (SARB) Statements \& Response}

Although we assume that the SARB's policies had no effect on the Federal Reserve's policies, this does not mean the SARB ignored US policy. On October $5^{\text {th }}, 2007$, during the beginnings of the financial crisis, then governor of the SARB, T.T. Mboweni, commented that, 
although world markets were facing turmoil, there was little danger for spillover to South Africa. Throughout 2007, the Monetary Policy Committee of South Africa mentioned continuing increases in food and oil prices and raised rates accordingly to combat the inflationary pressures. However, they were sensitive to rumblings of international financial turmoil caused by the mortgage crisis in the US. On April $4^{\text {th }}, 2008$, Mboweni, in a public lecture, stated that the South African economy was proving to be resilient to the crisis, but inflationary pressures were mounting, primarily through increased foreign capital inflows. On the $22^{\text {nd }}$ of May, 2008, and on the $28^{\text {th }}$ of May, 2008, Mboweni further commented on strong inflationary pressures in South Africa, although he again assigned blame to rising energy and food costs rather than financial flows. Throughout 2008, the Monetary Policy Committee continued to comment on strong inflationary pressures prevailing from 2007, but these concerns tailed off at the end of the year as the effects of the global financial crisis began to be felt and the world economy entered a downturn.

Throughout 2009, the South African economy was hit strongly by the financial crisis. The SARB lowered their policy rate to $7 \%$ and it stayed at this level until the end of the year. Also, on November $3^{\text {rd }} 2009$, A.D. Mminele, Deputy Governor of SARB, mentioned that the rand and other emerging currencies were appreciating against the US dollar, primarily due to weakness in the US market and QE. In 2010, the Monetary Policy Committee continued to monitor inflation developments in the South African economy. Particularly, the committee specifically identified large capital flows into emerging markets due to weakness in the global economy (September $9^{\text {th }}$ report) and appreciation of the rand against the dollar (November $18^{\text {th }}$ report). Throughout 2011, the Monetary Policy Committee commented on continued inflationary pressures, from food and energy prices, and also from strong capital flows into South Africa 
(September $22^{\text {nd }}$ report). Specifically, in an address on the $27^{\text {th }}$ of May, 2011, Mminele mentioned the potential for emerging markets to overheat given significant capital inflows from the advanced economies. During 2012, the Monetary Policy Committee mentioned continued global instability, due to the Greece crisis in the Eurozone, but South Africa stayed primarily on the same economic path as in 2011. On May $7^{\text {th }}, 2012$, in an address in Zurich, the former governor of the SARB, Gill Marcus, remarked that "the low global interest rate environment sparked a search for yield that was given further impetus by quantitative easing." Even into 2012, the effects of the financial crisis and quantitative easing were being felt. ${ }^{13}$

\subsection{Data and Empirical Model}

3.4.1 Data

To test the theoretical results and evidence from the SARB's statements we use a VAR with an exogenous variable, a measure of US monetary policy, to observe the effects of US easing on South Africa. The variables included in the model are the exchange rate (rands per dollar), inflation, the All-Share South Africa stock index, the South African Reserve Bank's policy rate, and a monetary factor that captures the effects of US monetary policy changes. We chose to use a principal component to proxy the Federal Reserve's monetary policy (rather than simply using the Federal Funds rate or monetary base) to attempt to capture the effects of the $\mathrm{QE}$ programs. Specifically, this should help us measure the effects of QE even though the Federal Funds rate hit the zero lower bound in 2008. The principal component was constructed using the monetary variables available in a new data set released by McCracken and $\mathrm{Ng}(2014)$.

Specifically, we used the variables listed in Group 5 of the paper which include M1, M2, M3, real M2, the adjusted monetary base, total reserves, non-borrowed reserves, commercial and industrial loans, real estate loans, non-revolving credit, credit-to-PI ratio, the money stock,

\footnotetext{
${ }^{13}$ Documents containing all the Monetary Policy Committee statements are available upon request.
} 
consumer vehicle loans, total consumer loans and leases, and securities. The @ princomp program from the RATS software was used to construct the principal component. Each variable (with the exception of the principal component) was checked for the presence of a unit root. The results of the Adjusted Dickey-Fuller tests are in Table 1. For each series, the hypothesis of a unit root could not be rejected; as such, the series were log first differenced to account for the unit roots with the exception of the South African policy rate, which was only differenced.

To capture pre- and post-QE effects, we split the monetary policy principal component into two separate variables. The first variable (labeled conv below) is the principal component over the 1960:Q1-2008:Q3 time period and captures the effect of Federal Reserve monetary policy on the South African economy during time periods in which the Federal Reserve used conventional open market operations to conduct monetary policy. The second time variable (labeled nonconv below) spans the 2008:Q4- 2014:Q3 time period and is constructed to capture the effects of the non-conventional Federal Reserve policies on the South African economy. The dates for the beginning of the quantitative easing programs were taken from Fawley and Neely (2013).

\subsubsection{Model}

In order to capture the potentially differing effects of the Federal Reserve's policy, we estimated the following VAR:

$$
\text { (1) } \Delta X_{t}=A_{O}+B(L) \Delta X_{t-p}+C(L) \operatorname{conv}_{t-p}+D(L) \text { non-conv } v_{t-p}+\varepsilon_{t}
$$

where $X_{t}$ is a vector containing South Africa's real GDP, inflation, the exchange rate, stock market index, and South Africa's policy rate and, as noted above, conv is the US monetary factor over the 1960:Q1-2008:Q3 time period and non-convis the monetary policy principal component over the 2008:Q4- 2014:Q3 time period and where $B(L), C(L)$, and $D(L)$ are lag polynomials. Conv and non-conv are assumed exogenous as it seems unlikely that changes in 
the South African economy affected the Federal Reserve's policy decisions. Our modelling strategy in (1) is similar to previous literature that examined asymmetric effects in the VAR. This is along the lines of a VARX described in Luetkepohl (2005) and is similar to the methodology used by Wu and Cavallo (2011). Previous papers such as Cover (1992) and Jones et. al. (2015) split a series into positive and negative components to shock the system. In our model, we split the series based upon time. As noted in Kilian and Vigfusson (2011), VARs produce unbiased estimates of the coefficients in $c_{i}$ and $d_{i}$ so they are included in each equation of the VAR. The lag length of (1) was selected using the Akaike Information Criteria (AIC) which suggested $p=3$.

\subsection{Results}

\subsubsection{Results using McCracken and Ng (2014) Factor}

Figure 3.2 and Figure 3.3 display the cumulative impulse response functions for the conventional and non-conventional time periods along with 95\% confidence intervals obtained from 5000 Monte Carlo replications. As seen in Figure 3.2, South Africa's GDP increases by roughly 2 standard deviations after 3 quarters. The effects of the shock diminish over the next 8 quarters, but a 1 standard deviation increase persists. South Africa's CPI responds immediately to the US monetary shock, and increases by approximately 4 standard deviations after 12 quarters. The point estimate suggests a U.S monetary shock induces a contemporaneous 1 standard deviation appreciation of the rand relative to the US dollar. The rand reaches a high of approximately a 1.25 standard deviation appreciation 2 quarters after the shock and then depreciates rapidly to its initial value. From 3 quarters onwards, the point estimates suggest a slight depreciation of the rand, but there is no statistical significance. The South African stock exchange initially increases in value by approximately 2.5 standard deviations. However, the increase in value is transitory and the stock exchange returns to its initial valuation after 2 quarters. The point estimates remain positive but become statistically insignificant from 2 
quarters on. Lastly, the South African policy rate shows no contemporaneous statistically significant effects. From 3 quarters on, the policy rate shows a statistically significant increase of approximately 3 standard deviations.

As mentioned previously, the impulse responses to a 1 standard deviation shock to the US monetary factor during the QE era are shown in Figure 3.3. South Africa's GDP experiences a contemporaneous increase of about 1.5 standard deviations. The increase in GDP reaches a peak of 5 standard deviations from quarters 1 to 3 . From the 3rd quarter on, there is a gradual decline and, following the $8^{\text {th }}$ quarter, the point estimates remain positive but become statistically insignificant. The point estimates suggest there is a large contemporaneous increase in inflation of approximately 2.5 standard deviations although the results are statistically insignificant. After 6 quarters, the point estimates become statistically significant. After 12 quarters, the cumulative impact on inflation is an increase of roughly 10 standard deviations. The responses of GDP and inflation support Reinhart and Reinhart's (2008) research which shows that low interest rates in developed economies tend to "push" investment into emerging markets. In this case, we see upward pressure in both the inflation and GDP impulse responses.

The rand experiences a contemporaneous appreciation of approximately 6 standard deviations. However, the rand rapidly depreciates and returns to its initial valuation by quarter 2 . From quarter 2 on, the point estimates suggest a depreciation of approximately 3 standard deviations but they are statistically insignificant. This provides some evidence for Chen et al. (2011) whom show that low interest rates in developed countries can lead to a depreciation of emerging markets' currencies although the results are not as strong in our study. Furthermore, Glick and Leduc (2012) predict that a monetary expansion in the US causes a depreciation of the dollar against foreign currencies. We observe this in the results, although the effect is not as 
persistent as in Glick and Leduc's paper as the dollar starts appreciating in quarter 2 of the forecast. Similarly, Bauer and Neely (2014), Neely (2015), and Rudebusch (2013) show monetary easing in the US causes a depreciation of the dollar. Again, we have evidence supporting their claim, although the depreciation is relatively short lived against the rand.

The South African stock exchange contemporaneously increases by 6 standard deviations and has a peak increase of 7 standard deviations in quarter 2 . However, in quarter 3 , the stock exchange rapidly returns to its initial valuation. Following quarter 3 , the point estimates show a slight increase in value but are statistically insignificant. These results reinforce Ammer, Vega, and Wongswan (2010) and Ehrmann and Fratzscher (2009). Both conclude that a monetary tightening in the US leads to worse performance in US and foreign equity markets. In our results, we look at a monetary expansion, but the results are consistent with both works; specifically, a monetary expansion in the US leads to increases in the value of South Africa's stock exchange, at least temporarily. Lastly, the South African policy rate point estimates initially increase in value, but are statistically insignificant. Following quarter 2, the rate increases by roughly 5 standard deviations, and the increase is highly persistent.

Interestingly, note that the above results also support the slightly older macroeconomic spillover and monetary policy literature from the 1990s. Calvo, Leiderman, and Reinhart (1993) demonstrate that capital inflows may distort developing countries' exchange rates and decrease exports. Our results confirm Calvo, Leiderman, and Reinhart's finding that developed nations' monetary policy may distort emerging markets exchange rates. Fernandez-Arias (1996) details capital "push" and "pull" perspectives. The "pull" perspective is that developing countries enact policies that make them more desirable for foreign investment. The "push" perspective is that capital flows and other macroeconomic indicators in developing countries are susceptible to 
international macroeconomic conditions. Fernandez-Arias notes, if international interest rates fall, it often "pushes" capital into emerging economies, creating macroeconomic volatility. Fernandez-Arias finds that "push" factors dominate "pull factors" in regards to capital flows to emerging economies. Our results indicate, in accordance with Fernandez-Arias, that there are significant "push" factors from the US to South Africa, particularly in regards to inflation. Lastly, we find evidence in both the stock market and inflation impulse responses confirming Taylor and Sarno's (1997) assertion that investors in developed nations chase higher returns in new markets when domestic interest rates are low, putting inflationary pressures on emerging markets.

\subsubsection{Results using Divisia M4}

In addition to the main results (and further results in Appendix 1), another VAR was run using the Divisia M4 measure from the Center for Financial Stability. ${ }^{14}$ This is a broad measure of money and includes currency, travelers checks, demand deposits, other checkable deposits, savings deposits, retail money market funds, small time deposits, institutional money market funds, large time deposits, overnight and term repos, commercial paper, and Treasury bills (Barnett et al. (2013)). This broad measure of money is useful because, when the federal funds rate hit the zero lower bound during the Great Recession, the Divisia measure still allows for a measure of expansionary or contractionary policy. Figure 3.6 shows the percentage firstdifference (growth rate) of the Divisia M4 measure. As can be seen, in general, the money supply has been expanding, as measured by the Divisia M4 method. However, note that, initially during the Great Recessions, the money supply contracted.

Figure 3.7 shows the cumulated impulse responses using the VAR method described in the main body of the paper. The responses in the figure are to a positive, one standard deviation

\footnotetext{
${ }^{14}$ Available at http://www.centerforfinancialstability.org/amfm_data.php.
} 
shock to the Divisia growth rate (an expansionary monetary policy shock) during the QE period. The response of GDP shows an increase of roughly 0.5 standard deviations but is statistically significant only during the $2^{\text {nd }}$ quarter from the shock. After the $2^{\text {nd }}$ quarter, the effect becomes insignificant. Inflation initially shows a decrease of about 1 standard deviation, but the effect reverses, and, after 12 quarters, the results shows an increase in inflation of about 1 standard deviation. The rand shows a consistent depreciation of about 0.5 standard deviations. Interestingly, the stock index decreases by about 1.5 standard deviations after 12 quarters. Lastly, the South African interest rate initially decreases by about 2 standard deviations, but the effect becomes insignficant around quarter 6 (although the point estimates remain negative).

These results differ from the McCracken and $\mathrm{Ng}$ results and also from the results using the "shadow rate" of Lombari and Zhu (2014) in Appendix 1. However, they do share some similarites with work by Bhattarai et al. (2015) who use a panel VAR method to study the effect of U.S. quantitative easing on a group of emerging market economies. Bhattarai et al. (2015) find that, consistent with these findings, a QE shock did little to output (industrial production) of emerging economies and caused an initial decrease in long-term interest rates that became insignificant over time (p.23). In contrast, the inflation, stock index, and exchange rate responses differ from Bhattarai et al. (2015). Bhattarai et al. (2015) find insignificant effects of QE on inflation for emerging economies but I find positive, significant long-term effects. Bhattarai et al. (2015) find a positive response in the stock index for emerging economies due to U.S. quantitative easing, but, using the Divisia measure, the stock index declines due to a U.S. easing shock. Lastly, the emerging market response in Bhattarai et al. (2015) shows a consistent appreciation, but, using the Divisia measure, the rand appears to depreciate. 


\subsection{Conclusion}

Using a relatively long time-series and a VAR methodology, we have shown that quantitative easing appears to have meaningful effects on South Africa at least when using the monetary measures of McCracken and $\mathrm{Ng}$ (2014) and Lombardi and Zhu (2014). Using these two measures as proxies for monetary policy, there seems to be significant effects on GDP, the rand-to-dollar exchange rate, inflation, the stock market in South Africa, and South Africa's policy rate as a result of the Federal Reserve's QE programs. This corresponds with much of the macroeconomic spillover and monetary policy literature. Additionally, compared to normal monetary operating procedures, the quantitative easing era produced different results. The impulse responses we compiled showed that the QE programs had a significantly larger effect than normal monetary policy operations. This makes sense intuitively: the QE programs undertaken by the US resulted in a massive expansion of the US money supply and the Federal Reserve's balance sheet and this historically large expansion produced larger than normal effects in emerging economies. This corresponds with the "wall of money" story seen in the media and also in reports by investment banks, such as Goldman Sachs. ${ }^{15}$

However, when using different measures of monetary policy, such as the Divisia M4 measure, the impacts of monetary policy on South Afica differ. The McCraken and Ng (2014) and Lombardi and Zhu (2014) results are similar but the Divisia results are quite different. This is concerning as it it indicates getting the correct measure of monetary policy is vitally important for gauging economic impacts. Thus, using the correct monetary measure is important for all capital flow studies and especially for studies investigating specific impacts of monetary policy. Otherwise, results can vary quite significantly even considering one country such as South

\footnotetext{
15 Jason Webb. “Goldman Sees Record 'Wall of Money’ Flooding Emerging Markets.” Bloomberg Business, 10 September 2010.
} 
Africa, much less a panel of countries as others such as Bhattarai et al. (2015) have used. In sum, U.S. monetary policy likely does have an impact on global economic conditions but it is important to consider what monetary measure is being used and how this may impact results. 
Figure 3.1 U.S. Monetary Base

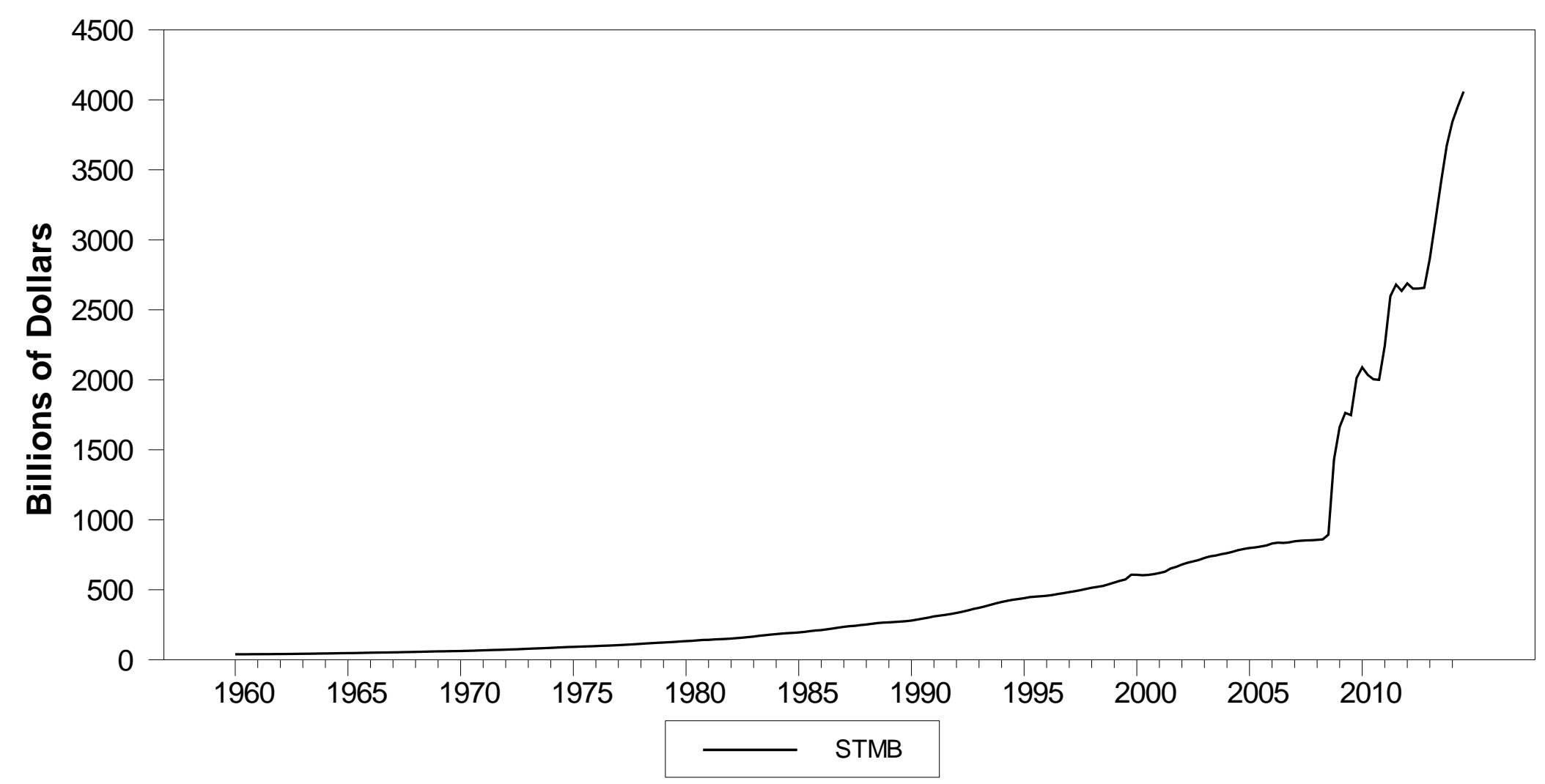


Figure 3.2 Cumulated Responses Non-QE Era
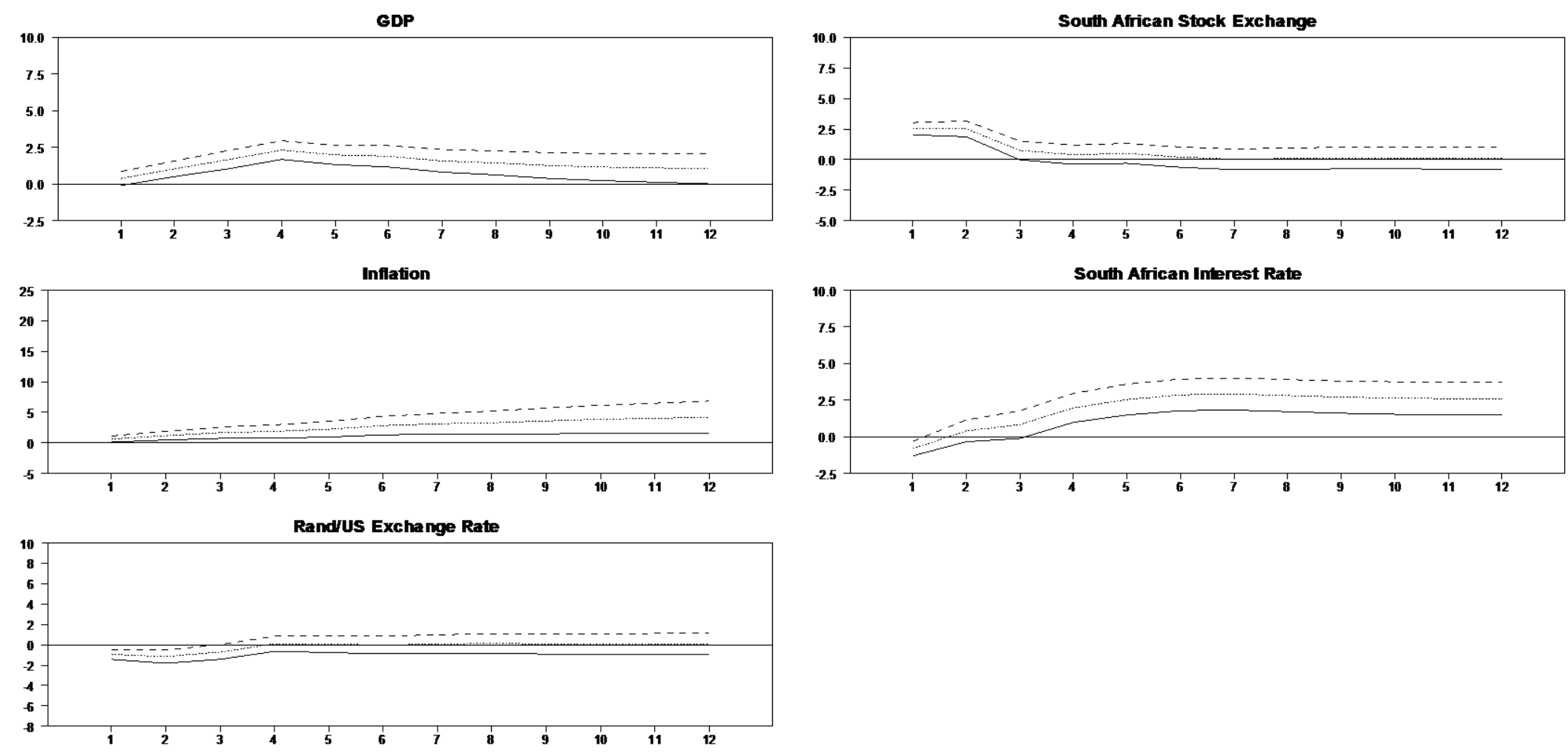
Figure 3.3 Cumulated Responses QE Era
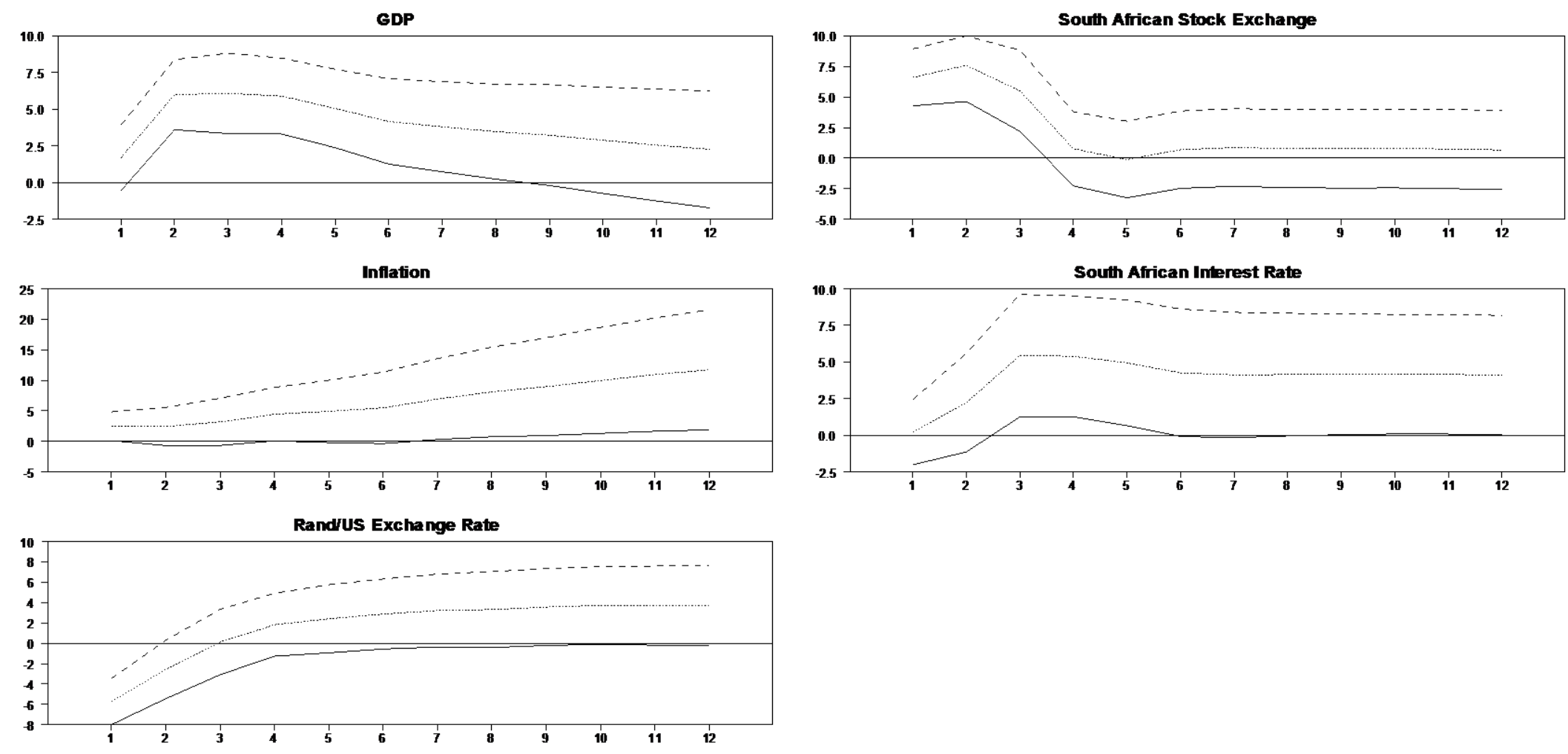
Table 3.1 Adjusted Dickey-Fuller Unit Root Tests

\begin{tabular}{c|c|c|}
\hline \hline Table 1: & \multicolumn{2}{|c|}{ ADF Unit Root Tests } \\
\hline \hline & w / Constant & w / Constant \&Trend \\
\hline SA GDP & 1.29 & -0.62 \\
\hline SA CPI & 5.15 & 0.83 \\
\hline SA Stock Market & 2.68 & 0.74 \\
\hline SA Policy Rate & $-2.80^{*}$ & -2.75 \\
\hline SA Exchange Rate & 0.26 & -2.55 \\
\hline \hline
\end{tabular}




\subsection{Appendix 1: Robustness Check Using US Shadow Rate Measure}

For robustness, we evaluate the model again with a shadow US policy rate developed by

Lombardi and Zhu (2014). The results are presented in Figure 3.4 and Figure 3.5. The results for monetary operations during the non-quantitative easing era are much weaker than when we used our principal component measure. Particularly, the inflation, exchange rate, and stock market responses are statistically insignificant. Interestingly, the QE era responses display roughly the same response as when we used our monetary policy principal component. However, the magnitude of the responses tended to be somewhat smaller. This gives us additional confidence in our main results and shows that, perhaps, the monetary factor captures additional information about the Federal Reserve's monetary policy that other measures may have not fully included. 
Figure 3.4 Cumulated Responses Non-QE Era using Shadow Rate
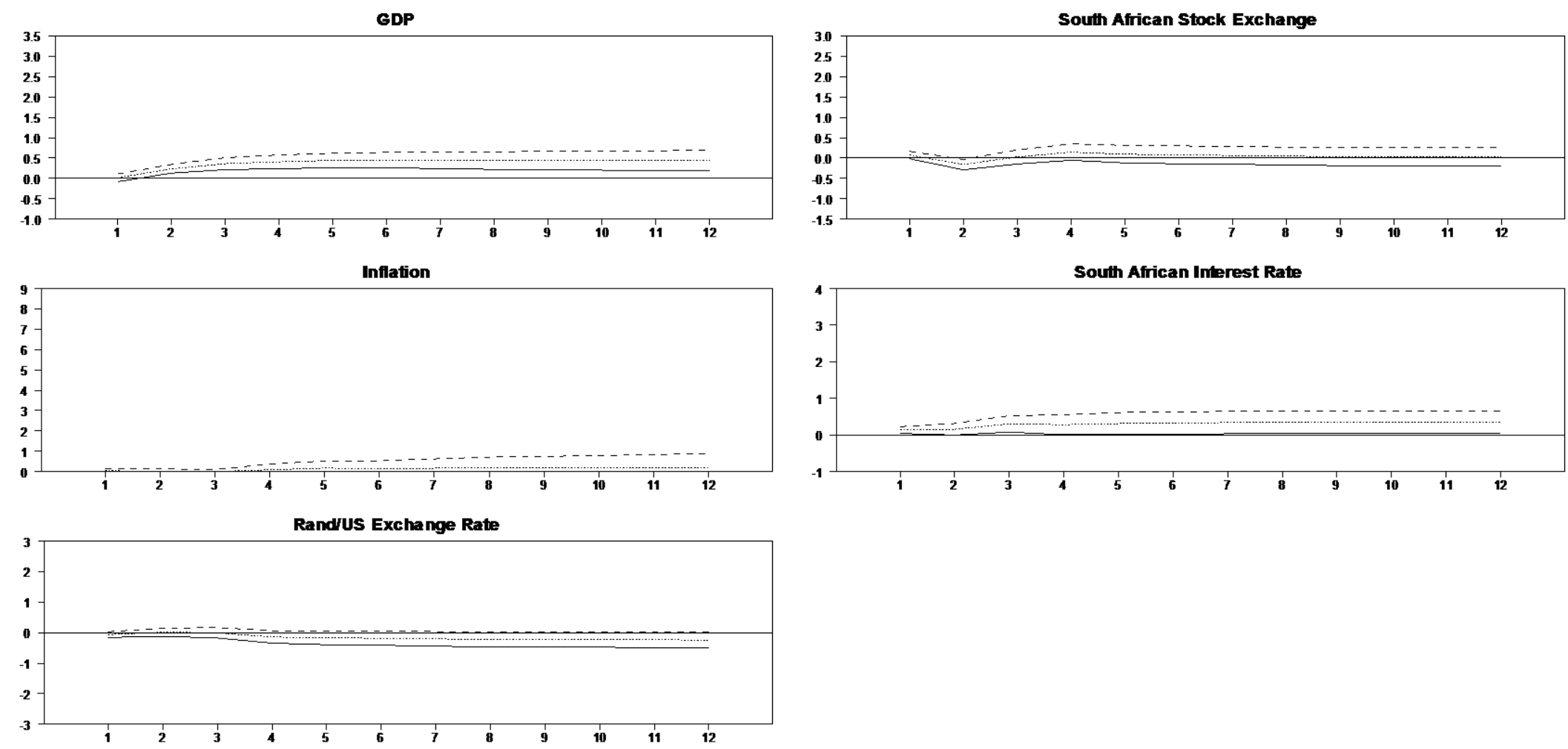
Figure 3.5 Cumulated Responses QE Era using Shadow Rate
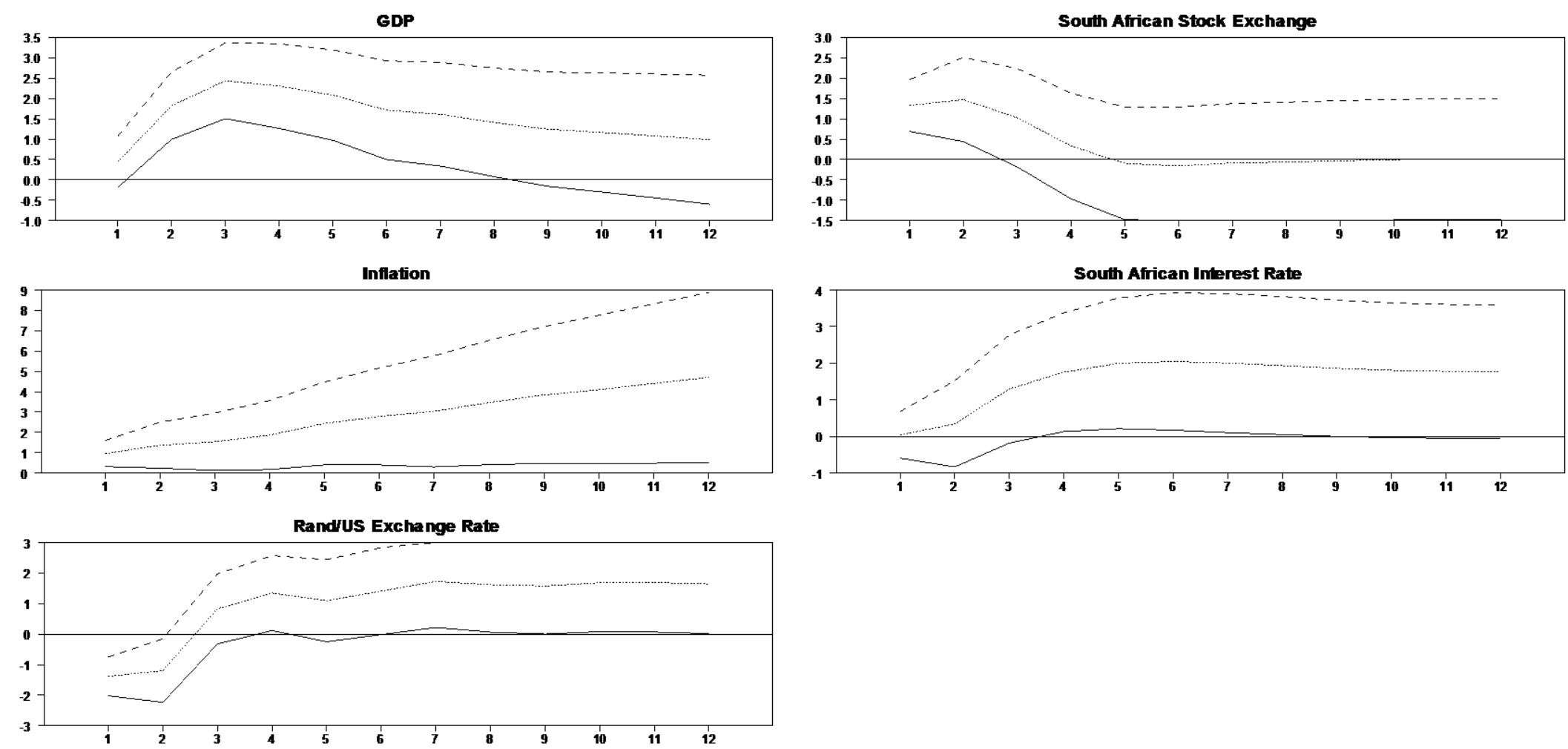
Figure 3.6: First-difference of Divisia M4

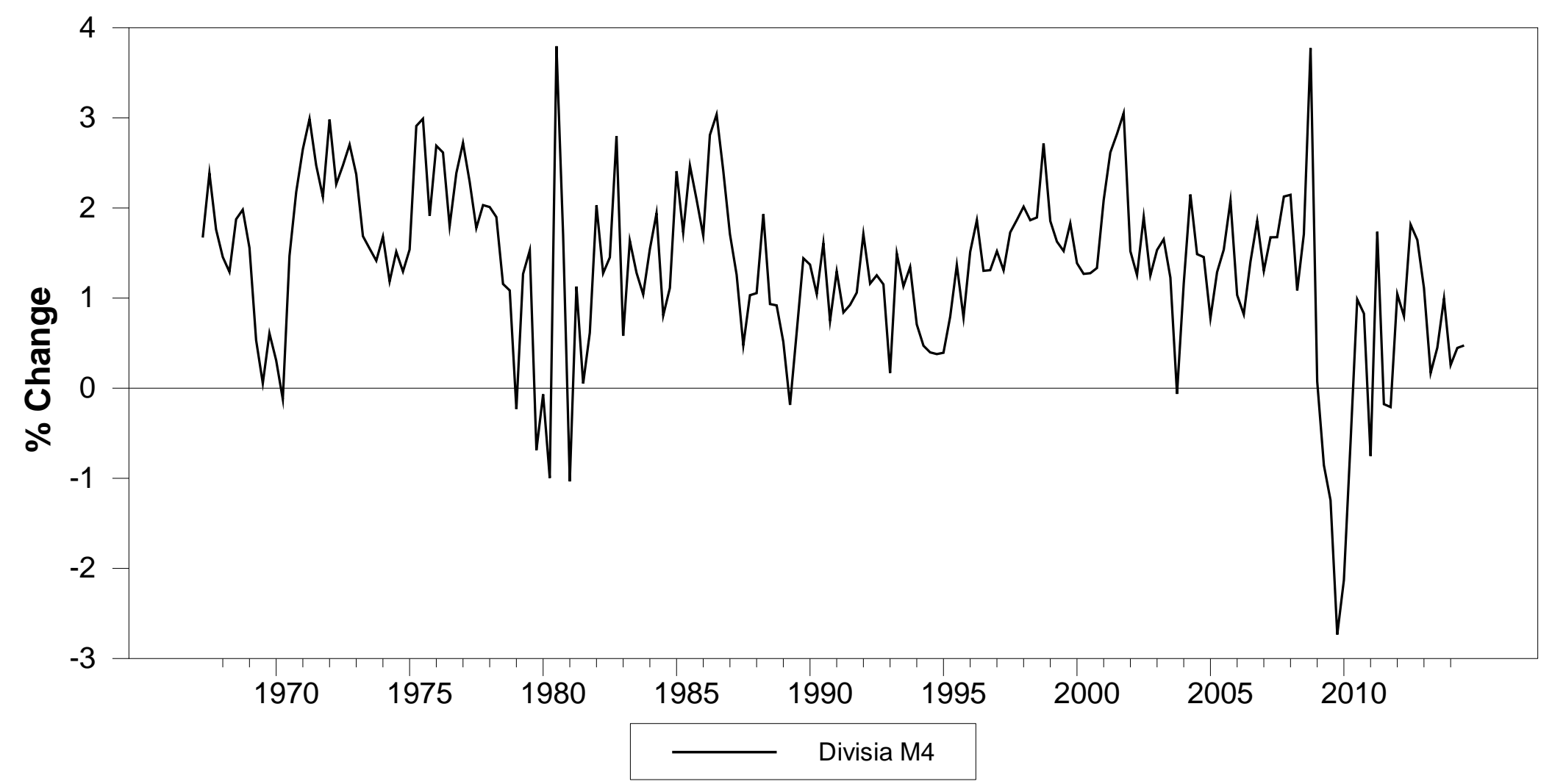


Figure 3.7 Impulse Responses during QE period using Divisia M4

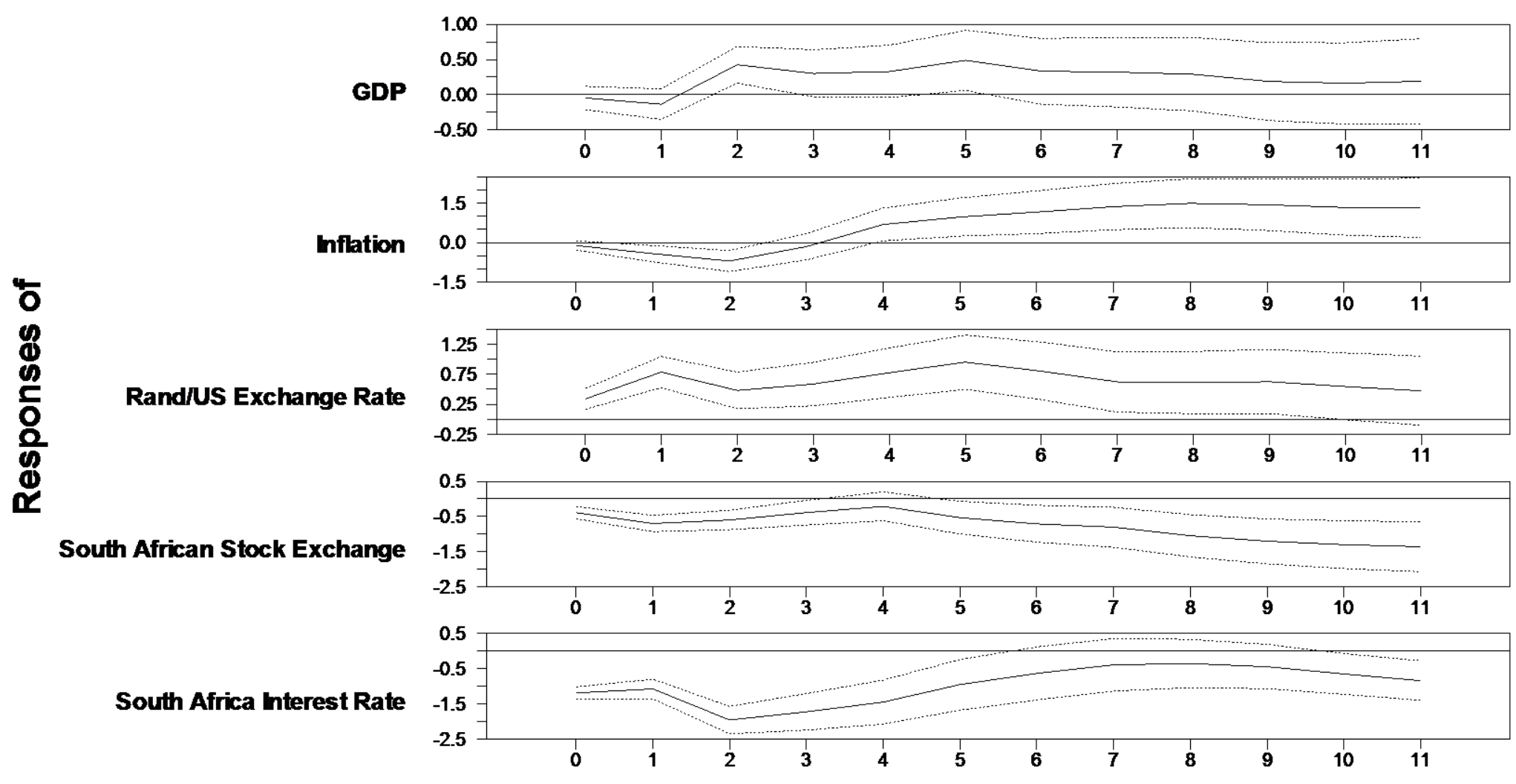




\section{Bibliography}

Acemoglu, Daron et al. "When Does Policy Reform Work? The Case of Central Bank

Independence.” Brookings Papers on Economics Activity (2008): 351-429.

Alesina, Alberto and Lawrence H. Summers. "Central Bank Independence and Macroeconomic Performance: Some Comparative Evidence.” Journal of Money, Credit, and Banking 25 (May 1993): 151-162.

Alfaro L., Kalemli-Ozcan S. and Volosovych V. "Why Doesn't Capital Flow from Rich to Poor Countries? An Empirical Investigation.” NBER, working paper \#11901. 2005.

Akerlof, George A. "The Market for Lemons: Quality Uncertainty and the Market Mechanism.” Quarterly Journal of Economics 84 (1970): 488-500.

Arellano, Manuel. "On the Testing of Correlated Effects with Panel Data." Journal of Econometrics 59.1-2 (1993): 87-97.

Ammer, John, Clara Vega, and Jon Wongswan. "International Transmission of U.S. Monetary Policy Shocks: Evidence from Stock Prices.” Journal of Money, Credit, and Banking 42 (Sep. 2010): 179-198.

Bade, Robin and Michael Parkin. "Central Bank Laws and Monetary Policy." Department of Economics, University of Western Ontario. 1988, working paper.

Barba, Aldo and Massimo Pivetti. "Rising Household Debt: Its Causes and Macroeconomic Implications - A Long-Period Analysis." Cambridge Journal of Economics 33.1 (2008): $113-137$.

Barnett, William A. et al. "The New CFS Divisia Monetary Aggregates: Design, Construction, and Data Sources.” Open Economies Review 24.1 (2012): 101-124. 
Barro, Robert J. and David B. Gordon. "Rules, Discretion, and Reputation in a Model of Monetary Policy.” Journal of Monetary Economics 12 (1983): 101-121.

Bauer, Michael and Christopher Neely. "International Channels of the Fed's Unconventional Monetary Policy.” Journal of International Money and Finance 44 (2014): 24-46.

Bauer, Michael and Glenn Rudebusch. "The Signaling Channel for Federal Reserve Bond Purchases.” Federal Reserve Bank of San Francisco, working paper. 2013.

Bekaert, Geert. "Market Integration and Investment Barriers in Emerging Equity Markets." World Bank Economic Review 9.1 (1995): 75-107.

Bernard, Andrew B., J. Bradford Jensen, and Peter K. Schott. "Importers, Exporters, and Multinationals: A Portrait of Firms in the U.S. That Trade Goods." NBER, working paper $\# 11404.2005$.

Bevan A. and Estrin S. "The Determinants of Foreign Direct Investment into European Transition Economies.” Journal of Comparative Economics 32 (2004): 775-787.

Bhattaria, Saroj, Arpita Chatterjee, and Woong Yong Park. "Effects of US Quantitative Easing on Emerging Market Economies.” Federal Reserve Bank of Dallas Globalization and Monetary Policy Institute, working paper \#255. 2015.

Bodea, Cristina, and Raymond Hicks. "International Finance and Central Bank Independence: Institutional Diffusion and the Flow and Cost of Capital.” The Journal of Politics 77.1 (2015): 268-284.

Brennan, Jordan. "Rising Corporate Concentration, Declining Trade Union Power, and the Growing Income Gap: American Prosperity in Historical Perspective.” Levy Economics Institute, working paper. March 2016. 
Budd, Edward C. and David F. Seiders. "The Impact of Inflation on the Distribution of Income and Wealth.” American Economic Review 61.2 (1971): 128-138.

Calvo, Guillermo, Leonardo Leiderman, and Carmen M. Reinhart. "Capital Inflows and Real Exchange Rate Appreciation in Latin America: The Role of External Factors.” IMF. IMF Staff Papers, 1993.

Calvo, Guillermo, Leonardo Leiderman, and Carmen M. Reinhart. "Inflows of Capital to Developing Countries in the 1990s." Journal of Economic Perspectives 10.2 (1996): 123139.

Cameron, A. Colin and Douglas L. Miller. “A Practitioner's Guide to Cluster-robust Inference.” Working paper, 2015.

Chen, Qianying et al. "International Spillovers of Central Bank Balance Sheet Policies.” Bank for International Settlements, working paper. 2011.

Chinn, Menzie D. and Hiro Ito. "What Matters for Financial Development? Capital Controls, Institutions, and Interactions." Journal of Development Economics 81.1 (October 2006): 163-192.

Christensen, Jens and Glenn Rudebusch. "The Response of Interest Rates to US and UK Quantitative Easing.” The Economic Journal, 122 (Nov. 2012): 385-414.

Coibion, Olivier, et al. "Innocent Bystanders? Monetary Policy and Inequality in the U.S." NBER, working paper. 2012.

Cover, James Peery. "Asymmetric Effects of Positive and Negative Money-Supply Shocks.” Quarterly Journal of Economics, 107.4 (1992): 1261-1282.

Craine, Roger and Vance Martin. "International Monetary Policy Surprise Spillovers." Journal of International Economics, 75 (2008): 180-196. 
Cukierman, Alex, Steven B. Webb, and Bilin Neyapti. "Measuring the Independence of Central Banks and Its Effect on Policy Outcomes.” The World Bank Economic Review 6 (Sep. 1992): 353-398.

Cukierman, Alex. Central Bank Strategy, Credibility, and Independence: Theory and Evidence. Cambridge, MA: MIT Press, 1992.

Cynamon, Barry and Steven Fazzri. "Inequality and Household Finance during the Consumer Age." Levy Economics Institute, working paper. 2013.

D’Amico, Stefania, William English, David Lopez-Salido, and Edward Nelson. "The Federal Reserve's Large-Scale Asset Purchase Programmes: Rationale and Effects.” The Economic Journal, 122 (Nov. 2012): 415-446.

Danby, Colin. "Balance of Payments: Categories and Definitions." University of Washington. Online manuscript. Accessed 2/27/2014.

Das, Piyali. “Decomposition of Debt-GDP Ratio for United Kingdom: 1984-2009.” Indiana University, working paper. 2011.

Debelle, Guy. "Household Debt and the Macroeconomy." BIS Quarterly Review 2004: 51-64.

Diebold, Francis and Kamil Yilmaz. "Better to Give Than to Receive: Predictive Directional Measurement of Volatility Spillovers.” International Journal of Forecasting 28 (2012): $57-66$.

Dunning, J. H. Multinational Enterprises and the Global Economy. Reading, MA: AddisonWesley. 1993.

Easterly, William and Stanley Fischer. "Inflation and the Poor." Journal of Money, Credit, and Banking 33 (2001): 160-178. 
Eaton, Jonathan, Samuel Kortum, and Francis Kramarz. "Dissecting Trade: Firms, Industries, and Export Destinations." American Economic Review 94.2 (2004): 150-154.

Ehrmann, Michael and Marcel Fratzscher. "Global Financial Transmission of Monetary Policy Shocks." Oxford Bulletin of Economics and Statistics, 71 (2009): 739-759.

Facundo Alvaredo, Anthony B. Atkinson, Thomas Piketty, Emmanuel Saez, and Gabriel Zucman. WID- The World Wealth and Income Database. http://www.wid.world/.

Fawley, Brett and Christopher Neely. "Four Stories of Quantitative Easing." Federal Reserve Bank of St. Louis Review, 95 (2013): 51-88.

Fernandez-Arias, Eduardo. “The New Wave of Private Capital Inflows: Push or Pull?” Journal of Development Economics 48 (1996): 389-418.

Fisher, Irving. "The Debt-Deflation Theory of Great Depressions.” Econometrica 1 (1933): 337357.

Gagnon, Joseph, Matthew Rasking, Julie Remache, and Brian Sack. “The Financial Market Effects of the Federal Reserve's Large-Scale Asset Purchases." International Journal of Central Banking, 7 (2011): 3-43.

Glick, Reuven and Sylvain Leduc. "Central Bank Announcements of Asset Purchases and the Impact on Global Financial and Commodity Markets.” Journal of International Money and Finance, 31 (2012): 2078-2101.

Goldstein, Itay and Assaf Razin. “An Information-based Trade-off Between Foreign Direct Investment and Foreign Portfolio Investment.” Journal of International Economics 70.1 (2006): 271-295.

Goldstein, Itay, Assaf Razin, and Hui Tong. "Liquidity, Institutional Quality, and the Composition of International Equity Flows.” NBER, working paper 15727. 2010. 
Hashimoto, Yuko, and Konstantin M. Wacker. "The Role of Risk and Information for International Capital Flows: New Evidence from the SDDS.” IMF. 2012, working paper. Hausman, Joshua and Jon Wongswan. "Global Asset Prices and FOMC Announcements." Journal of International Money and Finance, 30 (2011): 547-571.

Helpman, Elhanan. "Trade, FDI, and the Organization of Firms." Journal of Economic Literature 44 (Sep. 2006): 589-630.

Helpman, Elhanan, Marc J. Melitz, and Stephen R. Yeaple. "Export Versus FDI with Heterogeneous Firms.” American Economic Review 94.1 (2004): 300-315.

Humanicki, Marcin, Robert Kelm, and Krzysztof Olszewski. "Foreign Direct Investment and Portfolio Investment in the Contemporary Globalized World: Should They Still Be Treated Separately?” National Bank of Poland, working paper \#167. 2013.

International Monetary Fund. Balance of Payments Manual and International Investment Position Manual. Washington DC: IMF, 2009.

Jones, Paul, Eric Olson, and Mark Wohar. “Asymmetric Tax Multipliers.” Journal of Macroeconomics 43 (2015): 38-48.

Kilian, Lutz and Robert J. Vigfusson. "Are the Responses of the U.S. Economy Asymmetric in Energy Price Increases and Decreases?” Quantitative Economics 2.3 (2011): 419-453.

Kirshner, Jonathan. "The Political Economy of Low Inflation.” Journal of Economic Surveys 15.1 (2001): 41-70.

Klomp, Jeroen, and Jakob de Haan. "Central Bank Independence and Inflation Revisited.” Public Choice 144 (2010): 445-457.

Koop, Gary, M. Hashem Pesaran, and Simon Potter. "Impulse Response Analysis in Nonlinear Multivariate Models." Journal of Econometrics 74 (1996): 119-147. 
Krishnamurthy, Arvind and Annette Vissing-Jorgensen. "The Effects of Quantitative Easing on Interest Rates: Channels and Implications for Policy.” Brooking Papers on Economic Activity. Fall 2011.

Kumhof, Michael, Romain Ranciere, and Pablo Winant. "Inequality, Leverage, and Crises." International Monetary Fund, working paper. 2013.

Kuznets, Simon. "Economic Growth and Income Inequality." American Economic Review 45 (1955): 1-28.

Kydland, Finn E. and Edward C. Prescott. "Rules Rather than Discretion: The Inconsistency of Optimal Plans.” Journal of Political Economy 85 (June 1977): 473-492.

Lee, Junsoo and Mark C. Strazicich. "Minimum Lagrange Multiplier Unit Root Test with Two Structural Breaks." The Review of Economics and Statistics 85.4 (2003): 1082-9.

Levy, Frank and Peter Temin. "Inequality and Institutions in $20^{\text {th }}$ Century America." NBER, working paper \#13106. 2007.

Lombardi, Marco and Feng Zhu. "A Shadow Policy Rate to Calibrate US Monetary Policy at the Zero Lower Bound.” BIS, working paper \#452. 2014.

Luetkepohl, Helmut. New Introduction to Multiple Time Series Analysis. New York: Springer. 2005.

Marcus, Gill. "Challenges to South African Monetary Policy in a World of Volatile Capital Flows.” Swiss Chamber Southern Africa. Zurich, Switzerland. 7 May 2012. Address.

Mason, J.W. and Arjun Jayadev. "'Fisher Dynamics' in US Household Debt, 1929-2011." American Economic Journal: Macroeconomics 6 (2014): 214-234.

Mboweni, T.T. "Central Banks in Times of Turmoil.” Gordon Institute of Business Science. 28 May 2008. Address. 
Mboweni, T.T. "What is Happening in Financial Markets?" Cape Town Club. Cape Town, South Africa. 5 October 2007. Address.

Mboweni. T.T. "Monetary Policy, Inflation Targeting, and Inflation Pressures." Bureau for Economic Research Annual Conference. Johannesburg, South Africa. 22 May 2008. Address.

Mboweni. T.T. "Origins and Causes of Recent Financial Market Turbulence and Its Implications for the CMA.” Windhoek, Namibia. 4 April 2008. Public lecture.

McCracken, William and Serena Ng. "FRED-MD: A Monthly Database for Macroeconomic Research.” Working paper, 2014.

Mminele, A.D. "Monetary Policy in Volatile and Uncertain Times." Association of Corporate Treasurers of Southern Africa. Johannesburg, South Africa. 27 May 2011. Address.

Mminele, A.D. "South Africa Amidst the Crisis." Spire Awards Ceremony. Johannesburg, South Africa. 3 November 2009. Address.

Neely, Christopher. "Unconventional Monetary Policy Had Large International Effects.” Journal of Banking and Finance 52 (2015): 101-111.

Patnaik, Ila, and Ajay Shah. "Did the Indian Capital Controls Work as a Tool of Macroeconomic Policy?" IMF Economic Review 60.3 (2012): 439-464.

Papaioannu, M. G., and L. K. Duke. "The Internationalization of Emerging Equity Markets." Finance and Development September (1993): 36-39.

Pesaran, H. Hashem and Yongcheol Shin. "Generalized Impulse Response Analysis in Linear Multivariate Models." Economics Letters 58.1 (1998): 17-29.

Pfeffer B. "FDI and FPI - Strategic Complements?" MAGKS Joint Discussion Paper Series in Economics \#12. 2008. 
Piketty, Thomas. Capital in the Twenty-First Century. Cambridge, MA: Belknap Press, 2014.

Reinhart, Carmen M. and Vincent R. Reinhart. "Capital Flow Bonanzas: An Encompassing View of the Past and Present." NBER International Seminar on Macroeconomics 5 (2008): 962.

Rogoff, Kenneth. "The Optimal Degree of Commitment to an Intermediate Monetary Target." The Quarterly Journal of Economics 100 (Nov. 1985): 1169-1189.

Romer, Christina and David Romer. "Monetary Policy and the Well-Being of the Poor." Economic Review - Federal Reserve Bank of Kansas City, 1999: 21-49.

STATA Corporation. "Bootstrap-Bootstrap Sampling and Estimation.” PDF document from STATA help files.

Strazicich, Mark C., Junsoo Lee, and Edward Day. "Are incomes converging among OECD countries? Time series evidence with two structural breaks." Journal of Macroeconomics 26.1 (2004): 131-145.

Taylor, Mark and Lucio Sarno. "Capital Flows to Developing Countries: Long and Short-term Determinants.” The World Bank Economic Review 11 (Sep. 1997): 451-470.

Walsh, Carl E. "Optimal Contracts for Central Bankers." The American Economic Review 85 (March 1995): 150-167.

Wooldridge, Jeffery M. Econometric Analysis of Cross Section and Panel Data. Cambridge, MA: MIT Press. 2002.

Wooldridge, Jeffery M. "Cluster-sample Methods in Applied Econometrics: An Extended Analysis." Working paper, 2006.

Wolff, Edward N. "Household Wealth Trends in the United States, 1962-2013: What Happened Over the Great Recession?” NBER, working paper \#20733. 2014. 
Wolff, Edward N. "The Asset Price Meltdown and the Wealth of the Middle Class.” Working paper, 2012.

Wolff, Edward. "Recent Trends in Household Wealth in the United States: Rising Debt and the Middle-Class Squeeze_-an Update to 2007.” Levy Economics Institute, working paper. 2010.

Wu, Tao and Michele Cavallo. "Measuring Oil-Price Shocks Using Market Based Information." $I M F$, working paper. 2011.

Zsolt, Darvas. "Real Effective Exchange Rates for 178 Countries: A New Database.” Bruegel. 2012, working paper. 